\title{
The prevalence, implications, and clinical course of pregnancy-related pelvic girdle pain
}

by

Stefan Malmqvist

Thesis submitted in fulfilment of the requirements for the degree of PHILOSOPHIAE DOCTOR $(\mathrm{PhD})$

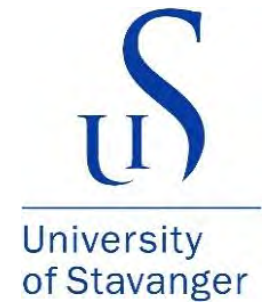

Faculty of Health Science 


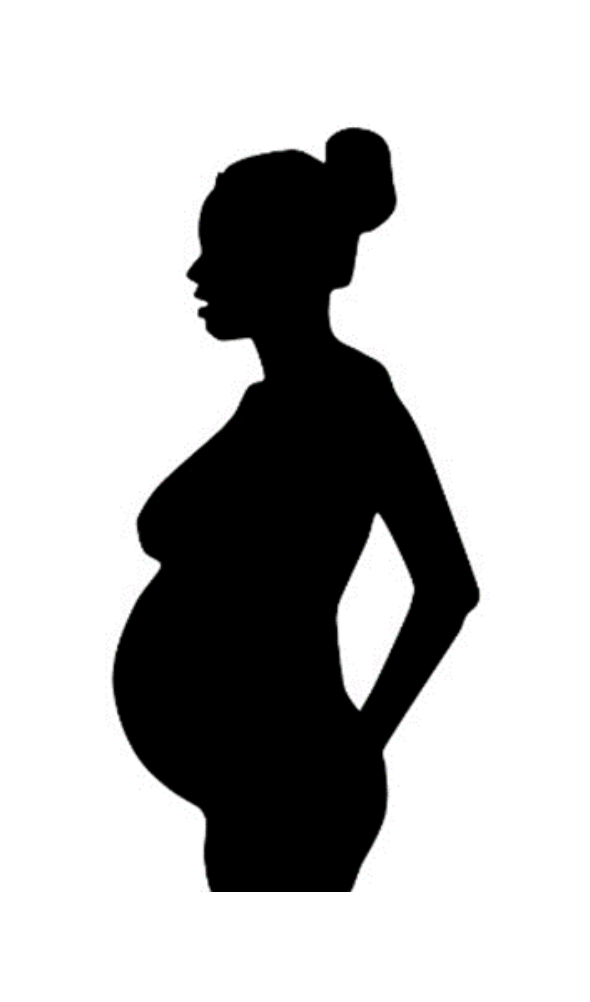


Scientific Environment

\section{Scientific environment}

The work presented in this thesis was carried out in association with the Norwegian Centre for Movement Disorders and Department of Obstetrics and Gynaecology at Stavanger University Hospital, Stavanger, Norway. The Research Department at Stavanger University Hospital has organized the necessary office facilities at Forskningens Hus.

My supervisors have been Jan Petter Larsen MD PhD, neurologist and professor at the University of Stavanger, and Kolbjørn Brønnick, PhD, psychologist and professor at Faculty of Health Sciences, University of Stavanger. My co-supervisor has been Inger Økland, MD PhD, obstetrician, Associate Professor II at the University of Stavanger, and Head of research at Stavanger University Hospital. The statistic work in all three papers has been guided, supervised, and conducted by Kolbjørn Brønnick.

Knut Andersen, chiropractor, $\mathrm{PhD}$, has been co-author of all three papers, Inger Kjaermann King, chiropractor, MSc, has been co-writing 
Scientific Environment

paper I and paper II, and Anne-Mari Gausel, chiropractor, PhD, was cowriting paper III.

I have received financial support as a doctoral research fellow from The Western Norway Regional Health Authority (Helse Vest). 


\section{Acknowledgements}

The work presented in this thesis would not have been possible without the advice, support, and assistance of many people. I am deeply grateful to the members of the pelvic girdle pain research group at Forskningens Hus in Stavanger; my esteemed supervisors Jan Petter Larsen, MD PhD, neurologist, and Professor at the University of Stavanger, Kolbjørn Kallesten Brønnick, PhD, Professor, Department of Public Health, The Faculty of Health Sciences, University of Stavanger, and co-supervisor Inger Økland, $\mathrm{MD} \mathrm{PhD}$, obstetrician, Associate Professor II at the University of Stavanger, and Head of research at Stavanger University Hospital. Their insightful advice and feedbacks pushed me to sharpen my thinking and brought my work to a higher level.

I also extend my sincere thanks to my chiropractic colleagues in the research group; Knut Andersen PhD, Inger Kjaermann King MSc, and Anne Marie Gausel PhD, for their great collaboration at every stage of the project.

The statistics in all three papers was brilliantly guided, supervised and conducted by Professor Kolbjørn Kallesten Brønnick. 
My sincere gratitude to my good old friends, Hans-Christer Holmberg, Professor at Department of Health Sciences, Mid Sweden University, Östersund, for proofreading the thesis, and Iben Axèn, Associate professor in Musculoskeletal Health at Karolinska Institute, Stockholm, and Research Leader, ELIB, for tireless support, endurance, and outstanding feedback pace when updating and completing the thesis.

This project would not have been possible without data collected at The Stavanger University Hospital. I convey my profound gratitude to the midwives, physicians, nurses, and auxiliary nurses at the Women's ward and Women's outpatient clinic for their tremendous work in recruiting participants to both data collections.

I would also like to extend my thanks to the Norwegian Chiropractic Association for giving me the financial muscles in acquiring the SMStrack licence, needed for the prospective data collection. I am very grateful for this financial support. 
Finally, my deepest appreciation and warmest gratitude to my beloved wife Inkeri, and my two daughters Joanna and Caroline. Words cannot express how grateful I am for their support, belief in me, and immense patience during the years. Finally, I want to acknowledge my first grandchild Elias, for being my power source and main inspiration to complete this work. 


\section{Summary}

\section{Background}

Pelvic girdle pain (PGP) during pregnancy is common and, indeed, has always been considered normal. It is commonly associated with moderate to severe pain that impairs everyday activities such as getting up from a chair, bending, walking, working in the home and caring for children, as well as, of course, paid employment. Also, PGP is a frequent cause of sick leave during pregnancy. The aetiology of PGP is poorly understood and there is no official nomenclature, no effective evidencebased preventive measures or treatment, known risk factors or detailed knowledge of the clinical course of the various subgroups of this condition.

\section{Objectives}

The objectives for this project were to determine the prevalence of PGP during pregnancy in a random population of women, detect factors associated with the development of this condition, explore what influences taking sick leave due to PGP, and examine whether pregnant women with PGP, who have been sub-grouped on the basis 
of two clinical tests, differ with regards to demographic characteristics and/or the clinical course of PGP during the second half of their pregnancy.

\section{Methods}

The thesis consists of three papers, based on two separate data collections at Stavanger University Hospital. Paper I and II originate from a retrospective cohort study conducted in 2009 , in which women giving birth at Stavanger University hospital in a 4-month period were asked to fill in a questionnaire on demographic features, pain, disability, PGP, pain-related activities of daily living, sick leave in general and for PGP, frequency of exercising before and during pregnancy, and Oswestry Disability Index.

Inclusion criteria were singleton pregnancy of at least 36 weeks and competence in the Norwegian language. Drawings of the pelvic and low back area were used for the localization of pain. PGP intensity was then rated retrospectively on a numerical rating scale. Non-parametric tests, multinomial logistic regression and sequential linear regression analysis were used in the statistical analysis. 
Paper III originate from a prospective longitudinal cohort study carried out in 2010. Inclusion criteria were the as for the retrospective data collection and took place at the second-trimester routine ultrasound examination. All eligible women $(n=503)$ filled in questionnaires and answered a weekly SMS question during pregnancy until delivery. Women with pain in the pelvic area underwent a clinical examination following a test procedure recommended in the European guidelines for the diagnosis and treatment of PGP.

\section{Results}

Paper I report that nearly $50 \%$ of the women experienced moderate and severe PGP during pregnancy. Approximately half of them had PGP syndrome, whereas the other half experienced lumbopelvic pain. Ten percent of the women experienced moderate and severe LBP alone. These pain syndromes increased sick leave and impaired general level of function during pregnancy. Approximately $50 \%$ of women with PGP had pain in the area of the symphysis pubis. The analysis of risk factors did not present a unidirectional and clear picture. 
In Paper II PGP is reported to be a frequent and major cause of sick leave during pregnancy among Norwegian women, which is also reflected in activities of daily living as measured with scores on all Oswestry disability index items. In the multivariate analysis of factors related to sick leave and PGP were work satisfaction, problems with lifting and sleeping, and pain intensity risk factors for sick leave. Also, women with longer education, higher work satisfaction and fewer problems with sitting, walking, and standing, were less likely to take sick leave in pregnancy, despite the same pain intensity as women being on sick leave. In Paper III, 42\% (212/503) reported pain in the lumbopelvic region and $39 \%(196 / 503)$ fulfilled the criteria for a probable PGP diagnosis. $27 \%$ $(137 / 503)$ reported both the posterior pelvic pain provocation (P4) and the active straight leg raise (ASLR) tests positive at baseline in week 18, revealing 7.55 (95\% CI 5.54 to 10.29) times higher mean number of days with bothersome pelvic pain compared with women with both tests negative. They presented the highest scores for workload, depressed mood, pain level, body mass index, Oswestry Disability Index and the number of previous pregnancies. Exercising regularly before and during pregnancy was more common in women with negative tests. 


\section{Conclusions}

Pelvic pain in pregnancy is a health care challenge in which moderate and severe pain develops rather early and has important implications for society. The observed associations between possible causative factors and moderate and severe LBP and PGP in the analysis of the retrospective data may, together with results from other studies, bring some valuable insights into their multifactorial influences and provide background information for future studies.

Some pregnant women with PGP show a higher pain tolerance, most likely dependant on education, associated with work situation and/or work posture, which decreases sick leave. These issues are recommended to be further examined in a prospective longitudinal study since they may have important implications for sick leave frequency during pregnancy.

If both P4 and ASLR tests were positive mid-pregnancy, a persistent bothersome pelvic pain of more than 5 days per week throughout the remainder of pregnancy could be predicted. Increased individual control over work situation and an active lifestyle, including regular exercise before and during pregnancy, may serve as a PGP prophylactic. 


\section{List of publications}

\section{Paper I}

Malmqvist S, Kjaermann I, Andersen K, Økland I, Brønnick K, Larsen JP. Prevalence of low back and pelvic pain during pregnancy in a Norwegian population. J Manipulative Physiol Ther. 2012;35:272-8.

\section{Paper II}

Malmqvist S, Kjaermann I, Andersen K, Økland I, Larsen JP, Brønnick $\mathrm{K}$. The association between pelvic girdle pain and sick leave during pregnancy; a retrospective study of a Norwegian population.

BMC Pregnancy Childbirth. 2015; 15:23

\section{Paper III}

Malmqvist S, Kjaermann I, Andersen K, Gausel AM, Økland I, Larsen JP, Brønnick K. Can a bothersome course of pelvic pain from midpregnancy to birth be predicted? A Norwegian prospective longitudinal SMS-track study. BMJ Open 2018;8:e021378. 


\section{Abbreviations}

Active straight leg raise test

ASLR

Activities of daily living

Analysis of variance

Body Mass Index

Long dorsal sacroiliac ligament test

Low back pain

Numerical rating scale

Oswestry Disability Index

Pelvic girdle pain

Pelvic Girdle Questionnaire

Pelvic pain

Posterior pelvic pain provocation test

Roland-Morris Disability Questionnaire

Sacroiliac joint

Short message service

Transversus abdominis muscle

Visual Analogue Scale
ADL

ANOVA

BMI

LDL

LBP

NRS

ODI

PGP

PGQ

PP

P4

RMDQ

SIJ

SMS

$\operatorname{TrA}$

VAS 


\section{Table of contents}

Scientific Environment ................................................................... iii

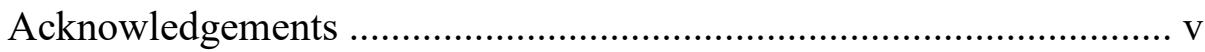

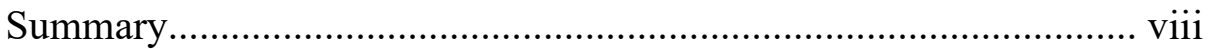

List of publications....................................................................... xiii

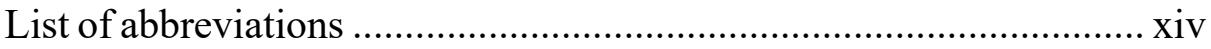

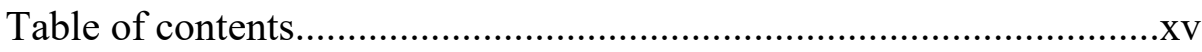

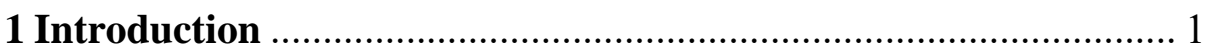

1.1 Historical perspective ............................................................ 1

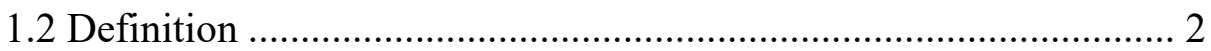

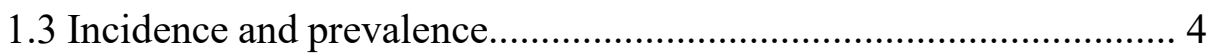

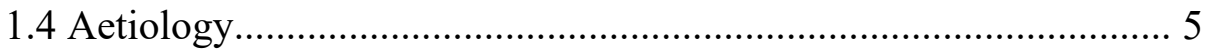

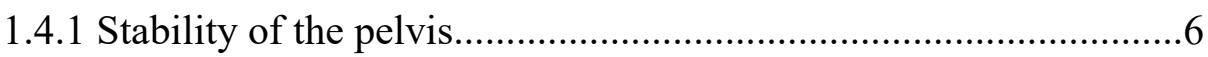

1.4.2 Biomechanical factors in PGP …......................................... 7

1.4.3 Hormonal factors in PGP ..................................................... 9

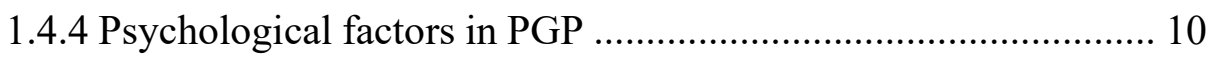

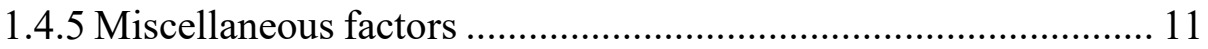

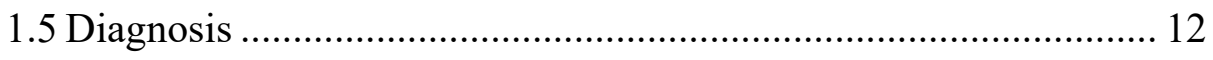

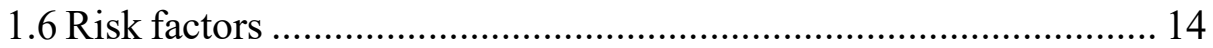

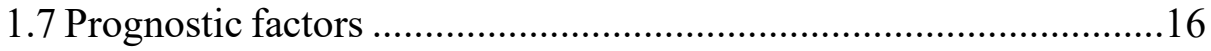

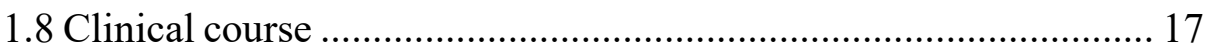

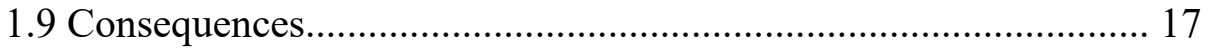




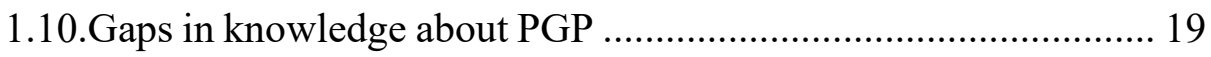

1.11 Three major objectives of the current project.............................. 20

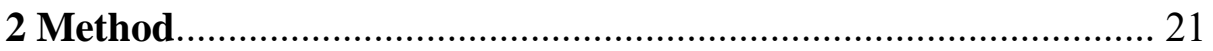

2.1 Study aims of the retrospective study (Papers I and II) .............21

2.1.2 Setting and inclusion criteria ..................................... 21

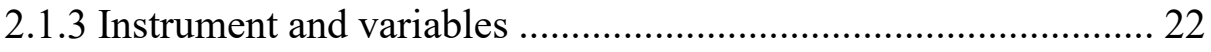

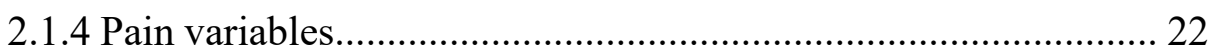

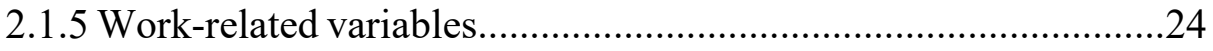

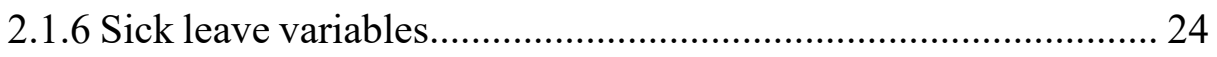

2.1.7 Assessment instruments, retrospective data collection 24 hours

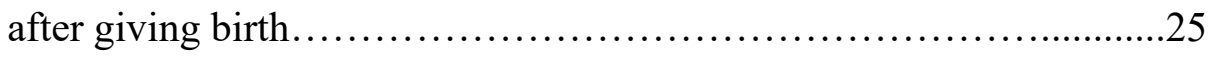

2.2 Study aims of the prospective study (Paper III) ..........................29

2.2.1 Setting and inclusion criteria.................................... 29

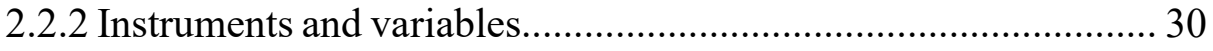

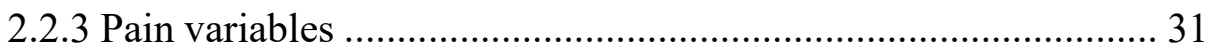

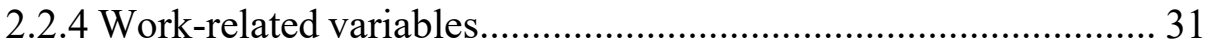

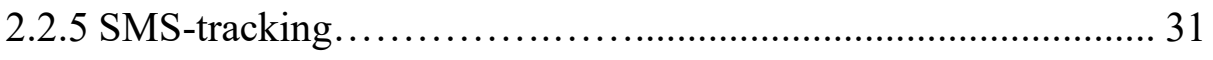

2.2.6 Assessment instruments and procedures at baseline; week 18... 32

2.3 Analysis of the retrospective data (Papers I and II) ..................... 36

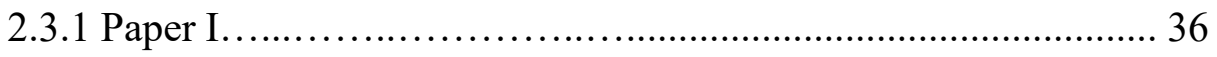

2.3.2 Independent variables in Paper I................................................. 37

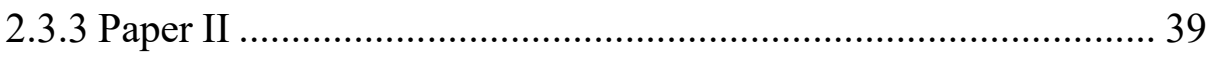




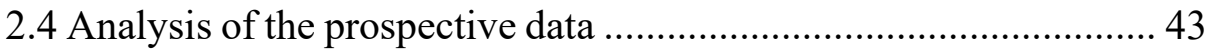

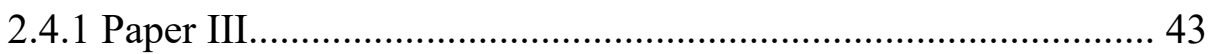

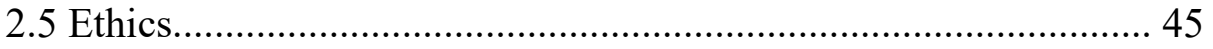

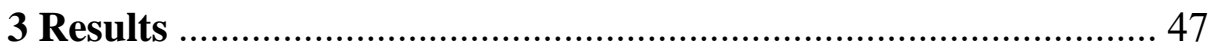

3.1 The retrospective data collection (Papers I and II) .........................47

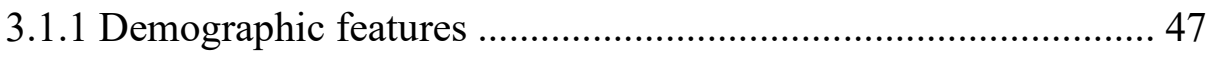

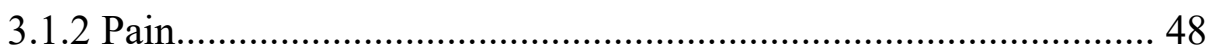

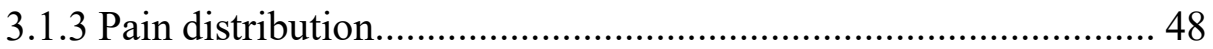

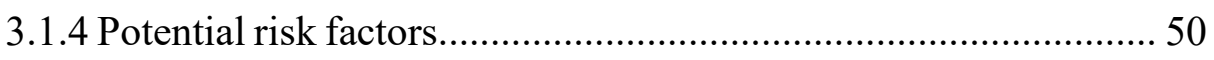

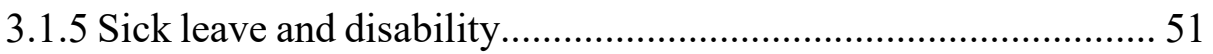

3.1.6 Factors associated with sick leave due to PGP............................ 54

3.2 The prospective data collection (Paper III) .................................... 57

3.2.1 Demographic and clinical features............................................ 58

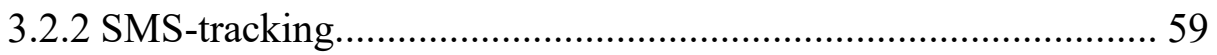

3.2.3 PGP course

3.2.4 Factors predicting the number of bothersome days per week....... 62

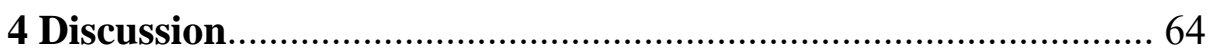

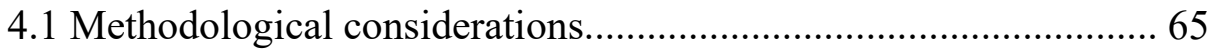

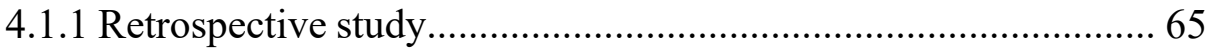

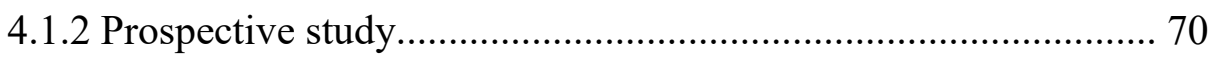

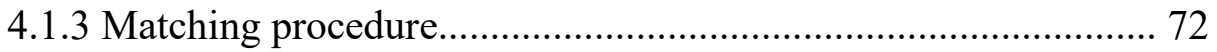

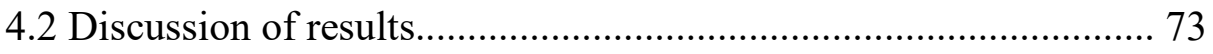

xvii 


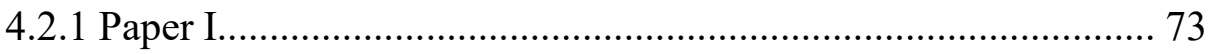

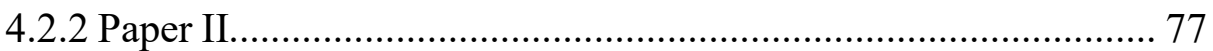

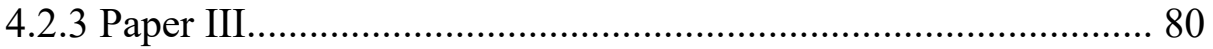

4.3 What does this thesis contribute to our knowledge about PGP?... 85

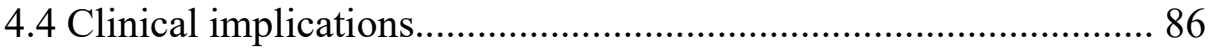

4.5 Implications for future research in this area.................................... 87

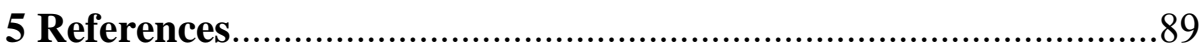

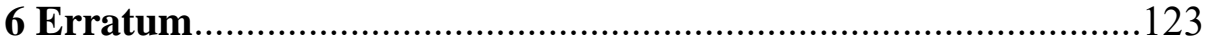

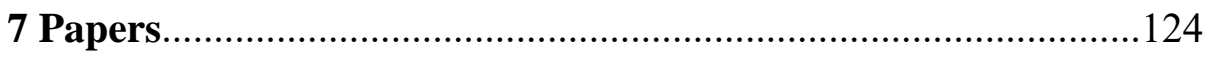

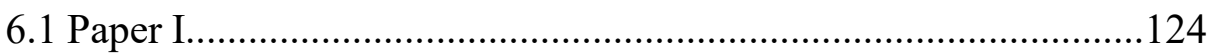

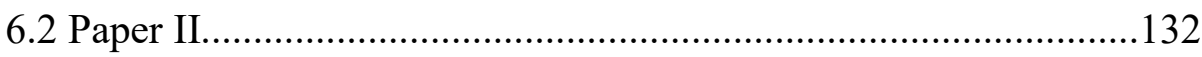

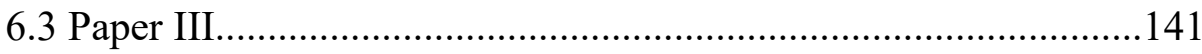

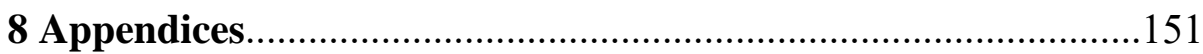

7.1 Questionnaire for the retrospective data collection.......................151

7.2 Questionnaire for the prospective data collection..........................160 


\section{Introduction}

Pelvic girdle pain (PGP) during pregnancy is common and, indeed, has always been considered normal. However, from the World Health Organization perspective, which defines health as "a state of complete physical, mental, and social well-being and not merely the absence of disease or infirmity", women who experience PGP are not healthy [1]. This condition is commonly associated with moderate to severe pain that impairs everyday activities such as getting up from a chair, bending, walking, working in the home and caring for children, as well as, of course, paid employment. The aetiology of PGP is poorly understood, and there is no official nomenclature [2,3], no effective evidence-based preventive measures or treatment, known risk factors or detailed knowledge of the clinical course of the various subgroups of this condition.

\subsection{Historical perspective}

PGP during pregnancy was mentioned by Hippocrates as symphysis pubis dysfunction in his theory of "disjunctio pelvica" more than 2,000 years ago [4]. For centuries, research on this condition focused primarily on the laxity of the pelvic joints and its aetiology. However, in the second 
half of the 1970s, this focus became more concerned with symptoms [5]. Questionnaires and illustrations allowed for a more detailed and accurate assessment of pain, which brought into question the assumption that joint relaxation is the main cause of this pain [6]. As a result of its potential negative impact on the woman's quality of life during pregnancy, as well as the cost of this condition on society, the medical profession has been paying more and more attention to PGP during the past 20 years [2].

\subsection{Definition}

PGP is defined as originating in the pelvic musculoskeletal system, excluding ailments of gynaecological and urological character. The PGP diagnosis is independent of pregnancy and sex, according to the European guidelines on diagnosis and treatment of PGP: "Pelvic girdle pain generally arises concerning pregnancy, trauma or reactive arthritis" [7]. Pain is experienced between the posterior iliac crest and the gluteal fold, particularly in the vicinity of the sacroiliac joints (SIJs). The pain may radiate from the posterior thigh. It can occur in conjunction with/or separately from the symphysis. For pregnancy-related PGP, the onset of symptoms occurs from approximately week 6 of the pregnancy and 
reaches peak pain intensity between the 24th and 36th week of pregnancy $[2,8]$.

Research on pain in the lower back area during pregnancy, published in the past 20 years, reveals that a dissensus regarding nomenclature still prevails. Studies of the condition have not used the same definition of PGP [9]. Commonly, studies include participants with pain in the lumbopelvic region without distinguishing PGP from low back pain [9]. PGP has been called symptom-giving pelvic girdle relaxation [10], peripartum pelvic pain [11], pelvic joint instability [12], posterior pelvic pain [13], pelvic instability, pregnancy-related lumbopelvic pain [14], pregnancy-related low back pain [15], and pregnancy-related pelvic girdle pain [16].

PGP can be divided into five subgroups according to joint involvement: symphysiolysis (separation of the symphysis pubis), one-sided SIJ syndrome (pain at one SIJ), double-sided SIJ syndrome (pain at both SIJs), the pelvic girdle syndrome (PGS) (in which both the symphysis and SIJs are affected), and a miscellaneous group [3, 7, 16-18]. The miscellaneous group is defined as inconsistent objective findings of daily pain in $\leq 1$ pelvic joint [17]. The pelvic girdle syndrome (PGS) group 
has the worst prognosis: $21 \%$ continue to have pain two years after delivery [17]. The symphysiolysis group have a $100 \%$ chance for a full recovery, not later than six months after delivery $[17,19]$. The groups with one-sided and/or double-sided SIJ syndrome also have a chance for full recovery in no later than 12 and 18 months, respectively [17]. No figures for recovery exist for the various group.

In this thesis, the term pelvic girdle pain (PGP) will be used, following the definition from the European guidelines on diagnosis and treatment of PGP above.

\subsection{Incidence and prevalence}

The incidence and prevalence of PGP vary depending on the definition, the diagnostic means utilized, and the design of the study [20]. Most of the literature reporting a prevalence (= the number of existing cases in a certain time period) and describing the epidemiological characteristics of PGP have been conducted in Europe [9]. Studies have reported prevalence rates ranging from as low as $7 \%$ to as high as $84 \%[8,21-$ 36]. However, these studies have not used the same guidelines to classify women with PGP. Some studies are based on self-report measures alone, 
such as pain location drawings and questionnaires $[21,25,26,30,31$, 37]. In contrast, others have used physical examination as well as selfreported measures to confirm the classification of PGP $[8,22,24,27,29$, 32]. Some studies are prospective and some retrospective, which makes comparison problematic. Retrospective designs are prone to recall bias, which may explain the large variability in the published data on prevalence rates [38]. The incidence $(=$ number of new cases in a certain time period) of pelvic girdle pain in pregnancy is unknown. Estimates from low-level evidence are contradictory, ranging from approximately $4 \%$ to $84 \%[32,39-41]$, is higher in late pregnancy $[21,24,26,32$, 42] and among women with a higher BMI [26].

\subsection{Aetiology}

Several etiological factors have been suggested for pregnancy-related PGP; biomechanical [22, 43-45], hormonal [8, 10, 46-49], metabolic [50], genetic [27, 40, 51, 52], and biopsychosocial factors [19, 53]. Biomechanical factors in combination with hormonal factors are proposed as the most plausible hypothesis $[3,7,52]$. 


\subsubsection{Stability of the pelvis}

In the European guidelines on diagnosis and treatment of PGP, a definition of optimal stability of the pelvis is described as: "The effective accommodation of the joints to each specific load demand through an adequately tailored joint compression, as a function of gravity, coordinated muscle and ligament forces, to produce effective joint reaction forces under changing conditions" [7]. Optimal stability of the pelvis consists of form and force closure (Figure 1) [54]. Form closure is due to the fit of the irregular surfaces of the sacrum and iliac bones physically locking the sacrum into the pelvic ring (arrows) between the two iliac bones (Panel A) [54]. The dorsal interosseous ligament maintains the integrity of the joint. Force closure is the compressive

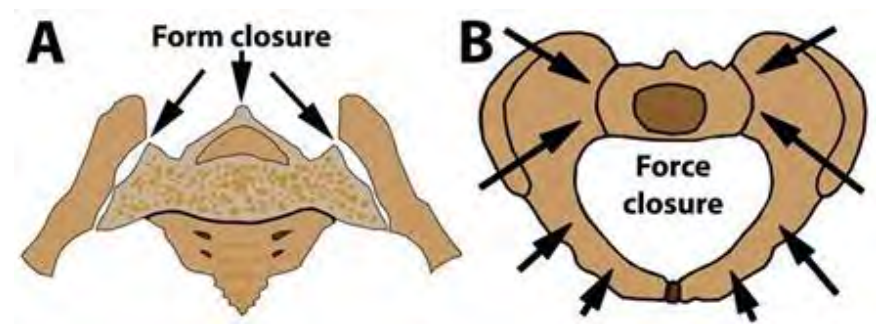

Figure 1. Form and force closure of the pelvic ring 
effect exerted on the pelvic ring by the coordinated contraction of the abdominopelvic muscles, which shut the sacrum between the iliac bones and stops it from rotating outward (Panel B) [54].

\subsubsection{Biomechanical factors in PGP}

In general, bracing the SIJ by sufficient force closure of lumbopelvic muscles and the nutation of the ilium are thus essential for an efficient load transfer to the legs [55]. A systematic review found that patients with PGP have increased motion in their pelvic joints compared with healthy pregnant controls [56]. This increased motion in the pelvic joints diminishes load transmission efficiency and increases the shear forces across the joints [3]. These increased shear forces might be responsible for pain in pregnant women with PGP [57].

Significantly reduced strength of the transversus abdominis (TrA), lumbar multifidus, internal oblique muscles, the pelvic floor musculature, and insufficient coordination of all lumbopelvic muscles is often observed in patients with PGP [58-61]. This impairment in muscle strength and coordination is caused by abdominal stretching and a shift of body gravity centre when PGP commences in the second and third 
trimester of pregnancy, resulting in reduced force closure [62, 63]. Which, in turn, can generate neuromuscular compensatory strategies [62, 63], namely the butt-gripping and the chest-gripping strategy. In the buttgripping procedure, there is an overuse of the posterior buttock muscles. In the chest-gripping approach, the external oblique is in overuse and compensating for the underuse of the TrA [63]. These actions are hypothesized to increase sheared forces in the SIJ, thus being accountable for pain $[3,56]$.

Researchers investigated resultant pain regarding the SIJ as a pain generator when injecting the joint with an irritant solution in healthy subjects $[64,65]$. Their finding agrees with referred pain patterns reported on direct SIJ capsular stimulation, with decreased pain when treated by injecting an anaesthetic into the SIJ. Such referred pain patterns are often observed in women with PGP [66], suggesting that the SIJ may be a source of pain in PGP.

Pregnant women with PGP have also shown hypersensitivity in superficial and deep tissue in the lumbopelvic region and distant to it, indicating widespread hypersensitivity to the SIJ [67]. However, the 
stage of pregnancy does not correlate with a self-reported disability, pain, or hypersensitivity, indicating that these symptoms likely are related to several factors, including altered biomechanics (of somatic and visceral tissues). Emotional health, poorer sleep quality, and changes in hormonal status are factors [67].

\subsubsection{Hormonal factors in PGP}

Hormones may be involved in several different factors related to PGP, including modulation of pain and collagen synthesis, as well as inflammatory processes $[19,52]$. During pregnancy, the gonadal hormones enhance pain sensitivity directly, potentially by modulating the responses of primary afferents on neurons of the dorsal horn and at supraspinal locations [63] and indirectly through their influence on emotional status [68].

At present, there is little evidence concerning the likely involvement of high levels of relaxin in the elevated laxity of pelvic joints. It is known that hormonal changes associated with pregnancy are compensated for by adequate changes in the force of sacroiliac closure [7, 58]. Furthermore, the widening of the symphysis in response to high levels 
of relaxin can be physiological if it does not exceed $10 \mathrm{~mm}[69,70]$. A wider gap can be viewed as a pathological consequence of the inadequate force of the sacroiliac closure $[56,71]$.

The number of previous deliveries has also been found to be associated with a risk of PGP [25]. Pain associated with a previous pregnancy or delivery may increase sensitivity to pain in the pelvic girdle in a subsequent pregnancy [16], like increased sensitivity to pain resulting from previous pain is well known [72]. A link between early menarche and PGP has been suggested [47], believed to be due to the influence of pre-pregnancy hormonal factors rather than altered hormones during pregnancy.

\subsubsection{Psychological factors in PGP}

Research has shown that emotional states play a significant role in pregnancy [73]. Psychosocial factors have long been associated with chronic pain, and the bio-psycho-social model has become the leading theory of the development and management of chronic pain [74]. Psychosocial factors have also been demonstrated to play a crucial role in the transition from acute and sub-acute pain to chronicity [75-77]. In 
patients with musculoskeletal pain, psychosocial factors appear to exacerbate the clinical component of pain $[78,79]$. They have shown to influence future disability, pain, self-reported improvement after treatment in LBP patients [80-84].

Even though pregnancy itself negatively influences health-related quality of life, lumbopelvic pain increases this influence [85]. Pregnancy-related lumbopelvic pain has also been shown to have a great negative emotional and psychological impact on women [86]. This impact is often associated with dominant psychological factors (somatization, catastrophizing, pathological fear and/or elevated anxiety, depression), as well as social factors (such as a history of sexual abuse) [52]. Daily stress is a demonstrated risk factor for pregnancy-related lumbopelvic pain [87]. Women with postpartum depressive symptoms are three times more likely to report lumbopelvic pain than those without [88].

\subsubsection{Miscellaneous factors}

PGP association with metabolic comorbidities such as diabetes has been reported, but the underlying etiological mechanism has not been 
identified [89]. Epidemiologic research elucidates that women with PGP are more likely to have a mother or sister with PGP $[27,40]$.

In summary, the stability of the pelvis during pregnancy is dependent on form closure and adequate motor control, being potentially compromised by the reduced or excessive force of closure as well as influenced by emotions.

\subsection{Diagnosis}

The diagnosis of PGP can only be reached after the exclusion of lumbar causes. The specific clinical tests must reproduce pelvic pain or functional disturbance. In the European Guidelines on diagnosis and treatment of PGP, the recommended evaluated tests for diagnosing PGP have a very high specificity indicating that the patient does not suffer from PGP if they are negative [7]. However, the sensitivity is low. Hence it is recommended to perform all the recommended tests and not rule out PGP if one test is negative. Tests recommended for PGP clinical examination are for pain in the SIJ: Posterior pelvic pain provocation test (P4), Patrick's Faber test, palpation of the long dorsal SIJ ligament, and Gaenslen's test. For pain at the symphysis pubis, palpation of the 
symphysis and the modified Trendelenburg test are recommended. Together with pain and disability scales, these diagnostic tests are useful in recording PGP symptoms, severity, and subgroup classification [90].

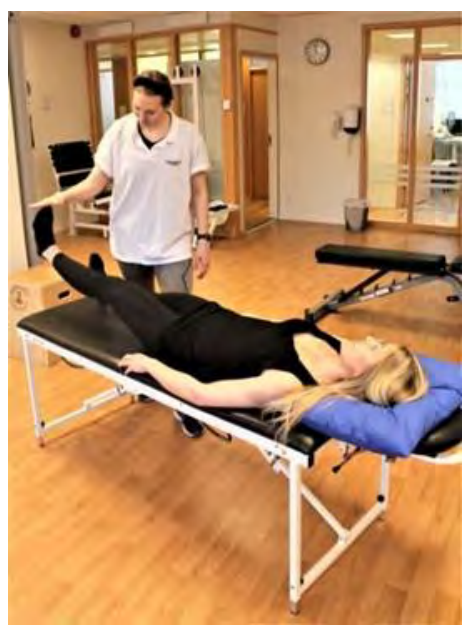

In order to distinguish between reduced force closure and excessive force closure [54], the Active Straight Leg Raise test (ASLR), illustrated here, is considered one of the most appropriate tests available for evaluating the functional stability of the pelvis [52]. The test is in a review even referred to as "the golden standard for testing the functional ability of the pelvis"[19]. In a pregnant sample, the specificity of this test was $88 \%$,

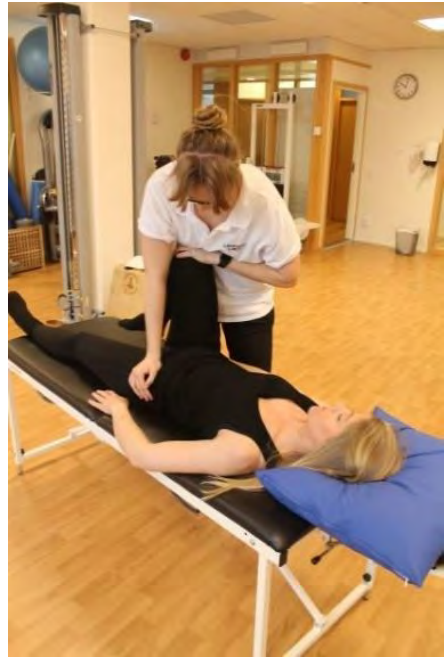
and the sensitivity was moderate (54\%) [91]. If combined with the $\mathrm{P} 4$ test (illustrated here), the sensitivity increases to $68 \%$.

Reduced force closure represents pain associated with excessive strain to the SIJ, surrounding connective tissues and 
myofascial structures due to ligamentous laxity [92] coupled with motor control deficits of muscles that control force closure of the SIJs [45]. This form of PGP presents with a positive ASLR test [45], as a delayed onset activity of the obliquus internus abdominis, multifidus, and gluteus maximus muscles discloses this motor control deficit. Thus, an alteration in lumbopelvic stabilization disrupts load transference through the pelvis [92].

Excessive force closure occurs when the peripheral nociceptive drive is generated by excessive, abnormal and sustained loading of SIJs, surrounding connective tissue, and myofascial structures from the excessive activation of the motor system local to the pelvis in response to a transfer of the increased weight load in the woman [93]. This form of PGP generates localized pain to the SIJs, the surrounding connective tissue, and in myofascial structures such as the pelvic floor and piriformis muscles [93]. It returns a positive P4 test and a negative ASLR test.

\subsection{Risk factors}

Risk factors for developing PGP consistently found in research are previous pelvic or lower back pain $[94,95]$ and a history of trauma to the 
back or pelvis [16, 31]. Multiparity [33, 94], increased body mass index, physically demanding work, emotional distress, and smoking also increase women's risk $[7,9,25,96]$.

Probable risk factors are increased workload, inactive lifestyle, higher age in pregnancy, generalized joint hypermobility [97, 98], and stress [2, 7, 25, 62, 99]. Research has shown that physically active women, regularly engaging in high-impact exercises before the first pregnancy, have a reduced risk of experiencing PGP in pregnancy [100].

The recommended diagnostic tests described above may also serve as prognostic tests and indicate the risk of disability and future pain in pregnant women [101]. Research shows that women with pain in all three pelvic joints (bilateral SIJs and symphysis) and with many positive tests have a markedly worse prognosis than women with other combinations of self-reported pain location [17]. These results suggest that a clinical examination, including a few tests performed in early pregnancy, may identify women at risk of a more severe PGP late in pregnancy [102]. 


\subsection{Prognostic factors}

High pain intensity [32], severe pelvic pain in three pelvic joints [102], the use of crutches [103], other pain conditions [104], menarche at a young age [47], previous low back pain [32], comorbidities [104], obesity [103], multiparity [105] and experience of emotional distress [104], are factors identified to influence the prognosis in pelvic girdle pain during pregnancy negatively.

Studies of testing have shown that pain in the pelvic joints, bilateral positive $\mathrm{P} 4$ tests, and certain positive pain provocation tests in the early stages of pregnancy are significantly associated with disability and pain intensity at gestation week 30 [102]. A poor ASLR performance and localized pressure pain hypersensitivity in the pelvis during pregnancy is correlated with low physical health-related quality of life postpartum and pain quality [106]. Distress in early pregnancy is also significantly associated with disability at gestation week 30 , but not with pain intensity [32]. However, the ability to manage emotional distress during pregnancy, and a belief in improvement, may prevent the persistence of pelvic girdle pain postpartum [107]. 


\subsection{Clinical course}

Research on the clinical course of PGP in pregnancy is scarce. The data have usually been collected at the baseline and at one or more followups [39, 108] which have shown that the onset of PGP varies significantly, from the end of the first trimester to a couple of months postdelivery, including the labour stage. A peak of symptoms seems to exist closer to the third trimester between the 24th and 36th weeks of pregnancy. With only a few measurement points in time, stability may be indicated, and a fluctuating PGP course may be undetected. Hence prospective frequent data collection is warranted to describe the clinical course accurately. It has been suggested that a clinical examination including a few tests performed in early pregnancy, with follow-ups over time, may identify women at risk of a more severe course of PGP late in pregnancy [102].

\subsection{Consequences}

PGP during pregnancy is associated with depressive symptoms and greatly affects the experience of being pregnant, roles in relationships and social context [86]. For women with young children, PGP negatively 
affects the role of being a mother, a situation that further strains the pregnancy experience [109]. Women with PGP have less day to day mobility than women with back pain only and require crutches or wheelchairs more frequently $[41,110]$. In addition, emotional distress is significantly associated with disability [32].

PGP is one of the major causes of sick leave in pregnancy $[16,27,87$, $111,112]$. Despite an increasing number of women working throughout their reproductive years, only a small number of studies regarding the frequency and duration of sick leave during pregnancy and prevalence estimates differ according to study methodology and populations examined [112-116]

PGP accounts for up to $72 \%$ of sick leave in pregnancy with an average length of 12-15 weeks $[16,27,87,111,112]$. Women with the involvement of several joints and a high pain level also have longer sickleave duration than others [102], making PGP during pregnancy a major public health issue [27]. Different occupational groups may have various sick leave patterns, and occupational factors may contribute to sick leave 
in $50 \%$ of pregnancies [112]. Sick leave patterns may be linked to sick leave benefits without fully explaining them [112].

\subsection{Gaps in knowledge about PGP}

Although PGP can significantly impact pregnant women's health and quality of life, varying definitions of approach diagnosis and study designs have estimated its incidence and prevalence problematic $[9,19]$. One additional challenge in this respect is the wide range of outcomes measured, from self-report symptoms alone (e.g., location and severity of the pain as indicated from questionnaires $[21,25,26,30,31$, 37 or in combination with physical examinations [8, 22, 24, 27, 29, 102]. Moreover, most demographic and clinical characterizations of subgroups of patients demonstrating different PGP symptoms have not been longitudinal, with repeated data collection. More standardized research is required to identify women at risk of developing PGP during pregnancy and identify the predictors of deleterious clinical courses. In addition, even though PGP is a major cause of sick leave during pregnancy, relatively little is known about this connection. For instance, can differences in tolerance levels for pain and/or demographic and psychosocial characteristics and clinical symptoms 
explain why some women take sick leave while others do not [20, 117]? Furthermore, in connection with prospective PGP studies are data usually collected at baseline with only one or few follow-ups. The PGP course during pregnancy thus remains to be examined in detail $[15,32,118-120]$.

\subsection{The three major objectives of the current project}

1: To determine the prevalence of PGP during pregnancy in a random population of women and factors that may be associated with the development of this condition.

2: To explore factors that influence taking sick leave due to PGP during pregnancy, including pain-related activities of daily living and the nature of employment, including the physical workload involved.

3: To examine whether pregnant women with PGP who have been subgrouped based on two clinical tests differ regarding demographic characteristics and/or the clinical course of PGP (i.e., the number of days per week with bothersome symptoms) during the second half of their pregnancy. 


\section{Method}

\subsection{Study aims of the retrospective study (Papers I and II)}

The objectives of the study were to investigate the cumulative prevalence of LBP, PGP and combined lumbopelvic pain (LBPP) during pregnancy, including features possibly associated with the development of PGP in an unselected population of women. Further objectives were to explore the frequency of sick leave in pregnancy due to PGP, assess the relationship between different types of pain-related activities of daily living, examine physical workload, type of work concerning sick leave, and explore factors that make women less likely to take sick leave for PGP.

\subsubsection{Setting and inclusion criteria}

The data collected in the retrospective study were conducted at Stavanger University Hospital maternity ward in March - July 2009. The hospital has the only birth department in the southern part of the county of Rogaland, with a population of approximately 330000 inhabitants. The annual number of deliveries at the hospital varies between 4400 and 4800. Inclusion criteria were a singleton pregnancy of at least 36 weeks 
and good competence in the Norwegian language. Within 24 hours after delivery, the women received verbal and written information about the study from a midwife. Participation was voluntary, but all eligible women were encouraged to participate in obtaining the inclusion of an unselected sample.

\subsubsection{Instrument and variables}

The women filled in a questionnaire specially designed by the research group, based on previous studies and the experience of the team. The questionnaire contained demographic information, questions regarding pain distribution in the pelvic girdle area, pain-related activities of daily living (ADL), sick leave in general and due to PGP, and frequency of exercising before and during pregnancy. The questionnaire (in Norwegian) can be found in Appendices.

\subsubsection{Pain variables}

The women marked the location of the pain on illustrations of the pelvic girdle and low back included in the questionnaire package. The pelvic girdle and the low back were labelled and separated according to boundaries described in the European guidelines for the diagnosis and treatment of PGP [7]. 
The question on pain intensity ("Rate in each square, representing each month in pregnancy, the average pelvic pain you have experienced") was rated retrospectively on a numerical rating scale (NRS) [121] from 0 to 100 , to collect information on the presentation of symptoms and the peak intensity of pain during pregnancy. In this study, the score was anchored at 0 , meaning "No pain", and 100 meaning "Unbearable pain". For the analyses, "average pain PGP intensity" was calculated as the mean of the values reported in all months.

Information on pain-related ADL was collected through the Oswestry Disability Index (ODI) [122], which, at the time, was one of the principal condition-specific outcome measures for defining disabling effects from spinal disorders and PGP. A patient-completed questionnaire gives a subjective percentage score of the level of function (disability) in 10 ADLs in patients with low back pain [122]. Every activity contains six statements on how well the activity is performed. The statements are scored from 0 to 5 . The scores for all questions answered are summed, then multiplied by two to obtain the index (range $0-100)$. Zero is equated with no disability, and 100 is the maximum disability possible. 


\subsubsection{Work-related variables}

The questionnaire also provided information on the total number of years of education (including elementary school), the level of physical workload (measured with five answer categories ranging from 'sedentary' to 'heavy', following a scale used in the Stockholm Public Health questionnaire [123]. The type of work (in free text) and work satisfaction (a five-level scale runs from very bad to very good) [124, 125].

\subsubsection{Sick leave variables}

Sick leave was estimated in two different ways. First, the women were asked about their total number of weeks of full-time sick leave during pregnancy and the total number of weeks with part-time sick leave and sick leave percentage. In the analyses, weeks of sick leave in total were calculated by adding the full-time sick leave weeks to the part-time weeks adjusted for sick leave percentage. After reporting the total amount of sick leave, the women were asked to specify the primary cause of their sick leave. Second, in the section concerning pain intensity during pregnancy, the women were asked whether they had been on sick 
leave due to PGP in any month of the pregnancy and indicated when. It was, therefore, not possible to determine the number of consecutive weeks of $100 \%$ sick leave due to any specific cause from the available information. For instance, several women only reported "pain" without any specific pain area details as the primary cause of sick leave in pregnancy. All the available information was combined in the analyses to establish if the women were on sick leave due to PGP. If the women reported any sick leave due to PGP in any month of the pregnancy, they were classified as having sick leave due to PGP. The women, who explicitly stated that PGP was the primary cause of their sick leave, but who did not indicate sick leave due to PGP in any specific month of pregnancy in the questionnaire's pain intensity-section were also classified as having sick leave due to PGP.

2.1.7 Assessment instruments, retrospective data collection 24 hours after giving birth

\begin{tabular}{|l|l|l|}
\hline $\begin{array}{l}\text { Instruments and } \\
\text { variables of interest }\end{array}$ & $\begin{array}{l}\text { Description of answer } \\
\text { options }\end{array}$ & Reference \\
\hline Questionnaire & & \\
\hline
\end{tabular}


Method

\begin{tabular}{|c|c|c|}
\hline Education (years) & $\begin{array}{l}\text { Number of years (including } \\
\text { elementary school) }\end{array}$ & \\
\hline Physical workload & $\begin{array}{l}\text { Five levels; from very easy } \\
\text { to very heavy. Sixth option: } \\
\text { not working }\end{array}$ & [123] \\
\hline Profession & Free text & \\
\hline Job satisfaction & $\begin{array}{l}5 \text { level Likert scale; from } \\
\text { very bad to very good }\end{array}$ & [126] \\
\hline Weeks on sick leave & $\begin{array}{l}\text { Number of weeks, or: not } \\
\text { been on sick leave }\end{array}$ & \\
\hline $\begin{array}{l}\text { Weeks on full time and } \\
\text { part-time, including } \\
\text { percentage sick leave }\end{array}$ & Number of weeks & \\
\hline Cause for sick leave? & Free text & \\
\hline Height & Centimetres & \\
\hline Weight (most recently) & $\mathrm{Kg}$ & \\
\hline $\begin{array}{l}\text { Weight before } \\
\text { pregnancy }\end{array}$ & $\mathrm{Kg}$ & \\
\hline Weight before delivery & $\mathrm{Kg}$ & \\
\hline $\begin{array}{l}\text { Depressed until now in } \\
\text { this pregnancy }\end{array}$ & $\begin{array}{l}\text { Four categories: Never, } \\
\text { on/off, often, almost all the } \\
\text { time }\end{array}$ & \\
\hline $\begin{array}{l}\text { If you have been } \\
\text { depressed: In which } \\
\text { month/s? }\end{array}$ & Nine options: Month 1-9 & \\
\hline
\end{tabular}


Method

\begin{tabular}{|c|c|c|}
\hline Chronic disease? & Yes/No & \\
\hline If yes, which disease? & Free text & \\
\hline $\begin{array}{l}\text { The number of previous } \\
\text { births? }\end{array}$ & Number & \\
\hline $\begin{array}{l}\text { Pelvic pain in previous } \\
\text { pregnancies? }\end{array}$ & Yes/No & \\
\hline $\begin{array}{l}\text { Hormonal treatment to } \\
\text { achieve this pregnancy? }\end{array}$ & Yes/No & \\
\hline $\begin{array}{l}\text { Regular exercising (2- } \\
3 \mathrm{x} / \text { week) before this } \\
\text { pregnancy? }\end{array}$ & Yes/No & \\
\hline $\begin{array}{l}\text { Regular exercising (2- } \\
3 \mathrm{x} / \text { week) in this } \\
\text { pregnancy? }\end{array}$ & Yes/No & \\
\hline Injuries to the pelvis? & Yes/No & \\
\hline Type of injury & Free text & \\
\hline $\begin{array}{l}\text { Low back or pelvic pain } \\
\text { before this pregnancy? }\end{array}$ & Yes/No & \\
\hline $\begin{array}{l}\text { Low back pain onset in } \\
\text { which month? }\end{array}$ & Nine options: Month 1-9 & \\
\hline Low back pain location & Pain drawing & [127-129] \\
\hline $\begin{array}{l}\text { The low back pain level } \\
\text { in months } 1-9\end{array}$ & NRS 1-100 for each month & [121] \\
\hline
\end{tabular}




\begin{tabular}{|c|c|c|}
\hline $\begin{array}{l}\text { Month/s with sick leave } \\
\text { for low back pain in this } \\
\text { pregnancy? }\end{array}$ & Nine options: Month/s 1-9 & \\
\hline $\begin{array}{l}\text { Pelvic pain onset in } \\
\text { which month }\end{array}$ & Nine options: Month 1-9 & \\
\hline Pelvic pain location & $\begin{array}{l}\text { Pain drawing; pelvis } \\
\text { back/front }\end{array}$ & {$[40]$} \\
\hline $\begin{array}{l}\text { The pelvic pain level in } \\
\text { months } 1-9 \text { ? }\end{array}$ & NRS 0-100 for each month & [121] \\
\hline $\begin{array}{l}\text { Month/s with sick leave } \\
\text { for pelvic pain in this } \\
\text { pregnancy? }\end{array}$ & Nine options: Month/s 1-9 & \\
\hline \multicolumn{3}{|l|}{$\begin{array}{l}\text { Oswestry Disability } \\
\text { Index (ODI) }\end{array}$} \\
\hline $\begin{array}{l}\text { An linstrument } \\
\text { measuring level of } \\
\text { disability in activities of } \\
\text { daily living (ADL) }\end{array}$ & $\begin{array}{l}\text { A subjective percentage } \\
\text { score of the level of function } \\
\text { in } 10 \text { ADLs. Every activity } \\
\text { contains six statements, } \\
\text { scored } 0 \text { to } 5 .\end{array}$ & {$[122]$} \\
\hline
\end{tabular}




\subsection{Study aims of the prospective study (Paper III)}

The objective of this study was to explore if pregnant women with probable PGP, sub-grouped according to the clinical tests recommended in the European guidelines, differed in demographic and clinical characteristics at mid-pregnancy and the weekly number of days with bothersome symptoms through the second half of pregnancy. The hypothesis was that sacroiliac dysfunction and failing force closure diagnosed at mid-pregnancy might predict a course of bothersome symptoms through the second half of pregnancy.

\subsubsection{Setting and inclusion criteria}

Data collection was conducted at the obstetric outpatient clinic, Stavanger University Hospital, Norway, from mid-March to mid-June 2010. Pregnant women who had their second-trimester routine ultrasound examination in pregnancy week 18 were asked by a midwife about their experience of pain in the lumbopelvic region and were informed about the study. The inclusion criteria were ongoing lumbopelvic pain or isolated pelvic pain, singleton pregnancy and good proficiency in the Norwegian language. 


\subsubsection{Instruments and variables}

On acceptance to participate, the women were asked to sign a letter of consent. They were given an envelope with questionnaires on demographic and clinical features, used in a previous retrospective study on pelvic girdle pain $[20,28]$ to fill in at home. A chiropractor consultation for a physical examination was arranged, and the women were asked to bring the filled-in questionnaires with them to the examination. For comparative purposes, women without pain symptoms were informed about the study, given a letter of consent to fill in if they accepted to join the study, and a questionnaire on demographic features to fill in and hand to the receptionist on departure. All consenting women were followed from week 18 of their pregnancy to week six postpartum with weekly automated text messages (SMS).

Two licensed chiropractors performed a physical examination of the pelvic region, including diagnostic tests recommended in the European guidelines for diagnosing and treating pelvic girdle pain [7] and a neurologic examination of the lower extremities. The results of their examination were recorded as PGP or not PGP diagnosis. 


\subsubsection{Pain variables}

The women marked the pain location on drawings with the pelvis and the low back separated. Pain intensity was rated on a numerical rating scale (NRS) from 0 to 100 , anchored at 0 , meaning "No pain" and meaning 100 "Unbearable pain" [121]. Information on pain-related ADL was collected through the Oswestry Disability Index (ODI) [122]. At the time of data collection, the ODI was one of the main outcome measures for defining the disabling effects of spinal disorders and PGP [7, 122].

\subsubsection{Work-related variables}

Answers to a question on job satisfaction were recorded on a 5-point Likert scale with increments in two opposite directions ('Very bad' and 'Very good') and a neutral point in the middle [123].

\subsubsection{SMS-tracking}

Every Sunday, the women received an automated SMS asking how many days the previous week they had experienced bothersome pelvic pain [130]. The question was repeated 24 hours later if there was no reply [130]. The question should be answered with one single number between 
0 and 7 [130]. The response was automatically entered into a database, which contained continuous information updates from each participant throughout the study [130].

\subsubsection{Assessment instruments and procedures at baseline;} week 18

\begin{tabular}{|c|c|c|}
\hline $\begin{array}{l}\text { Instruments and } \\
\text { variables } \\
\text { interest }\end{array}$ & $\begin{array}{l}\text { Description of answer } \\
\text { options }\end{array}$ & Reference \\
\hline $\begin{array}{l}\text { Group-designed } \\
\text { questionnaire }\end{array}$ & & {$[28]$} \\
\hline Education (years) & $\begin{array}{l}\text { Number of years (including } \\
\text { elementary school) }\end{array}$ & \\
\hline Physical workload & $\begin{array}{l}\text { Five levels; from very easy to } \\
\text { very heavy. Sixth option: not } \\
\text { working }\end{array}$ & [123] \\
\hline Profession & Free text & \\
\hline Job satisfaction & $\begin{array}{l}5 \text { level Likert scale; from } \\
\text { very bad to very good }\end{array}$ & {$[124,125]$} \\
\hline $\begin{array}{l}\text { Weeks on sick leave/ } \\
\text { not been on sick leave }\end{array}$ & Number of weeks & \\
\hline $\begin{array}{l}\text { Weeks on full time } \\
\text { and part-time, }\end{array}$ & Number of weeks & \\
\hline
\end{tabular}


Method

\begin{tabular}{|c|c|c|}
\hline $\begin{array}{l}\text { including percentage } \\
\text { sick leave }\end{array}$ & & \\
\hline Cause for sick leave? & Free text & \\
\hline Height & Centimetres & \\
\hline $\begin{array}{l}\text { Weight (most } \\
\text { recently) }\end{array}$ & $\mathrm{Kg}$ & \\
\hline $\begin{array}{l}\text { Weight before } \\
\text { pregnancy }\end{array}$ & $\mathrm{Kg}$ & \\
\hline $\begin{array}{l}\text { Depressed until now } \\
\text { in this pregnancy }\end{array}$ & $\begin{array}{l}\text { Four categories: Never, } \\
\text { on/off, often, almost all the } \\
\text { time }\end{array}$ & [131] \\
\hline $\begin{array}{l}\text { If you have been } \\
\text { depressed: In which } \\
\text { weeks? }\end{array}$ & $\begin{array}{l}\text { Five categories: Weeks 1-4, } \\
5-8,9-12,13-16,17-20 .\end{array}$ & \\
\hline Chronic disease? & Yes/No & \\
\hline If yes, which disease? & Free text & \\
\hline $\begin{array}{l}\text { The number of } \\
\text { previous births? }\end{array}$ & Number. & \\
\hline $\begin{array}{l}\text { Pelvic pain in previous } \\
\text { pregnancies? }\end{array}$ & Yes/No & \\
\hline $\begin{array}{l}\text { Hormonal treatment to } \\
\text { achieve this } \\
\text { pregnancy? }\end{array}$ & Yes/No & \\
\hline
\end{tabular}


Method

\begin{tabular}{|l|l|l|}
\hline $\begin{array}{l}\text { Regular exercising (2- } \\
\text { 3x/week) before this } \\
\text { pregnancy? }\end{array}$ & Yes/No & \\
\hline $\begin{array}{l}\text { Regular exercising (2- } \\
\text { 3x/week) in this } \\
\text { pregnancy? }\end{array}$ & Yes/No & \\
\hline $\begin{array}{l}\text { Injuries to the pelvis? } \\
\text { Type of injury }\end{array}$ & Yes/No & \\
\hline $\begin{array}{l}\text { Low back pain until } \\
\text { now in this } \\
\text { pregnancy? }\end{array}$ & Yes/No & \\
\hline $\begin{array}{l}\text { Pelvic pain until now } \\
\text { in this pregnancy? }\end{array}$ & Yes/No & \\
\hline $\begin{array}{l}\text { Low back pain onset } \\
\text { in which weeks? }\end{array}$ & $\begin{array}{l}\text { Five categories: Weeks 1-4, } \\
5-8,9-12,13-16,17-20\end{array}$ & \\
\hline $\begin{array}{l}\text { Low back pain } \\
\text { location }\end{array}$ & Pain drawing & \\
\hline $\begin{array}{l}\text { Low back pain level in } \\
\text { weeks 1-4, 5-8, 9-12, } \\
\text { 13-16, 17-20? }\end{array}$ & NRS 0-100 & \\
\hline $\begin{array}{l}\text { Sick leave for low } \\
\text { back pain in this } \\
\text { pregnancy? }\end{array}$ & $\begin{array}{l}\text { Five categories: Weeks 1-4, } \\
\text { which weeks? }\end{array}$ & \\
\hline Pelvic pain onset in & $\begin{array}{l}\text { Five categories: Weeks 1-4, } 13-16,17-20 \\
5-8,9-12,13-16,17-20\end{array}$ \\
\hline
\end{tabular}


Method

\begin{tabular}{|c|c|c|}
\hline Pelvic pain location & $\begin{array}{l}\text { Pain drawing; pelvis } \\
\text { back/front }\end{array}$ & {$[40]$} \\
\hline $\begin{array}{l}\text { Pelvic pain level in } \\
\text { weeks } 1-4,5-8,9- \\
12,13-16,17-20 ?\end{array}$ & NRS 0-100 & [121] \\
\hline $\begin{array}{l}\text { Sick leave for pelvic } \\
\text { pain in this } \\
\text { pregnancy? }\end{array}$ & $\begin{array}{l}\text { Five categories: Weeks 1-4, } \\
5-8,9-12,13-16,17-20\end{array}$ & \\
\hline $\begin{array}{l}\text { Modified } \\
\text { Trendelenburg`s test }\end{array}$ & Positive/Negative & [22] \\
\hline $\begin{array}{l}\text { Active straight leg } \\
\text { raise (ASLR) }\end{array}$ & $\begin{array}{l}\text { 6-point scale; From "not } \\
\text { difficult at all" to "unable to } \\
\text { do." }\end{array}$ & [132] \\
\hline $\begin{array}{l}\text { Posterior pelvic pain } \\
\text { provocation test }(\mathrm{P} 4)\end{array}$ & Positive/Negative & [133] \\
\hline Gaenslen`s test & Positive/Negative & {$[95]$} \\
\hline Patrick`s FABER test & Positive/Negative & {$[22]$} \\
\hline $\begin{array}{l}\text { Long dorsal sacroiliac } \\
\text { ligament test }\end{array}$ & Positive/Negative & {$[22]$} \\
\hline $\begin{array}{l}\text { Symphysis palpation } \\
\text { test }\end{array}$ & Positive/Negative & {$[22]$} \\
\hline $\begin{array}{l}\text { Oswestry Disability } \\
\text { Index (ODI) }\end{array}$ & & \\
\hline $\begin{array}{l}\text { An instrument } \\
\text { measuring level of }\end{array}$ & $\begin{array}{l}\text { A subjective percentage score } \\
\text { of the level of function based }\end{array}$ & [122] \\
\hline
\end{tabular}


Method

\begin{tabular}{|l|l|l|}
\hline $\begin{array}{l}\text { disability in activities } \\
\text { of daily living (ADL) }\end{array}$ & $\begin{array}{l}\text { on 10 ADL`s. Every activity } \\
\text { contains six statements, } \\
\text { scored from } 0 \text { to 5. }\end{array}$ & \\
\hline SMS-Track & $\begin{array}{l}\text { Answer with a single number } \\
0-7 .\end{array}$ & {$[130]$} \\
$\begin{array}{l}\text { No. of days with } \\
\text { pain in the previous } \\
\text { week? }\end{array}$ & & \\
\hline
\end{tabular}

\subsection{Analysis of the retrospective data (Papers I and II)}

\subsubsection{Paper I}

The objective of this paper was to examine the prevalence and incidence of LBP, PGP and LBPP during pregnancy, including features possibly associated with the development of PGP in an unselected population of pregnant women. In this analysis, we studied the influence of the following variables on LBP, PGP and LBPP during pregnancy: 
Method

\begin{tabular}{|l|l|}
\hline \multicolumn{2}{|c|}{ 2.3.2 Independent variables in Paper I } \\
\hline Pre-pregnancy variables & Pregnancy variables \\
\hline -BMI before pregnancy [134] & -Age at delivery [41] \\
-LBP in previous pregnancies [2] & -BMI at delivery [134] \\
-PGP in previous pregnancies & -Exercised at least 2-3 \\
[135] & times/week during pregnancy \\
-LBP in the year before pregnancy & {$[135]$} \\
[87] & -Weeks of full-time sick leave \\
-PGP in the year before pregnancy & during pregnancy [127] \\
[2] & -Received treatment for LBP \\
-Exercised at least 2-3 times/week & and/or PGP during pregnancy \\
before pregnancy [135] & {$[40]$} \\
-Number of years of education [40] & -ODI [7, 101] \\
-Physically heavy work [2] & -Moderate and severe pain \\
-Number of previous births [87] & distribution according to pain \\
drawings [30]
\end{tabular}

Descriptive data on demographic and clinical features were presented by mean values and standard deviations for continuous variables and frequencies for categorical variables. The dependent variable: pain symptoms, was classified into three pain levels through analyses of variance. The cut-off point with the largest $\mathrm{F}$ ratio between mild and 
moderate and severe pain was found at 35 in the NRS (0-100). Thus, patients were grouped into three pain categories:

-No pain $(\mathrm{NRS}=0)$

-Mild pain $(\mathrm{NRS} \leq 35)$

-Moderate and severe pain (NRS $>35$ ).

Kruskal-Wallis statistics were used to explore these pain groups for differences regarding pre-pregnant and pregnant variables. Multivariate hierarchical logistic regression analysis was used to calculate whether the pre-pregnancy and pregnancy variables could predict moderate to severe PGP (with no pain as the reference category). Mild pain was omitted from the analysis because of presumed low clinical interest for their ADL. In the first block of the analysis, age, educational level, and the number of previous births were entered, followed by a block containing the average LBP level throughout the pregnancy. The last block used backwards stepwise regression using the likelihood ratio removal criterion, including the variables workload, BMI before the pregnancy, BMI at birth, feelings of depression during pregnancy, physical activity before, and physical activity during pregnancy. Thus, 
the first two blocks served mainly as statistical controls with the forced entry of all variables before exploring the final block variables.

All analyses were performed in SPSS 16 (IBM, New York, NY), and results were considered significant at $\mathrm{P} \leq .05$.

\subsubsection{Paper II}

The primary objective of this paper was to examine the frequency of sick leave in pregnancy due to PGP and to assess the relationship with different types of pain-related ADLs, physical workload, and type of work. Variables entered into the analysis were age [136], years of education [40], BMI before pregnancy [134], number of total sick leave weeks during pregnancy [127], physical workload [2], work satisfaction [21], average PGP [2], average LBP [137], depressed [131], no. of previous births [40], regular exercise 2-3 times per week before pregnancy [135], seated work [138], Oswestry disability index; 10 items [41].

A further objective was to explore factors associated with less sick leave due to PGP by contrasting two groups of women with PGP, differing by having been versus not having been on sick leave for their pain. The final 
objective was to explore the relative contribution of PGP to the total amount of sick leave in pregnancy.

In this paper, the women were classified into three groups (the dependent variable):

-Women who did not report sick leave

-Women who reported sick leave but without indicating PGP as the cause -Women who reported sick leave and stated PGP as a partial origin of their sick leave.

Descriptive data on demographic and clinical features were reported as mean values, standard deviations for continuous variables, and as frequencies for categorical variables.

For comparisons of the three groups with different sick leave patterns, the non-parametric Kruskal-Wallis statistics were used, applying Bonferroni correction to counteract multiple comparisons. The next step in the analysis was pairwise follow-ups with the group who had sick leave due to PGP as a reference whenever significant omnibus group differences were found in the previous Kruskal-Wallis test. For categorical data, chi-square statistics were calculated, and $2 \times 2$ table 
follow-ups were used for pairwise comparisons between the group with sick-leave due to PGP vs the other groups.

Multinomial logistic regression analysis was then performed to investigate the independent input of variables hypothesized to affect sick leave due to PGP. Forced entry was implemented for the variables age, education, parity, and average PGP to adjust for them in the final model. In an exploratory approach, single items from ODI (except sex and pain intensity) were entered in a stepwise procedure together with the variable's workload, work satisfaction and seated work (= working in a sitting position), using a likelihood ratio-based criterion with $\mathrm{p}<.05$ for entry and $\mathrm{p}<.10$ for exclusion.

A sequential linear regression analysis was performed, using the total number of calculated weeks of sick leave (weeks of $100 \%$ sick leave + weeks of part-time sick leave multiplied by sick leave percentage) for any reason as a dependent variable to explore the factors linked with the total amount of sick leave in pregnancy:

-In the first block, the grand mean of monthly reported PGP was entered to analyze the unadjusted effect of PGP on weeks of sick leave. 
-In the next block, all appropriate ODI items were entered using a stepwise procedure ( $p<.05$ to enter, $p<.01$ to omit a variable).

-In block 3, the variables years of education, pre-pregnant BMI, workload, age, standing work, and mobile work were entered, using the same stepwise procedure as in block 2 .

-Finally, the variables work satisfaction and depression in pregnancy were entered with a stepwise procedure.

Only block 1 contained a forced entry variable, average PGP, as the objective was to explore unadjusted and adjusted effects of PGP on weeks of sick leave. In order to explore factors that may diminish the influence of PGP on sick leave, all women with PGP who did not report sick leave in pregnancy were identified.

When calculating causal effects using observational data, it is desirable to replicate a randomized experiment as closely as possible by obtaining intervention, in this case, sick leave, and control groups with comparable covariate distributions. This goal can often be obtained by choosing wellmatched samples of these groups, thereby reducing bias due to the covariates [139]. Thus, a macro was written in Microsoft Excel (Visual Basic) then selected a random woman having been on sick leave, who 
matched the mean PGP score of a woman with no sick leave. If a perfect match was not found, a difference of $+/-1$ point on the PGP score was approved. If still no match was found, the subject was rejected. Hence, this procedure resulted in two equal groups regarding mean PGP, but with and without sick leave. The same variables were compared in these two equal groups for the sick leave due to PGP vs no sick leave and sick leave due to other reasons groups in a Mann-Whitney U test. Effect sizes (the strength of the relationship between two variables) were reported as standardized mean differences (Cohen's D), using Bonferroni correction, which can be interpreted as small (around 0.3), medium (around 0.5) and large (0.8 to infinity) [140].

The analyses were conducted using SPSS 21 (IBM, New York, NY), and results were considered significant at $\mathrm{p}<.05$.

\subsection{Analysis of the prospective data}

\subsubsection{Paper III}

The objective of this paper was to examine if pregnant women with probable PGP, sub-grouped following the results from two valid and reliable clinical tests recommended in the European guidelines, differ in 
demographic and clinical characteristics at mid-pregnancy and the weekly number of days with bothersome symptoms through the second half of pregnancy. The hypothesis was that sacroiliac dysfunction and failing force closure diagnosed at mid-pregnancy might predict a course of bothersome symptoms through the second half of pregnancy.

Demographic descriptive data were shown as mean and median values with standard deviation for continuous variables and frequencies for categorical variables.

For univariate comparisons between symptomatic and asymptomatic subgroups, the non-parametric Kruskal-Wallis statistic was performed. Categorical predictors in our model were four groups, following the results from the ASLR and P4 tests:

-P4 positive

-ASLR positive

-Both P4 and ASLR positive

-ASLR and P4 negative

The time (pregnancy week) and the interaction term between time and test group explore whether the trajectory of SMS-reported number of bothersome days differed between the test groups. Age, parity, and BMI 
before pregnancy have previously shown significant association with PGP and were added to our model [134].

The longitudinal trajectory of the SMS- responses were modelled using a generalized estimating equations (GEE) approach, extending the generalized linear model to correlated longitudinal data and clustered data within subjects. The within-subject dependencies resulting from repeated measurement were modelled, assuming an autoregressive relationship in the working correlation matrix. As the outcome variable was count data (weekly number of bothersome days with pain), the Poisson distribution was assumed with a log-link function.

A robust non-parametric Brown-Forsythe ANOVA then examined equality of variances and data distribution within and between test groups. Data were analyzed using SPSS software (version 22.0; SPSS Inc, Chicago, IL, USA). A p-value $<0.05$ was considered statistically significant.

\subsection{Ethics}

Both projects (retrospective and prospective) were carried out following the Helsinki Declaration II (https://www.who.int/bulletin/archives/79 (4) 
373.pdf). The Regional Ethics Committee approved the retrospective study of Western Norway (rek-vest, ref.no. 2009/356-CAG). The Regional Ethics Committee approved the prospective research project of Northern Norway (rek-nord, ref. no. 2010/174).

All participants received written and oral information about each study's aim and the test procedures in the prospective study. All individuals provided written informed consent before participation. They were informed that participation was voluntary and that they could discontinue participation in the prospective study at any point without explanation. No risks to the women in the studies were identified. 


\section{RESULTS}

\subsection{The retrospective data collection (Papers I and II)}

At Stavanger University Hospital, 1204, women gave birth during the inclusion period. All women were invited to participate, and after exclusions, 994 women were eligible for the study. However, 336 women did not return a questionnaire, and 89 did not fully complete the questionnaire. Thus, the final study population consisted of 569 women, $58 \%$ of the total possible sample.

To examine if the study sample was representative of the source population, we compared to age and parity from the study sample with all women who gave birth during the study period and found an almost perfect match.

\subsubsection{Demographic features}

The women's mean age was 30 years, mean years of education was 14.7 years, and slightly more than one-third of the women were primiparous. The mean BMI was 23.8, and almost half of the women exercised 2 to 3 times per week 
before pregnancy. The mean amount of sick leave during the pregnancy was 9.6 weeks.

\subsubsection{Pain}

Approximately a quarter of the participants did not report any LBPP during their pregnancy. A further $13 \%$ had only experienced mild pains, while the cumulative prevalence for moderate and severe pain during pregnancy was $57.4 \%(\mathrm{n}=$ 327). Moderate and severe combined LBPP was experienced by $21.6 \%(\mathrm{n}=123)$, moderate and severe PGP was experienced by $26.0 \%(\mathrm{n}=148)$, and almost $10 \%$ of the women $(\mathrm{n}=56)$ had moderate and severe pain in the lumbar area. Twenty-three per cent of all women, $40 \%$ of those who developed moderate and severe pain, reported such pain already after five months of pregnancy.

\subsubsection{Pain distribution}

Table 1 below illustrates the distribution of pain in the pelvic area for all women reporting pain in this region, divided into women with moderate and severe LBPP and those with moderate and severe PGP alone. More than half of all women 
$(52 \%)$ experienced pain at the symphysis, and circa $20 \%$ experienced pain only in this area. Approximately $33 \%$ had pain at all three pelvic joints, and $24 \%$ had pain at one sacroiliac joint alone. Almost half the women with moderate and severe lumbopelvic pain experienced pain at all three pelvic joints.

Table 1: Prevalence of moderate and severe pain distribution according to the pain drawings among women reporting pain during pregnancy.

\begin{tabular}{|c|c|c|c|}
\hline Pain location & $\begin{array}{c}\text { All women with } \\
\text { pelvic pain } \\
N=348\end{array}$ & $\begin{array}{l}\text { Moderate and } \\
\text { severe } \\
\text { pelvic girdle pain } \\
\quad N=148\end{array}$ & $\begin{array}{l}\text { Moderate and } \\
\text { severe } \\
\text { lumbopelvic pain } \\
\quad N=123\end{array}$ \\
\hline $\begin{array}{r}\text { At all pelvic joints, } N \\
\text { (\%) }\end{array}$ & $113(32.5)$ & $40(27.0)$ & $58(47.2)$ \\
\hline At symphysis, $N(\%)$ & $67(19.3)$ & $33(22.3)$ & $18(14.6)$ \\
\hline At one SI joint, $N(\%)$ & $83(23.9)$ & $38(25.7)$ & $24(19.5)$ \\
\hline At both SI joints, $N(\%)$ & $60(17.2)$ & $27(16.2)$ & $16(13.0)$ \\
\hline Other areas, $N(\%)$ & $7(2.0)$ & $1(0.7)$ & $2(1.6)$ \\
\hline Missing data, $N(\%)$ & $18(5.2)$ & $9(6.1)$ & $5(4.1)$ \\
\hline
\end{tabular}




\subsubsection{Potential risk factors}

In the multivariate analysis, we examined the impact of clinical and demographic variables on moderate to severe PGP. The first block of the binary logistic regression analyses was not statistically significant $(p=0.379)$, indicating that age, education, and the number of previous births did not contribute to the prediction of moderate to severe PGP. The following block, however, was highly significant ( $\mathrm{p} \leq 0.001)$, showing that a high level of LBP reduced the risk of PGP ( $\mathrm{p} \leq 0.001$; odds ratio: 0.845, [CI; 0.798-0.894]). The final block containing previously entered variables, and the variables remaining after the backward stepwise procedure (BMI before pregnancy and physical activity before pregnancy), was also highly significant $(\mathrm{p} \leq 0.001)$. The resulting omnibus logistic regression model was significant ( $\mathrm{p} \leq 0.001$, Nagelkerke $R 2=0.319)$. Predictor variables in the full multivariate model were average LBP ( $\mathrm{x} \leq 0.001$, odds ratio; 0.837, [CI: $0.790-0.887])$, BMI before pregnancy $(\mathrm{p}=0.011$, odds ratio: 1.074, [CI: 1.016-1.134]), and physical activity before pregnancy $(\mathrm{p}=0.015$, odds ratio; 1.826 , [CI: 1.126-2.960]). So, both higher BMI before pregnancy and higher physical activity levels 
before pregnancy were independent potential risk factors for PGP after controlling for age, education, number of previous pregnancies, and LBP. Average LBP during pregnancy reduced the risk of moderate to severe PGP.

\subsubsection{Sick-leave and disability}

Women with moderate to severe LBPP had a mean sick-leave period of 15.5 weeks, those with moderate to severe PGP 10.7 weeks, and women with moderate to severe LBP 9.1 weeks. Women with mild pain had a mean sick-leave period of 6.5 weeks, indicating that experiencing moderate to severe pain had different clinical consequences from experiencing less pain. The same pattern was found for disability, measured with the ODI. Women with PGP were seeking more care than women with lumbar pain, and those with moderate to severe pain received more treatment than those with mild pain.

In the analysis to explore the frequency of sick leave in pregnancy due to PGP and to assess the relationship of different types of pain-related ADLs, physical workload, and type of work with sick leave due to PGP, one woman was excluded from the analyses (she did not report having a 
job, profession, nor workload). This analysis thus consisted of 568 women. Of these, $165(29 \%)$ reported that they had experienced isolated PGP during the pregnancy. The sample's demographic and descriptive statistics for the variables used in the multivariate analyses are shown in Table 2. Several significant differences were found between subjects who reported sick leave due to PGP vs those who did not.

Table 2: Demographic data and descriptive statistics of women with and without sick leave for variables used in the multivariate analyses.

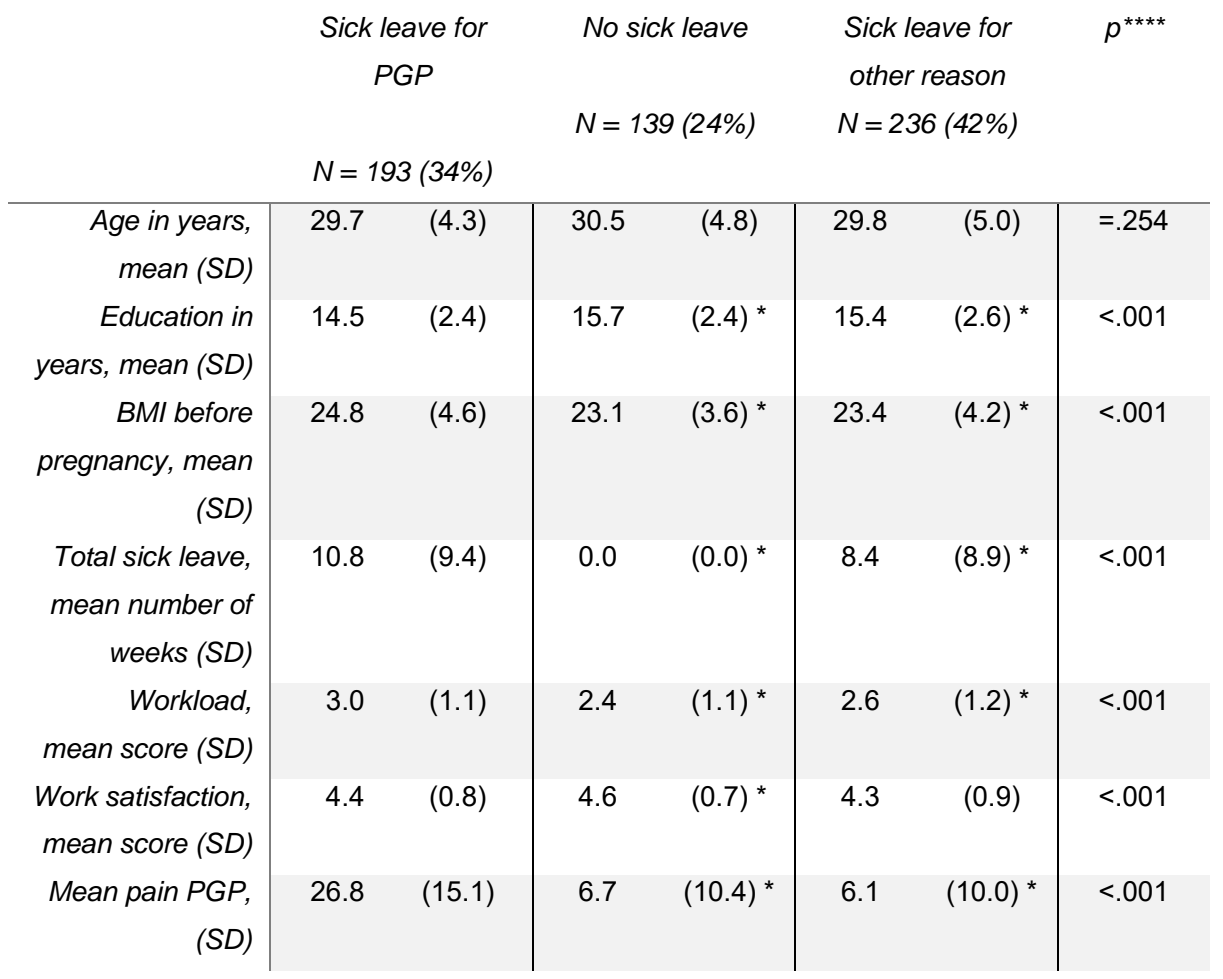


Results

\begin{tabular}{|c|c|c|c|c|c|c|c|}
\hline $\begin{array}{r}\text { Mean pain } L B P \\
(S D)\end{array}$ & 13.2 & $(16.9)$ & 4.7 & $(9.1)^{*}$ & 6.6 & $(11.4)^{*}$ & $<.001$ \\
\hline $\begin{array}{r}\text { Pain-related } A D L \\
(O D I), \text { mean } \\
\text { score }(S D)\end{array}$ & 1.9 & $(0.8)$ & 0.9 & $(0.9)^{*}$ & 1.0 & $(0.8)^{*}$ & $<.001$ \\
\hline $\begin{array}{r}\text { Depressed, } \\
\text { mean score }(S D)\end{array}$ & 1.4 & $(0.5)$ & 1.3 & $(0.5)$ & 1.4 & $(0.6)$ & $=.055$ \\
\hline $\begin{array}{r}\text { No. of previous } \\
\text { births, mean (SD) }\end{array}$ & 1.00 & $(0.06)$ & 0.94 & $(0.09)$ & 0.79 & $\begin{array}{c}(0.05) \\
* * *\end{array}$ & $<.05$ \\
\hline $\begin{array}{r}\text { Regular exercise } \\
\text { before pregnancy, } \\
N(\%)\end{array}$ & \multicolumn{2}{|c|}{$63(33 \%)$} & \multicolumn{2}{|c|}{$67(49 \%)^{* *}$} & \multicolumn{2}{|c|}{$94(40 \%)$} & $=.013$ \\
\hline $\begin{array}{r}\text { Seated work, } N \\
(\%)\end{array}$ & \multicolumn{2}{|c|}{$51(27 \%)$} & \multicolumn{2}{|c|}{$68(49 \%)$ * } & \multicolumn{2}{|c|}{$81(34 \%)$} & $<.001$ \\
\hline
\end{tabular}

In Table 3, a comparison was made for all single items from the ODI between the group with sick leave due to PGP, the group without sick leave, and sick leave due to other causes. Effect sizes were reported to enable a direct comparison using a standardized scale. All ODI-items were significantly higher in the group who had been on sick leave for PGP than in both the other groups. The effect sizes were all moderate to large (Cohen's d > 0.6). 
Table 3: Comparison of disability in activities (ODI single items) between women with sick leave due to PGP, women with no sick leave, and women with sick leave due to other causes.

\begin{tabular}{|c|c|c|c|c|c|}
\hline \multirow[b]{3}{*}{ ODI item } & \multirow{3}{*}{$\begin{array}{l}\text { Sick leave for } \\
\qquad \mathrm{N}=190 \\
\text { Mean (SD) }\end{array}$} & \multirow{2}{*}{\multicolumn{2}{|c|}{$\begin{array}{c}\text { No sick leave } \\
\mathrm{N}=96\end{array}$}} & \multirow{2}{*}{\multicolumn{2}{|c|}{$\begin{array}{l}\text { Sick leave for other } \\
\qquad N=154\end{array}$}} \\
\hline & & & & & \\
\hline & & $\begin{array}{l}\text { Mean } \\
(\mathrm{SD})\end{array}$ & E.S. ${ }^{a}$ & $\begin{array}{l}\text { Mean } \\
(\mathrm{SD})\end{array}$ & E.S. ${ }^{a}$ \\
\hline Pain intensity & $2.76(0.86)$ & $\begin{array}{c}1.67 \\
(1.13)\end{array}$ & 1.142 & $\begin{array}{c}1.81 \\
(0.99)\end{array}$ & 1.024 \\
\hline Personal care & $1.23(1.40)$ & $\begin{array}{c}0.59 \\
(0.97)\end{array}$ & 0.591 & $\begin{array}{c}0.53 \\
(0.98)\end{array}$ & 0.655 \\
\hline Lifting & $2.18(1.19)$ & $\begin{array}{c}0.95 \\
(1.12)\end{array}$ & 1.056 & $\begin{array}{c}1.30 \\
(1.16)\end{array}$ & 0.751 \\
\hline Walking & $1.63(0.99)$ & $\begin{array}{c}0.65 \\
(0.94)\end{array}$ & 1.007 & $\begin{array}{c}0.85 \\
(1.05)\end{array}$ & 0.762 \\
\hline Sitting & $1.68(0.96)$ & $\begin{array}{c}0.80 \\
(0.98)\end{array}$ & 0.905 & $\begin{array}{c}1.07 \\
(1.11)\end{array}$ & 0.589 \\
\hline Standing & $2.44(1.24)$ & $\begin{array}{c}1.17 \\
(1.28)\end{array}$ & 1.018 & $\begin{array}{c}1.48 \\
(1.27)\end{array}$ & 0.769 \\
\hline Sleeping & $1.67(1.02)$ & $\begin{array}{c}0.82 \\
(0.88)\end{array}$ & 0.872 & $\begin{array}{c}1.04 \\
(0.88)\end{array}$ & 0.657 \\
\hline Sex & $1.75(1.50)$ & $\begin{array}{c}0.76 \\
(1.19)\end{array}$ & 0.707 & $\begin{array}{c}0.76 \\
(1.30)\end{array}$ & 0.701 \\
\hline Social function & $1.89(1.26)$ & $\begin{array}{c}0.83 \\
(1.17)\end{array}$ & 0.862 & $\begin{array}{c}0.79 \\
(1.14)\end{array}$ & 0.911 \\
\hline Travelling & $1.63(1.26)$ & $\begin{array}{c}0.61 \\
(1.00)\end{array}$ & 0.860 & $\begin{array}{c}0.82 \\
(1.11)\end{array}$ & 0.680 \\
\hline
\end{tabular}

${ }^{a}$ All differences of means were statistically significant, assuming a Bonferroni corrected alpha of $p<.005$

\subsubsection{Factors associated with sick leave due to PGP}

Individual risk factors with odds-ratios and confidence intervals resulting from the multinomial regression analysis are shown in Table 4 
below. All results refer to the group with sick leave due to PGP as the reference category. The estimated pseudo-R2 was relatively high (Nagelkerke R2 $=.40$ ), and the total correct classification percentage was $62 \%$. Work satisfaction and lower scores for the ODI-items lifting, sleep, and average pain intensity significantly classified individuals to the no sick leave group.

Table 4: Risk factors for sick leave during pregnancy, with sick leave due to PGP as the reference category. For each factor, the odds ratio and p-value (in brackets) are displayed.

\begin{tabular}{r|cccccccc}
\multicolumn{2}{c}{ Age } & Education & $\begin{array}{c}\text { Pelvic } \\
\text { pain }\end{array}$ & $\begin{array}{c}\text { No of } \\
\text { previous } \\
\text { births }\end{array}$ & $\begin{array}{c}\text { ODI } \\
\text { lifting }\end{array}$ & $\begin{array}{c}\text { ODI } \\
\text { sleep }\end{array}$ & $\begin{array}{c}\text { ODI } \\
\text { social } \\
\text { life }\end{array}$ & $\begin{array}{c}\text { Work } \\
\text { satisfaction }\end{array}$ \\
\hline $\begin{array}{r}\text { Sick } \\
\text { leave } \\
\text { due to } \\
\text { other }\end{array}$ & 1.051 & 1.054 & 0.951 & 0.760 & 0.708 & 0.916 & 0.785 & 0.960 \\
reason & $(0.129)$ & $(0.262)$ & $(0.000)$ & $(0.128)$ & $(0.020)$ & $(0.622)$ & $(0.105)$ & $(0.814)$ \\
No sick & 1.056 & 1.113 & 0.955 & 0.915 & 0.622 & 0.521 & 1.206 & 1.607 \\
leave & $(0.157)$ & $(0.074)$ & $(0.001)$ & $(0.667)$ & $(0.011)$ & $(0.008)$ & $(0.294)$ & $(0.049)$ \\
& & & & & & & & \\
\end{tabular}

The matching procedure resulted in two groups, with 50 subjects in each group. The group with sick leave due to PGP and the group with no sick leave had similar PGP intensities (approximately 18/100). Univariate Mann-Whitney U test revealed that the group with no sick leave (the 
coping group) on average had longer education (15.8 vs 14.8 years), $p=$ 0.022 and higher work-satisfaction ( 4.66 vs 4.32$), \mathrm{p}=0.014$. Finally, the scores on several ODI items were lower in the coping group (with no sick leave), as seen in Table 5.

The methods section in Paper II describes an analysis using sequential linear regression with the total number of weeks as the dependent variable. This analysis is not included in the result section due to an unfortunate error, and the analysis was not performed as planned.

Table 5: Disability (ODI scores) in women with and without sick leave for PGP. For each item, the mean score and SD (in brackets) are displayed.

\begin{tabular}{r|cccc} 
ODI item & No sick leave for PGP & Sick leave for PGP & E.S. & $p$ \\
\hline Pain intensity & $2.30(0.84)$ & $2.33(0.88)$ & 0.039 & $=.954$ \\
Personal care & $0.90(1.11)$ & $0.94(1.14)$ & 0.033 & $=.889$ \\
Lifting & $1.40(1.21)$ & $1.90(1.29)$ & 0.395 & $=.044$ \\
Walking & $0.96(1.01)$ & $1.44(0.97)$ & 0.483 & $=.011$ \\
Sitting & $0.96(1.00)$ & $1.46(0.87)$ & 0.528 & $=.003^{*}$ \\
Standing & $1.50(1.33)$ & $2.00(1.22)$ & 0.392 & $=.031$ \\
Sleeping & $1.12(0.85)$ & $1.48(1.03)$ & 0.379 & $=.113$ \\
Sex & $1.18(1.41)$ & $1.23(1.49)$ & 0.037 & $=.969$ \\
Social function & $1.26(1.27)$ & $1.33(1.31)$ & 0.056 & $=.677$ \\
Travelling & $0.92(1.12)$ & $1.25(1.23)$ & 0.280 & $=.180$
\end{tabular}


In a quasi-experiment, a matching procedure (i.e., when the intervention is not randomly assigned) enables comparison of groups with similar characteristics to estimate the effect of an intervention, the outcome in this process differ from the ODI-results presented in Table 3 as the effect sizes between the groups are very different for the different items. If a strict Bonferroni-correction is applied, only the ODI score for sitting is significantly higher in the group with sick leave due to PGP $(p=0.003)$ compared to the group not on sick leave.

\subsection{The prospective data collection (Paper III)}

Five hundred and six women agreed to participate in this study, but three were excluded due to incomplete data. At the ultrasound examination in pregnancy week $18,42 \%(212 / 503)$ of the women reported pain in the lumbopelvic region. A clinical examination revealed that 39\% (196/503) of the women fulfilled the criteria for a probable PGP diagnosis, and 27\% (137/503) showed a positive response to ASLR and P4 tests, which were the tests most frequently found positive, followed by the long dorsal ligament test and the symphysis provocation test. 
A further 12 women reported pelvic pain but did not get any of the recommended clinical tests positive. Hence they were placed in the ASLR and P4 tests negative group'.

\subsubsection{Demographic and clinical features}

In Paper III does Tables 1 and 2 illustrate significant differences in some demographic and clinical features at baseline and test outcomes between the women with and without pelvic pain. Columns $a-e$ add up to 503 . Column $f$ contains all positive ASLR and P4 test, i.e., the sum of columns $c-e$, for comparison with columns $a$ and $b$. Column $b$ contains women with other tests positive, which are described in paper III on page 2 under the subheading "Sequence of stability and pain provocation tests for PGP”. The women reported pelvic pain, but all tests, including ASLR and $\mathrm{P} 4$, were negative, hence they were placed in column $b$.

Women with positive P4 and ASLR tests experienced a heavier workload. They also presented with a higher BMI at week 18, exercised less both before and during pregnancy, and reported a higher rate of feeling depressed during the pregnancy.

Physical disability (ODI) and pain level (NRS) at week 18 were higher in women with positive tests than in women reporting pain but having 
negative P4 and ASLR tests. Among women with a positive ASLR but negative P4 test, the highest number of previous pregnancies was reported.

Most of the women were with a positive ASLR and negative P4 test (58\%). Almost half of the women with both P4 and ASLR tests positive (47\%) had been on sick leave during pregnancy. Among women with a positive $\mathrm{P} 4$ and negative ASLR, $38 \%$ had been on sick leave, and among women with both tests negative, $30 \%$ had been on sick leave during pregnancy.

\subsubsection{SMS-tracking}

The SMS response rate was $75 \%$ (2148 responses to 2877 sent messages). Due to a declining response at the end of the pregnancy, we stopped our analysis at week 38. A GEE analysis revealed that all entered variables except age were significant predictors for the number of days with bothersome pelvic pain. Further, there was a significant interaction between the diagnostic group and time, implying that the number of days with bothersome pelvic pain developed differently for the different test groups. 


\subsubsection{PGP course}

The estimated weekly mean number of days with bothersome pelvic pain for the different test groups is presented in Figure 1 on page 61. Women with both P4 and ASLR tests positive experienced a high weekly mean number of days (4.8 days) with bothersome pelvic pain from week 18 and throughout the pregnancy. Women with both tests negative showed a steadily increasing number of bothersome days throughout the pregnancy, from 0.5 days in week 18 to 2 days in week 37 . The group with a P4 positive and an ASLR negative test had approximately three days of bothersome pelvic pain in week 18 , which was considerably lower than the group with both tests positive. However, the number of days with pain rapidly increased. In week 29 , the mean number of days with bothersome pelvic pain equalled the group with both tests positive (5.1 days) and matched this group. 
Figure 1: Estimated mean number of bothersome days in the latter half of pregnancy.

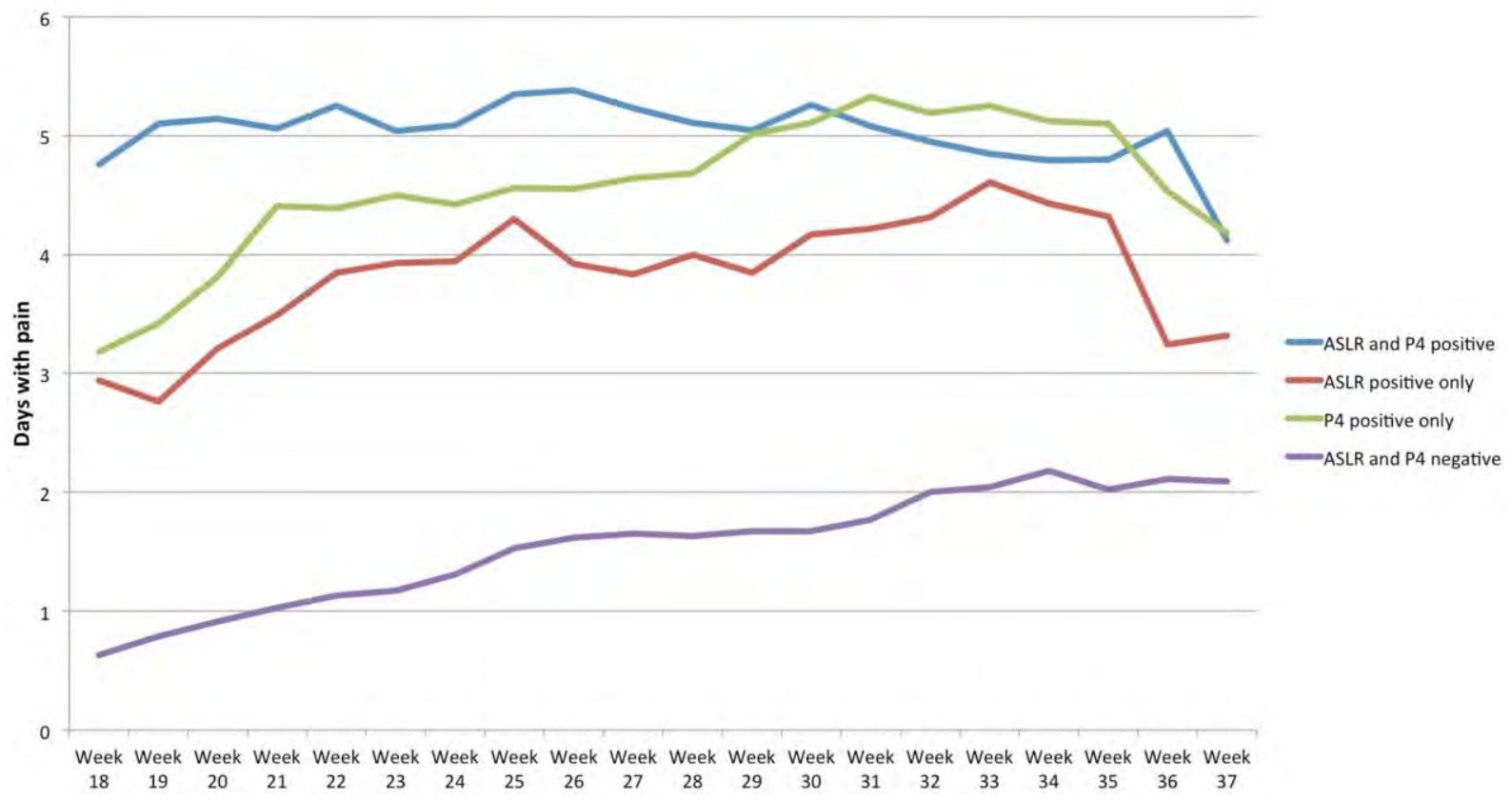

Women with a positive ASLR and a negative P4 test also showed three days of bothersome pelvic pain in week 18 . However, they never reached the mean number of bothersome days reported by women with P4 test positive and ASLR negative and both P4 and ASLR tests positive. 


\subsubsection{Factors predicting the number of bothersome days per} week

The estimated rate for experiencing bothersome days was 7.5 times higher in women with both ASLR and P4 tests positive than women with both tests negative (Table 6). Women with both tests positive had twice the number of bothersome days per week than the negative test group. For women with either P4 or ASLR test positive, the mean number of bothersome days was lower but still approximately 1.5 times higher than for women with both tests negative. For every pregnancy, the mean number of bothersome days increased by $13.5 \%$. Even a slightly higher BMI had a significant impact on the mean number of bothersome days. Age had no impact on this outcome. 
Table 6. Parameter estimates.

\begin{tabular}{|c|c|c|c|c|c|c|c|c|c|c|}
\hline \multirow[b]{2}{*}{$\begin{array}{r}\text { Paramet } \\
e r\end{array}$} & \multirow[b]{2}{*}{$B$} & \multirow[b]{2}{*}{$\begin{array}{l}\text { Std. } \\
\text { Error }\end{array}$} & \multicolumn{2}{|c|}{$\begin{array}{l}95 \% \text { Wald } \\
\text { Confidence } \\
\text { Interval }\end{array}$} & \multicolumn{3}{|c|}{ Hypothesis Test } & & \multicolumn{2}{|c|}{$\begin{array}{l}95 \% \text { Wald } \\
\text { Confidence } \\
\text { Interval for } \\
\operatorname{Exp}(B) \\
\end{array}$} \\
\hline & & & $\begin{array}{c}\text { Lowe } \\
r\end{array}$ & $\begin{array}{c}\text { Uppe } \\
r\end{array}$ & $\begin{array}{c}\text { Wald } \\
\text { Chi- } \\
\text { square }\end{array}$ & $\begin{array}{l}d \\
f\end{array}$ & Sig. & $\begin{array}{c}\operatorname{Exp}(B \\
)\end{array}$ & $\begin{array}{c}\text { Lowe } \\
r\end{array}$ & Upper \\
\hline $\begin{array}{c}P 4 \text { and } \\
A S L R \\
\text { positive }\end{array}$ & $\begin{array}{c}2.02 \\
1\end{array}$ & .1581 & $\begin{array}{c}1.71 \\
2\end{array}$ & $\begin{array}{c}2.33 \\
1\end{array}$ & $\begin{array}{c}163.48 \\
1\end{array}$ & 1 & $\begin{array}{c}0.00 \\
0\end{array}$ & 7.549 & $\begin{array}{c}5.53 \\
7\end{array}$ & $\begin{array}{c}10.29 \\
1\end{array}$ \\
\hline $\begin{array}{r}\text { ASLR } \\
\text { positive }\end{array}$ & $\begin{array}{c}1.54 \\
0\end{array}$ & $\begin{array}{c}.229 \\
7\end{array}$ & $\begin{array}{c}1.09 \\
0\end{array}$ & $\begin{array}{c}1.99 \\
1\end{array}$ & 44.992 & 1 & $\begin{array}{c}0.00 \\
0\end{array}$ & 4.667 & $\begin{array}{c}2.97 \\
5\end{array}$ & 7.319 \\
\hline $\begin{array}{r}P 4 \\
\text { positive }\end{array}$ & $\begin{array}{c}1.61 \\
7\end{array}$ & $\begin{array}{c}.183 \\
2\end{array}$ & $\begin{array}{c}1.25 \\
8\end{array}$ & $\begin{array}{c}1.97 \\
6\end{array}$ & 77.852 & 1 & $\begin{array}{c}0.00 \\
0\end{array}$ & 5.037 & $\begin{array}{c}3.51 \\
7\end{array}$ & 7.213 \\
\hline $\begin{array}{r}\text { Negative } \\
\text { tests }\end{array}$ & 0 * & & . & . & . & . & . & 1 & . & . \\
\hline Age & $\begin{array}{c}- \\
0.00 \\
9\end{array}$ & $\begin{array}{c}.006 \\
7\end{array}$ & $\begin{array}{c}- \\
0.02 \\
2\end{array}$ & $\begin{array}{c}0.00 \\
4\end{array}$ & 1.807 & 1 & $\begin{array}{c}0.17 \\
9\end{array}$ & 0.991 & $\begin{array}{c}0.97 \\
8\end{array}$ & 1.004 \\
\hline $\begin{array}{l}\text { No. of } \\
\text { births }\end{array}$ & $\begin{array}{c}0.13 \\
5\end{array}$ & $\begin{array}{c}.041 \\
5\end{array}$ & $\begin{array}{c}0.05 \\
3\end{array}$ & $\begin{array}{c}0.21 \\
6\end{array}$ & 10.551 & 1 & $\begin{array}{c}0.00 \\
1\end{array}$ & 1.144 & $\begin{array}{c}1.05 \\
5\end{array}$ & 1.241 \\
\hline $\begin{array}{r}B M I \\
\text { before } \\
\text { pregnanc } \\
y\end{array}$ & $\begin{array}{c}0.01 \\
3\end{array}$ & $\begin{array}{c}.006 \\
5\end{array}$ & $\begin{array}{c}0.00 \\
0\end{array}$ & $\begin{array}{c}0.02 \\
6\end{array}$ & 3.961 & 1 & $\begin{array}{c}0.04 \\
7\end{array}$ & 1.013 & $\begin{array}{c}1.00 \\
0\end{array}$ & 1.026 \\
\hline
\end{tabular}




\section{DISCUSSION}

Here, PGP incidence and prevalence were difficult to estimate because of the variability in terminology and diagnostic approaches in this field, which have changed during these studies. The project was initially based on the term "pelvic pain (PP) in pregnancy", illustrated in the first paper, with a plan to follow the diagnostic procedure introduced in the European guidelines and conduct thorough examinations for the correct diagnosis of PGP in the second data collection [7]. However, despite the new term pelvic girdle pain, PGP, and its recommended diagnostic testing procedure, a diverse nomenclature still prevails, with and without physical testing, including pelvic girdle syndrome [89, 141], pregnancyrelated lumbopelvic pain [14], pregnancy-related symphysis pubis dysfunction [142], pregnancy-related low back and pelvic pain [143], pregnancy-induced low back pain [144], posterior pelvic girdle pain (PPGP) [145], and pregnancy-related pelvic girdle pain [146]. Although the term PGP may be somewhat too narrow, focusing solely on the -pain associated with this condition without considering how it affects a woman's activity level and participation in daily activities, we chose to 
employ this term in our remaining studies since it is the term recommended by the European guidelines [7].

\subsection{Methodological considerations}

\subsubsection{Retrospective study}

The first of this project's two data collections were retrospective. Although retrospective studies in this field are not uncommon, we could not identify any study comparing postpartum recall of pelvic pain in pregnancy with prospectively prepartum recorded pain data. Whereas some studies find assessing pain retrospectively unreliable [126, 147, 148], others report acceptable validity levels up to a 3-months recall period $[149,150]$. It has been reported that pain is usually overestimated when pain intensity is high and underestimated when it is low $[126,148$, 151]. Pain and disability recall were found to be influenced by current pain and disability levels. In contrast, the influence of pain relief and disability reporting at the initial consultation one year earlier were less influential [152]. However, recall of chronic pain in terms of its average intensity, interference with activities (disability due to pain), number of 
days with pain and number of days with activity limitation in the previous six months show acceptable validity levels [150].

Pain recall seems to be good on a group level, but between and within individuals, the variability between monthly, quarterly, and yearly retrospective measurements are high [153]. Social support from, e.g., colleagues make you talk more about your pain and thereby increase the awareness of the pain and thus lead to an over-reporting of symptoms [153]. A meta-analysis aimed at determining whether pregnancy is associated with objective declines in cognitive functioning included 20 studies [154]. The conclusion was that performance related to memory, and executive functioning was significantly poorer in pregnant than in control women, particularly during the third trimester.

A literature review of studies using objective memory testing suggests that a mild antepartum decline in explicit verbal recall occurs in some women [155]. Diminished memory function may occur in a specific subset of pregnant women who display depressive symptoms associated with pregnancy [155]. 
Thus, the retrospectively collected data on pain during pregnancy may, in some circumstances, be biased. There was, unfortunately, no data in the project on the participants' social support or depression during pregnancy to allow controlling for these factors.

The retrospective data collection was completed for four months, in which all women $(\mathrm{n}=1204)$ giving birth at Stavanger University Hospital were asked to participate in the study. The hospital has the only birth department in the southern part of the county of Rogaland, Norway, with a population of about 330,000 inhabitants. The 994 women eligible for the study were found to match the general delivery database at the hospital regarding the age and parity of all women who gave birth during the study period. Thus, we are confident that the study sample represents women giving birth in the county of Rogaland.

Three-hundred and thirty-six $(\mathrm{n}=336)$ women did not return a questionnaire, and 89 did not complete a received questionnaire, resulting in a relatively low response rate $(569 / 994,57 \%)$, probably reflecting other priorities of the women in the stressful situation shortly after delivery. The response rate could also be caused by a particular 
lower interest in the study by women not experiencing any pain during pregnancy, introducing a bias toward overestimating the frequency of moderate to severe pelvic and lumbar pain Norwegian population. Research has shown that studies with low response rates, even as low as $20 \%$, may generate more accurate results than studies with higher response rates of $60 \%$ to $70 \%$ [156]. Reviews of response rates ranging from $5 \%$ to $54 \%$ have also reported that studies with a much lower response were often only marginally less accurate than those with higher response rates $[157,158]$. A low response rate does not naturally mean low validity. It only illustrates a potentially greater risk for this. Response rates remain informative and are on their own not a good representative for study validity [159].

The impact of PGP on general functioning was measured through patients' self-reports. Most of the instruments frequently utilized in clinical studies in this field were developed and tested for psychometric properties in patients with LBP, including disability instruments such as the Oswestry Disability Index (ODI) [122] and the Disability Rating Index (DRI) [160]. A condition-specific instrument for PGP, the Pelvic Girdle Questionnaire (PGQ), was developed one year after this project's 
data collection was completed. The PGQ assesses activity limitations and symptoms and is found to have good internal consistency, test-retest reliability, good construct validity, satisfactory discriminant validity, and reliability [161]. It is important to provide evidence for the comparative performance of instruments to inform future selection in research, and the PGQ has been used extensively in recent years [34, 67, 162-164].

An existing suitable questionnaire for the retrospective data collection objectives could not be found at the time of data collection. Instead, the research team, consisting of competent researchers in obstetrics, psychology, and neurology, constructed a questionnaire based on their expertise and experience, using validated scales (Appendix 1). Answers in the completed questionnaires did not produce any extreme outliers, so we are confident of their face and content validity.

In a Swedish study with a similar objective and design as in Paper I, 72\% of pregnant women had LBP or PGP during pregnancy [40]. In our study, $71 \%$ had experienced pain in the lumbopelvic area. Identical results from two neighbouring countries suggest the validity of the findings in Paper I. However, it is important to note that studies using questionnaires that have not been validated in the population of interest may be subject to 
measurement error, and any conclusions drawn should be interpreted in the light of this fact.

\subsubsection{Prospective study}

In striving for a homogenous study population, all women were consecutively recruited for data collection at the same stage in pregnancy, week 18, which is the baseline in this prospective data collection. On arrival for their $18^{\text {th }}$-week routine ultrasound examination, they were all screened by independent midwives for possible pelvic pain. Outcomes of the diagnostic tests recommended in the European guidelines for the diagnosis of PGP were systematically recorded. Two tests at baseline had by far the highest number positive reactions, the two with the highest specificity and highest sensitivity for sacroiliac joint pain and functional pelvic test: the posterior pelvic pain provocation test and the active straight leg raise test [7], i.e., diagnostic tests for excessive force closure and reduced force closure respectively.

Women with these two tests positive were followed with weekly SMS, introduced for the first time in this research field. The SMS instrument had previously been used in research on low back pain and had shown good recall and compliance and instant, easy data handling. This project 
experienced good patient compliance and data handling, but with a lower response rate of $75 \%$ due to failing technology in some telecommunication providers. The SMS-responses provided information on the number of days each week the participants had experienced bothersome PGP.

The text messaging monitoring objective was to follow up the examination at baseline with a short question once per week, which could quickly be replied to with a one-digit answer. The initial intention was to send a question on the women's current level of pain. However, an earlier study on LBP, using the SMS technology, had successfully administered the term "bothersome" instead of "pain" [130]. The measure "bothersomeness" has shown associations with measures of pain, disability, psychological health, and work absence. It has predicted six months outcome in patients with severe LBP [165]. Thus, instead of a question using the measures "pain" or painful", the SMS question in this prospective study had the following wording: 'How many days during the previous week has your pelvic pain been bothersome?' [120]. The participants were informed at baseline about the SMS question and 
how to reply. This technology seemed to be user-friendly as compliance was high.

\subsubsection{Matching procedure}

In order to investigate factors that may modify the effect of PGP on sick leave, a matching procedure of retrospective data (Paper II) was conducted. This procedure aimed to find pairs who differed with respect to sick leave but who matched on certain baseline characteristics to assess the effect of potential coping on sick leave. The matching procedure was carried out without obstacles. Challenges were to find random women been on sick leave, matching the average PGP score of women without sick leave. However, a macro found matching pairs, creating two groups with 50 subjects in each. The implication for previous results was that the scores on several ODI-items now differed from earlier analysis. Effect sizes between the groups now showed that women with longer education, higher work satisfaction and fewer problems with sitting, walking, and standing, were less likely to take sick leave in pregnancy, despite the same pain intensity as women being on sick leave. 


\subsection{Discussion of results}

\subsubsection{Paper I}

The retrospective data collection results revealed that nearly half $(47.6 \%)$ of the women in Rogaland, Norway, experienced moderate and severe pain in the lumbopelvic region during pregnancy. More specifically, moderate and severe combined LBPP was experienced by $21.6 \%(\mathrm{n}=$ 123), and moderate and severe PGP was experienced by $26.0 \%(n=148)$. Similarly, detailed pain information is sparse in the literature. However, this finding concurs with an earlier retrospective study with an identical design on LBPP in pregnancy, in which $23.2 \%$ of the women were rating 7 and above on VAS [40]. One other small retrospective study on PGP in athletes reported pain location but not pain severity [166]. They reported pain location mainly at the pubic symphysis $(33,3 \%)$ and both sacroiliac joints $(29,6 \%)$. Corresponding numbers in this thesis project was $19,3 \%$ and $17,2 \%$, respectively. The primary pain location in this project (reported by 32,5\%) was at all three pelvic joints simultaneously (a pelvic girdle syndrome), reported by $22,5 \%$ of the athletes [166]. One other study has reported that disability in pelvic girdle pain is associated with pain location and that pain at the pubic symphysis combined with 
bilateral pain at sacroiliac joints produced the largest impact on Disability Rating Index [102].

One reason for the difference in symptom distribution between the athletes mentioned above and the women in this thesis project may be that a high number of years of regular leisure physical activity before pregnancy decreases the risk of developing LBPP [135]. It has also been reported that women who exercise regularly and engage in high impact exercises up to five times weekly before the first pregnancy may have a reduced risk of pelvic girdle pain in pregnancy [100]. The mechanisms by which pre-pregnancy exercise influences the risk of pelvic girdle pain remains unknown. However, it is well known that both aerobic exercise and resistance training have a hypoalgesic effect on pain in healthy nonpregnant individuals and chronic pain patients [167]. Though exercise's long-term effect on pain remains unclear, women who exercise regularly pre-pregnancy are more likely to continue to exercise throughout pregnancy [168]. It is believed that the relationship between leisure-time exercise and pelvic girdle pain depends on both frequency and types of exercise [100]. 
The retrospective data also indicate that women with moderate and severe combined LBPP had approximately 50\% more sick leave days than women with PGP or LBP at the same pain level, and 2 - 3 times more sick leave days than women without pain or with only mild pain. A result not surprising since the most frequently reported cause of sick leave among pregnant women in other studies are combined LBPP [112, 113]. However, previous studies have not categorized the level of pain for either LBPP or PGP with sick leave during pregnancy.

A relatively recent cross-sectional study comparing 12 European countries found that $50.6 \%$ of the women had been on sick leave at some point during pregnancy. Nonetheless, the rates varied greatly, ranging from $31.7 \%$ (Sweden) to $71.3 \%$ (Poland) [113]. Duration of sick leave also showed considerable variation, with one Norwegian study reporting $50 \%$ of pregnant women being off work between 4 and 16 weeks [112]. This retrospective data collection disclosed that $34 \%$ of women reported a mean sick leave duration of 9,6 weeks for pain in the lumbopelvic region, which concurs relatively well with other studies regarding prevalence and duration. 
The results showed that work satisfaction, problems with lifting, sleeping, and pain intensity predicted sick leave for women with PGP. This result concurs with previous research where factors related to sick leave were sleeping problems, hyperemesis, chronic pain before or during pregnancy, workplace conflicts, multiparity, previous depression, insomnia and lower education [112]. One other study reported that disability, pain intensity and occupation were associated with sick leave due to lumbopelvic pain [117]. Thus, pain intensity, sleeping problems, and type of work/work satisfaction seem to be common factors for sick leave in pregnancy.

For analysis of function, this project utilized ODI in which "moderate disability" is considered in the scoring window of $21-40$ [122]. The analysis regarding the general level of function during pregnancy displayed moderate ODI values of $21.92 \%$ for LBP, $33.24 \%$ for PGP, and $37.66 \%$ for LBPP. This outcome of moderate disability concurs with previous research conducted in Australia in which the mean ODI scores for women with both LBP and PGP was 33.5\%, thus a higher disability level than women with PGP (26\%), or LBP alone (18\%) [31]. 
In this retrospective part of the thesis, $71 \%$ of the women had experienced pain in the lumbopelvic region. A previous Swedish study with a similar design and identical result lends strength to the validity of these findings [40].

\subsubsection{Paper II}

Further analysis of the data collected retrospectively demonstrated that women with long education, high work satisfaction, and little problem with sitting, walking, and standing, were less likely to take sick leave during pregnancy compared to women with short education, low work satisfaction and problems with sitting, standing, and walking, despite having the same pain intensity. These findings are partly in agreement with a recent study reporting that an advanced degree education was protective against sick leave for pregnant women [115]. Patients with lower educational levels, suffering from pain in the lumbopelvic area, appear to have less knowledge about self-care compared to patients with higher education [169]. 
The retrospective data analysis revealed that ADL's were significantly more difficult to carry out for pregnant women on sick leave for PGP than for women on sick leave for other causes. Independent significant risk factors were lower education, heavy workload, and low work satisfaction. This find concurs with previous research in which PGP is reported to affect daily activities, work ability and quality of life [24, 41, $170]$.

The primary reason for long-term sick leave, more than 14 consecutive days, seem to be conflicts at work, high workload, reproductive occupational hazards, and different national sick leave policies across Europe during pregnancy $[112,113,171,172]$. Recently published studies have displayed that nearly $10 \%$ of women with long-term sick leave during pregnancy reported such work-related reasons for sick leave $[113,115]$. Furthermore, studies within the Danish national birth cohort have found that a psychosocially demanding work environment and some physically demanding work measures are associated with an increased risk of pelvic pain in pregnancy [173]. Also, working night 
shifts during pregnancy significantly shifts longer than 12 hours and increases sick leave risk [174].

The matching procedure displayed that the group with no sick leave had, on average, longer education and higher work-satisfaction and the scores on several ODI items were lower in this group compared to the group of women who were on sick leave. This procedure also revealed unexpected differences in pain tolerance among those who did not take sick leave. What generates these differences is unclear, but may be due to education, work situation, and/or work posture.

Sitting was found to be the most challenging activity for women on sick leave. In a recent study, the prevalence of pain in the sitting position was in $73 \%$ for patients with a SIJ disorder, higher than for patients with lumbar disc herniation (49\%) and lumbar spinal canal stenosis (20\%) [175]. It is proposed that, in the sitting position, as the ischial tuberosity is fixed on the seat, distortion in the SIJ occurs, and pain develops [175]. The difficulty in performing a seated task during gestation may not be a unique effect of biomechanical adaptations due to pregnancy and result 
from the environmental context $[176,177]$. Patients with good social support may have access to good personal care, thus reducing their perceived pain and interfering with daily activities [178].

Our study found a higher prevalence of LBPP in women in the third trimester [20]. Such findings may be explained by the increase in muscle and ligament overload, especially during the third gestational trimester, when it is greater due to hormonal activity and the gravid uterus' growth [179].

An unfortunate unprecise use of PGP terms in Paper II may be misleading and needs clarification since they represent different constructs. "PGP score" (page 3) refers to pelvic pain score from the questionnaire, and "PGP intensity" (page 4) and "PGP intensity score" (page 6) refers to the ODI item "Pain intensity".

\subsubsection{Paper III}

This research appears to be the first, and to date, the only, prospective longitudinal study in which women with PGP in pregnancy have had a clinical examination mid-pregnancy and then have been followed with 
regular short message service. A literature search has not presented any paper outside this thesis demonstrating future longitudinal PGP trajectories antepartum. Thus, it is the first attempt to follow the course of PGP subclassified groups through the second half of pregnancy.

Our analysis revealed that if both P4 and ASLR tests were positive in pregnancy week 18, a persistent PGP of more than five days/week throughout the remainder of the pregnancy could be predicted. If either test was positive in week 18 , a similar course was shown. However, women with a positive P4 test only revealed a more uncomfortable course than women with a positive ASLR test. The latter never reached the bothersome levels of the P4-ASLR test group and the P4 only test group. Thus, women with the highest number of bothersome days per week with PGP were exposed to long dorsal sacroiliac ligament (LDL) strain (as indicated by the positive P4 test). Overloaded sacroiliac joints (SIJs) (as indicated by the positive P4 test), accompanied by reduced sacroiliac force closure (i.e., loss of functional control due to loss of cocontraction of the lumbopelvic muscles) (as the ASLR test was positive).

Although women who had a positive ASLR test and negative P4 test at baseline presented a comparatively low mean number of bothersome 
days with pain, they also had the highest mean number of previous pregnancies and the highest mean rate of pelvic pain in previous pregnancies. Our data also revealed that they exercised more frequently both before and during the present pregnancy compared to women in the other positive test groups. Regarding the level of pain, a recent systematic review found that prenatal exercise is an effective treatment to decrease the severity of LBP, PGP and LBPP during pregnancy [180]. Although the prenatal exercise was not found to decrease the odds of LBP, PGP and LBPP during pregnancy results from a meta-analysis provided evidence that different types of exercise performed alone or in combination, such as yoga, general or specific strengthening exercise and aerobics performed anywhere from once per week to once per day, significantly reduced the severity of LBP, PGP or LBPP related symptoms during pregnancy[180].

Considering that LBPP affects more than half of pregnant women and is associated with disability, depression, reduced quality of life and higher prevalence of sick leave during pregnancy [181], exercise may offer a cost-effective self-management strategy option to expecting 
mothers as part of a multimodal approach to decrease symptom severity [181].

Since sufficient force closure of the sacroiliac joints requires appropriate muscular, ligamentous, and fascial interaction, women with pelvic pain in previous pregnancies, may have experienced improved muscle activation, recovered function and decreased pain from exercise. Additionally, pain prevention and rehabilitation experience in previous pregnancies may work as an incitement to engage in physical activity and regular exercise, both before and during pregnancy.

Although the mechanisms through which exercise may reduce pain severity remains unclear, it is suggested that physical activity lessens the degree of biomechanical change occurring as pregnancy advances, such as decreasing the load on the spine, increasing joint stabilization and contributing to better spinal alignment and segmental motion [182]. From a more general standpoint, exercise may help reverse trunk muscle imbalance [60] or initiate a pain desensitization process leading to increased pain detection threshold [183]. 
Our analysis also revealed a significant difference in depression between women with different positive clinical tests. Distress has previously been identified as a factor associated with a higher likelihood of PGP in pregnancy, with a higher BMI and a higher gestational age [26]. One previous study found that distress contributes to disability but not to pain intensity [32]. Approximately $10 \%$ of women experience postpartum depression, with nearly $25 \%$ of them still in treatment after one year [184]. One review also provided strong evidence that physically active women experience significantly fewer symptoms of depression during the postpartum period compared with their inactive counterparts [185]. Nevertheless, some individuals seem to tolerate pain better, have less catastrophizing tendencies and show more positive social response to pain, regardless of exposure to stressful circumstances and/or internal distress [186].

The parameter estimates revealed that a slightly higher than average prepregnancy BMI significantly impacted the mean number of bothersome days. However, with a difference of only $1,3 \%$, the clinical relevance is questionable. Interestingly, in a recent published study on PGP in pregnancy does women with a combination of generalized joint 
hypermobility $(\mathrm{GJH})$ and $\mathrm{BMI} \geq 25 \mathrm{~kg} / \mathrm{m}^{2}$ report higher pain compared to women with normal joint mobility and BMI $<25 \mathrm{~kg} / \mathrm{m}^{2}$ [187]. Nonetheless, the researchers state that the association between GJH and BMI should be interpreted with caution due to the small study sample.

Finally, women with the possibility to control their own work situation have better health during pregnancy than women without such options. As indicated in this study, and confirmed in other research, many pregnant women seem to benefit from exercise as it increases pain tolerance, improves or maintains physical fitness, helps with weight management, reduces the risk of gestational diabetes in obese women, and enhances psychological well-being [100, 188-190].

\subsection{What does this thesis contribute to our knowledge about PGP?}

Our present findings confirm and re-emphasize that PGP can cause major impairment of a pregnant woman's health and well-being, as well as constituting a burden to society as a frequent and major cause of 
sick leave. We retrospectively showed how PGP affects a pregnant woman's ADL, revealing unexpected differences in tolerance for pain among those who did not take sick leave. Those who took less sick leave demonstrated higher pain tolerance, which was associated with their level of education and their situation and/or posture at work.

In addition, we demonstrate here that if both ASLR and P4 tests are positive mid-pregnancy, persistent and bothersome PGP can be expected for more than five days each week throughout the remainder of the pregnancy. The number of days each week with bothersome pelvic pain increases for every additional pregnancy.

\subsection{Clinical implications}

Clinicians need to be aware of the potential risk factors for PGP identified here, i.e., less education, a heavy workload and dissatisfaction with one's work. Moreover, the application of ASLR and P4 tests to assess the likelihood of persistent PGP will help the caregiver, together with his/her patient, design a treatment plan that can alleviate the pain involving, e.g., exercise, management of stress and a reduced workload. 


\subsection{Implications for future research in this area}

Usage of the SMS-Track system to collect research data, an apparent strength of the present work, is highly recommended. This approach results in a high response rate and provides information concerning the participant's situation instantly. In addition, the immediate recording of the responses minimizes further handling of the data and, thereby, the risk of error.

The potential risk factors for PGP identified here should now be examined in a prospective study that controls for confounders and includes the clinical examination of pregnant women's sub-groups offered different therapeutic interventions in a blinded design.

Some women with PGP appear to tolerate their symptoms more effectively than others, e.g., the women with higher education and more work satisfaction took less sick leave, even though their pain level was the same as in the sub-groups who take more sick leave. We also recommend the performance of a prospective longitudinal study designed to see if appropriate modification of workplaces can reduce the amount of sick leave taken by women who experience PGP. 
Finally, a gold standard for diagnosing PGP, particularly for the number of clinical tests to be performed, is still lacking. Further efforts to identify predictive and preventive factors, as well as diagnostic tests for PGP during pregnancy, are warranted. For example, it would be interesting to determine whether women with a history of PGP have elevated painrelated anxiety that influences their experience of pain. 


\section{REFERENCES}

1. Preamble to the Constitution of WHO as adopted by the International Health Conference, New York, 19-22 June, 1946. Geneva: World Health Organization; 1948. 100 p.

2. Wu WH, Meijer OG, Uegaki K, Mens JM, van Dieen JH, Wuisman PI, et al. Pregnancy-related pelvic girdle pain (PPP), I: Terminology, clinical presentation, and prevalence. Eur Spine J. 2004;13(7):575-89.

3. Vermani E, Mittal R, Weeks A. Pelvic girdle pain and low back pain in pregnancy: a review. Pain Pract. 2010;10(1):60-71.

4. Abramson D, Roberts SM, Wilson PD. Relaxation of the pelvic joints in pregnancy. Surg Gynecol Obstet. 1934;58:595-613.

5. Melzack R. The McGill Pain Questionnaire: major properties and scoring methods. Pain. 1975;1(3):277-99.

6. Mantle MJ, Greenwood RM, Currey HL. Backache in pregnancy. Rheumatol Rehabil. 1977;16(2):95-101.

7. Vleeming A, Albert HB, Ostgaard HC, Sturesson B, Stuge B. European guidelines for the diagnosis and treatment of pelvic girdle pain. Eur Spine J. 2008;17(6):794-819. 
8. Kristiansson P, Svardsudd K, von Schoultz B. Back pain during pregnancy: a prospective study. Spine (Phila Pa 1976). 1996;21(6):7029.

9. Ceprnja D, Chipchase L, Gupta A. Prevalence of pregnancyrelated pelvic girdle pain and associated factors in Australia: a crosssectional study protocol. BMJ Open. 2017;7(11):e018334.

10. MacLennan AH, MacLennan SC. Symptom-giving pelvic girdle relaxation of pregnancy, postnatal pelvic joint syndrome and developmental dysplasia of the hip. The Norwegian Association for Women with Pelvic Girdle Relaxation (Landforeningen for Kvinner Med Bekkenlosningsplager). Acta Obstet Gynecol Scand. 1997;76(8):760-4.

11. Mens JM, Vleeming A, Stoeckart R, Stam HJ, Snijders CJ. Understanding peripartum pelvic pain. Implications of a patient survey. Spine (Phila Pa 1976). 1996;21(11):1363-9; discussion 9-70.

12. Saugstad LF. Persistent pelvic pain and pelvic joint instability. Eur J Obstet Gynecol Reprod Biol. 1991;41(3):197-201.

13. Vas J, Aranda-Regules JM, Modesto M, Aguilar I, Baron-Crespo M, Ramos-Monserrat M, et al. Auricular acupuncture for primary care 
treatment of low back pain and posterior pelvic pain in pregnancy: study protocol for a multicentre randomised placebo-controlled trial. Trials. $2014 ; 15: 288$.

14. Gutke A, Kjellby-Wendt G, Oberg B. The inter-rater reliability of a standardised classification system for pregnancy-related lumbopelvic pain. Man Ther. 2010;15(1):13-8.

15. Gutke A, Ostgaard HC, Oberg B. Predicting persistent pregnancy-related low back pain. Spine (Phila Pa 1976). 2008;33(12):E386-93.

16. Kanakaris N, Roberts C, Giannoudis P. Pregnancy-related pelvic girdle pain: An update. BMC medicine. 2011;9:15.

17. Albert H, Godskesen M, Westergaard J. Prognosis in four syndromes of pregnancy-related pelvic pain. Acta Obstet Gynecol Scand. 2001;80(6):505-10.

18. van Kessel-Cobelens AM, Verhagen AP, Mens JM, Snijders CJ, Koes BW. Pregnancy-related pelvic girdle pain: intertester reliability of 3 tests to determine asymmetric mobility of the sacroiliac joints. J Manipulative Physiol Ther. 2008;31(2):130-6. 
19. Verstraete EH, Vanderstraeten G, Parewijck W. Pelvic Girdle Pain during or after Pregnancy: a review of recent evidence and a clinical care path proposal. Facts Views Vis Obgyn. 2013;5(1):33-43.

20. Malmqvist S, Kjaermann I, Andersen K, Okland I, Larsen JP, Bronnick K. The association between pelvic girdle pain and sick leave during pregnancy; a retrospective study of a Norwegian population. BMC Pregnancy Childbirth. 2015;15:237.

21. Van De Pol G, Van Brummen HJ, Bruinse HW, Heintz AP, Van Der Vaart CH. Pregnancy-related pelvic girdle pain in the Netherlands. Acta Obstet Gynecol Scand. 2007;86(4):416-22.

22. Albert H, Godskesen M, Westergaard J. Evaluation of clinical tests used in classification procedures in pregnancy-related pelvic joint pain. Eur Spine J. 2000;9(2):161-6.

23. Bastiaanssen JM, de Bie RA, Bastiaenen CH, Heuts A, Kroese ME, Essed GG, et al. Etiology and prognosis of pregnancy-related pelvic girdle pain; design of a longitudinal study. BMC Public Health. $2005 ; 5: 1$ 
24. Gutke A, Ostgaard HC, Oberg B. Pelvic girdle pain and lumbar pain in pregnancy: a cohort study of the consequences in terms of health and functioning. Spine (Phila Pa 1976). 2006;31(5):E149-55.

25. Bjelland EK, Eskild A, Johansen R, Eberhard-Gran M. Pelvic girdle pain in pregnancy: the impact of parity. Am J Obstet Gynecol. 2010;203(2):146 e1-6.

26. Kovacs FM, Garcia E, Royuela A, Gonzalez L, Abraira V, Spanish Back Pain Research N. Prevalence and factors associated with low back pain and pelvic girdle pain during pregnancy: a multicenter study conducted in the Spanish National Health Service. Spine (Phila Pa 1976). 2012;37(17):1516-33.

27. Larsen EC, Wilken-Jensen C, Hansen A, Jensen DV, Johansen S, Minck H, et al. Symptom-giving pelvic girdle relaxation in pregnancy. I: Prevalence and risk factors. Acta Obstet Gynecol Scand. 1999;78(2):105-10.

28. Malmqvist S, Kjaermann I, Andersen K, Okland I, Bronnick K, Larsen JP. Prevalence of low back and pelvic pain during pregnancy in a Norwegian population. J Manipulative Physiol Ther. 2012;35(4):2728. 
29. Mousavi SJ, Parnianpour M, Vleeming A. Pregnancy related pelvic girdle pain and low back pain in an Iranian population. Spine (Phila Pa 1976). 2007;32(3):E100-4.

30. Ostgaard HC, Andersson GB, Karlsson K. Prevalence of back pain in pregnancy. Spine (Phila Pa 1976). 1991;16(5):549-52.

31. Pierce H, Homer CS, Dahlen HG, King J. Pregnancy-related lumbopelvic pain: listening to Australian women. Nurs Res Pract. $2012 ; 2012: 387428$.

32. Robinson HS, Veierod MB, Mengshoel AM, Vollestad NK. Pelvic girdle pain--associations between risk factors in early pregnancy and disability or pain intensity in late pregnancy: a prospective cohort study. BMC Musculoskelet Disord. 2010;11:91.

33. Gashaw M, Gedlu S, Janakiraman B. Burden of pelvic girdle pain during pregnancy among women attending ante-natal clinic, Ethiopia:a cross-sectional study. BMC Pregnancy Childbirth. 2020;20(1):494.

34. Starzec M, Truszczynska-Baszak A, Tarnowski A, Rongies W. Pregnancy-Related Pelvic Girdle Pain in Polish and Norwegian Women. J Manipulative Physiol Ther. 2019;42(2):117-24. 
35. Weis CA, Barrett J, Tavares P, Draper C, Ngo K, Leung J, et al. Prevalence of Low Back Pain, Pelvic Girdle Pain, and Combination Pain in a Pregnant Ontario Population. J Obstet Gynaecol Can. 2018;40(8):1038-43.

36. Bakilan F ZD. Musculoskeletal problems during pregnancy. J Clin Med Kaz. 2020;60(6):53-5.

37. Ramachandra P, Maiya AG, Kumar P, Kamath A. Prevalence of musculoskeletal dysfunctions among Indian pregnant women. J Pregnancy. 2015;2015:437105.

38. Hassan E. Recall Bias can be a Threat to Retrospective and Prospective Research Designs. The Internet Journal of Epidemiology. 2005;3(2):

39. Bastiaanssen JM, de Bie RA, Bastiaenen CH, Essed GG, van den Brandt PA. A historical perspective on pregnancy-related low back and/or pelvic girdle pain. Eur J Obstet Gynecol Reprod Biol. 2005;120:314. 
40. Mogren IM, Pohjanen AI. Low back pain and pelvic pain during pregnancy: prevalence and risk factors. Spine (Phila $\mathrm{Pa}$ 1976). 2005;30(8):983-91.

41. Robinson HS, Eskild A, Heiberg E, Eberhard-Gran M. Pelvic girdle pain in pregnancy: the impact on function. Acta Obstet Gynecol Scand. 2006;85(2):160-4.

42. Leadbetter RE, Mawer D, Lindow SW. Symphysis pubis dysfunction: a review of the literature. J Matern Fetal Neonatal Med. 2004;16(6):349-54.

43. Mens JM, Vleeming A, Snijders CJ, Stam HJ, Ginai AZ. The active straight leg raising test and mobility of the pelvic joints. Eur Spine J. 1999;8(6):468-73.

44. Ostgaard HC, Andersson GB, Schultz AB, Miller JA. Influence of some biomechanical factors on low-back pain in pregnancy. Spine (Phila Pa 1976). 1993;18(1):61-5.

45. O'Sullivan PB, Beales DJ, Beetham JA, Cripps J, Graf F, Lin IB, et al. Altered motor control strategies in subjects with sacroiliac joint pain during the active straight-leg-raise test. Spine (Phila Pa 1976). 2002;27(1):E1-8. 
46. Albert H, Godskesen M, Westergaard JG, Chard T, Gunn L. Circulating levels of relaxin are normal in pregnant women with pelvic pain. Eur J Obstet Gynecol Reprod Biol. 1997;74(1):19-22.

47. Bjelland EK, Eberhard-Gran M, Nielsen CS, Eskild A. Age at menarche and pelvic girdle syndrome in pregnancy: a population study of 74973 women. BJOG. 2011;118(13):1646-52.

48. Hansen A, Jensen DV, Wormslev M, Minck H, Johansen S, Larsen EC, et al. Symptom-giving pelvic girdle relaxation in pregnancy. II: Symptoms and clinical signs. Acta Obstet Gynecol Scand. 1999;78(2):111-5.

49. MacLennan AH, Nicolson R, Green RC, Bath M. Serum relaxin and pelvic pain of pregnancy. Lancet. 1986;2(8501):243-5.

50. Cusi M, Saunders J, Van der Wall H, Fogelman I. Metabolic disturbances identified by SPECT-CT in patients with a clinical diagnosis of sacroiliac joint incompetence. Eur Spine J. 2013;22(7):1674-82.

51. Foulkes JF. Hereditary pelvic arthropathy of pregnancy. J Obstet Gynaecol Br Emp. 1957;64(1):131. 
52. O'Sullivan PB, Beales DJ. Diagnosis and classification of pelvic girdle pain disorders--Part 1: a mechanism based approach within a biopsychosocial framework. Man Ther. 2007;12(2):86-97.

53. O'Sullivan PB, Beales DJ. Diagnosis and classification of pelvic girdle pain disorders, Part 2: illustration of the utility of a classification system via case studies. Man Ther. 2007;12(2):e1-12.

54. Saunders J CM, Hackett L,Van der Wall H. A comparison of ultrasound guided PRP injection and prolotherapy for mechanical dysfunction of the sacroiliac joint. . Journal of Prolotherapy. 2018;10:e992-e9.

55. Vleeming A, Schuenke M. Form and Force Closure of the Sacroiliac Joints. PM R. 2019;11 Suppl 1:S24-S31.

56. Mens JM, Pool-Goudzwaard A, Stam HJ. Mobility of the pelvic joints in pregnancy-related lumbopelvic pain: a systematic review. Obstet Gynecol Surv. 2009;64(3):200-8.

57. Stuge B. Evidence of stabilizing exercises for low back- and pelvic girdle pain - a critical review. Braz J Phys Ther. 2019;23(2):1816. 
58. Aldabe D, Milosavljevic S, Bussey MD. Is pregnancy related pelvic girdle pain associated with altered kinematic, kinetic and motor control of the pelvis? A systematic review. Eur Spine J. 2012;21(9):1777-87.

59. Arumugam A, Milosavljevic S, Woodley S, Sole G. Effects of external pelvic compression on form closure, force closure, and neuromotor control of the lumbopelvic spine--a systematic review. Man Ther. 2012;17(4):275-84.

60. Gutke A, Ostgaard HC, Oberg B. Association between muscle function and low back pain in relation to pregnancy. J Rehabil Med. 2008;40(4):304-11.

61. Beales DJ, O'Sullivan PB, Briffa NK. The effects of manual pelvic compression on trunk motor control during an active straight leg raise in chronic pelvic girdle pain subjects. Man Ther. 2010;15(2):1909.

62. Katonis P, Kampouroglou A, Aggelopoulos A, Kakavelakis K, Lykoudis S, Makrigiannakis A, et al. Pregnancy-related low back pain. Hippokratia. 2011;15(3):205-10. 
63. Lee DG, Lee LJ, McLaughlin L. Stability, continence and breathing: the role of fascia following pregnancy and delivery. J Bodyw Mov Ther. 2008;12(4):333-48.

64. Fortin JD, Aprill CN, Ponthieux B, Pier J. Sacroiliac joint: pain referral maps upon applying a new injection/arthrography technique. Part II: Clinical evaluation. Spine (Phila Pa 1976). 1994;19(13):1483-9. 65. Fortin JD, Kissling RO, O'Connor BL, Vilensky JA. Sacroiliac joint innervation and pain. Am J Orthop (Belle Mead NJ). 1999;28(12):687-90.

66. Laslett M. Evidence-based diagnosis and treatment of the painful sacroiliac joint. J Man Manip Ther. 2008;16(3):142-52.

67. Palsson TS, Beales D, Slater H, O'Sullivan P, Graven-Nielsen T. Pregnancy is characterized by widespread deep-tissue hypersensitivity independent of lumbopelvic pain intensity, a facilitated response to manual orthopedic tests, and poorer self-reported health. J Pain. 2015; 16(3):270-82.

68. Szpunar MJ, Parry BL. A systematic review of cortisol, thyroidstimulating hormone, and prolactin in peripartum women with major depression. Arch Womens Ment Health. 2018;21(2):149-61. 
69. Shnaekel KL, Magann EF, Ahmadi S. Pubic Symphysis Rupture and Separation During Pregnancy. Obstet Gynecol Surv. 2015;70(11):713-8.

70. Wang Y, Li YQ, Tian MR, Wang N, Zheng ZC. Role of relaxin in diastasis of the pubic symphysis peripartum. World J Clin Cases. 2021;9(1):91-101.

71. Bjorklund $\mathrm{K}$, Bergstrom $\mathrm{S}$, Nordstrom ML, Ulmsten U. Symphyseal distention in relation to serum relaxin levels and pelvic pain in pregnancy. Acta Obstet Gynecol Scand. 2000;79(4):269-75.

72. Clark J, Nijs J, Yeowell G, Goodwin PC. What Are the Predictors of Altered Central Pain Modulation in Chronic Musculoskeletal Pain Populations? A Systematic Review. Pain Physician. 2017;20(6):487500.

73. Bulgakov AV. Specific features of psycho-emotional states of working women during pregnancy. Electron J Gen Med 2018;6(15):1-8

74. Gatchel R, Turk, DC. Psychosocial factors in pain : critical perspectives. New York: Guildford Press; 1999. 
75. Burton AK, Tillotson KM, Main CJ, Hollis S. Psychosocial predictors of outcome in acute and subchronic low back trouble. Spine (Phila Pa 1976). 1995;20(6):722-8.

76. Hoogendoorn WE, van Poppel MN, Bongers PM, Koes BW, Bouter LM. Systematic review of psychosocial factors at work and private life as risk factors for back pain. Spine (Phila Pa 1976). 2000;25(16):2114-25.

77. Macfarlane GJ, Thomas E, Croft PR, Papageorgiou AC, Jayson MI, Silman AJ. Predictors of early improvement in low back pain amongst consulters to general practice: the influence of pre-morbid and episode-related factors. Pain. 1999;80(1-2):113-9.

78. Linton SJ. A review of psychological risk factors in back and neck pain. Spine (Phila Pa 1976). 2000;25(9):1148-56.

79. Pincus T, Burton AK, Vogel S, Field AP. A systematic review of psychological factors as predictors of chronicity/disability in prospective cohorts of low back pain. Spine (Phila Pa 1976). 2002;27(5):E109-20.

80. Hill JC, Fritz JM. Psychosocial influences on low back pain, disability, and response to treatment. Phys Ther. 2011;91(5):712-21. 
81. Kamper SJ, Maher CG, Herbert RD, Hancock MJ, Hush JM, Smeets RJ. How little pain and disability do patients with low back pain have to experience to feel that they have recovered? Eur Spine J. 2010;19(9):1495-501.

82. Grotle M, Foster NE, Dunn KM, Croft P. Are prognostic indicators for poor outcome different for acute and chronic low back pain consulters in primary care? Pain. 2010;151(3):790-7.

83. Hill JC, Dunn KM, Lewis M, Mullis R, Main CJ, Foster NE, et al. A primary care back pain screening tool: identifying patient subgroups for initial treatment. Arthritis Rheum. 2008;59(5):632-41.

84. Hill JC, Whitehurst DG, Lewis M, Bryan S, Dunn KM, Foster NE, et al. Comparison of stratified primary care management for low back pain with current best practice (STarT Back): a randomised controlled trial. Lancet. 2011;378(9802):1560-71.

85. Robinson PS BA, Vollestad NK, Robinson HS. . The association between pregnancy, pelvic girdle pain and health-related quality of life a comparison of two instruments. J Patient Rep Outcomes 2018;2(45). 
86. Mackenzie J, Murray E, Lusher J. Women's experiences of pregnancy related pelvic girdle pain: A systematic review. Midwifery. 2018;56:102-11.

87. Albert HB, Godskesen M, Korsholm L, Westergaard JG. Risk factors in developing pregnancy-related pelvic girdle pain. Acta Obstet Gynecol Scand. 2006;85(5):539-44.

88. Gutke A, Josefsson A, Oberg B. Pelvic girdle pain and lumbar pain in relation to postpartum depressive symptoms. Spine (Phila Pa 1976). 2007;32(13):1430-6.

89. Eberhard-Gran M, Eskild A. Diabetes mellitus and pelvic girdle syndrome in pregnancy--is there an association? Acta Obstet Gynecol Scand. 2008;87(10):1015-9.

90. Robinson HS, Dagfinrud H. Reliability and screening ability of the StarT Back screening tool in patients with low back pain in physiotherapy practice, a cohort study. BMC Musculoskelet Disord. $2017 ; 18(1): 232$.

91. Mens JM, Huis In 't Veld YH, Pool-Goudzwaard A. The Active Straight Leg Raise test in lumbopelvic pain during pregnancy. Man Ther. 2012;17(4):364-8. 
92. Vleeming A, Schuenke MD, Masi AT, Carreiro JE, Danneels L, Willard FH. The sacroiliac joint: an overview of its anatomy, function and potential clinical implications. J Anat. 2012;221(6):537-67.

93. O'Sullivan PB, Beales DJ. Changes in pelvic floor and diaphragm kinematics and respiratory patterns in subjects with sacroiliac joint pain following a motor learning intervention: a case series. Man Ther. 2007;12(3):209-18.

94. Ceprnja D, Chipchase L, Fahey P, Liamputtong P, Gupta A. Prevalence and Factors Associated With Pelvic Girdle Pain During Pregnancy in Australian Women: A Cross-Sectional Study. Spine (Phila Pa 1976). 2021.

95. Gaenslen F. Sacro-iliac arthrodesis: indications, author's technic and end-results. JAMA. 1927;89(24):2031-5.

96. Bhardwaj A, Nagandla K. Musculoskeletal symptoms and orthopaedic complications in pregnancy: pathophysiology, diagnostic approaches and modern management. Postgrad Med J. 2014;90(1066):450-60.

97. Ahlqvist K, Bjelland EK, Pingel R, Schlager A, Nilsson-Wikmar L, Kristiansson P. The Association of Self-Reported Generalized Joint 
Hypermobility with pelvic girdle pain during pregnancy: a retrospective cohort study. BMC Musculoskelet Disord. 2020;21(1):474.

98. Ali A, Andrzejowski P, Kanakaris NK, Giannoudis PV. Pelvic Girdle Pain, Hypermobility Spectrum Disorder and Hypermobility-Type Ehlers-Danlos Syndrome: A Narrative Literature Review. J Clin Med. 2020;9(12).

99. Rost CC, Jacqueline J, Kaiser A, Verhagen AP, Koes BW. Prognosis of women with pelvic pain during pregnancy: a long-term follow-up study. Acta Obstet Gynecol Scand. 2006;85(7):771-7.

100. Owe KM, Bjelland EK, Stuge B, Orsini N, Eberhard-Gran M, Vangen S. Exercise level before pregnancy and engaging in high-impact sports reduce the risk of pelvic girdle pain: a population-based cohort study of 39184 women. Br J Sports Med. 2016;50(13):817-22.

101. Vollestad NK, Stuge B. Prognostic factors for recovery from postpartum pelvic girdle pain. Eur Spine J. 2009;18(5):718-26.

102. Robinson HS, Mengshoel AM, Bjelland EK, Vollestad NK. Pelvic girdle pain, clinical tests and disability in late pregnancy. Man Ther. 2010;15(3):280-5. 
103. Wuytack F, Daly D, Curtis E, Begley C. Prognostic factors for pregnancy-related pelvic girdle pain, a systematic review. Midwifery. 2018;66:70-8.

104. Bjelland EK, Stuge B, Engdahl B, Eberhard-Gran M. The effect of emotional distress on persistent pelvic girdle pain after delivery: a longitudinal population study. BJOG. 2013;120(1):32-40.

105. Gausel AM, Malmqvist S, Andersen K, Kjaermann I, Larsen JP, Dalen I, et al. Subjective recovery from pregnancy-related pelvic girdle pain the first 6 weeks after delivery: a prospective longitudinal cohort study. Eur Spine J. 2020;29(3):556-63.

106. Beales DJ, Gaynor O, Harris J, Fary R, O'Sullivan PB, Slater H, et al. Correlations between the active straight leg raise, sleep and somatosensory sensitivity during pregnancy with post-partum lumbopelvic pain: an initial exploration. Scand J Pain. 2019;19(1):5360.

107. Engeset J, Stuge B, Fegran L. Pelvic girdle pain affects the whole life--a qualitative interview study in Norway on women's experiences with pelvic girdle pain after delivery. BMC Res Notes. 2014;7:686. 
108. Elden H, Gutke A, Kjellby-Wendt G, Fagevik-Olsen M, Ostgaard HC. Predictors and consequences of long-term pregnancy-related pelvic girdle pain: a longitudinal follow-up study. BMC Musculoskelet Disord. $2016 ; 17: 276$.

109. Persson M, Winkvist A, Dahlgren L, Mogren I. "Struggling with daily life and enduring pain": a qualitative study of the experiences of pregnant women living with pelvic girdle pain. BMC Pregnancy Childbirth. 2013;13:111.

110. Noren L, Ostgaard S, Johansson G, Ostgaard HC. Lumbar back and posterior pelvic pain during pregnancy: a 3-year follow-up. Eur Spine J. 2002;11(3):267-71.

111. Orvieto R, Achiron A, Ben-Rafael Z, Gelernter I, Achiron R. Low-back pain of pregnancy. Acta Obstet Gynecol Scand. 1994;73(3):209-14.

112. Dorheim SK, Bjorvatn B, Eberhard-Gran M. Sick leave during pregnancy: a longitudinal study of rates and risk factors in a Norwegian population. BJOG. 2013;120(5):521-30. 
113. Truong BT, Lupattelli A, Kristensen P, Nordeng H. Sick leave and medication use in pregnancy: a European web-based study. BMJ Open. 2017;7(8):e014934.

114. Rieck KME, Telle K. Sick leave before, during and after pregnancy. Acta Sociologica. 2013;56(2):117-37.

115. Backhausen M, Damm P, Bendix J, Tabor A, Hegaard H. The prevalence of sick leave: Reasons and associated predictors - A survey among employed pregnant women. Sex Reprod Healthc. 2018;15:54-61. 116. Ariansen AM. Age, occupational class and sickness absence during pregnancy: a retrospective analysis study of the Norwegian population registry. BMJ Open. 2014;4(5):e004381.

117. Gutke A, Olsson CB, Vollestad N, Oberg B, Wikmar LN, Robinson HS. Association between lumbopelvic pain, disability and sick leave during pregnancy - a comparison of three Scandinavian cohorts. J Rehabil Med. 2014;46(5):468-74.

118. Robinson HS, Mengshoel AM, Veierod MB, Vollestad N. Pelvic girdle pain: potential risk factors in pregnancy in relation to disability and pain intensity three months postpartum. Man Ther. 2010;15(6):5228. 
119. Robinson HS, Vollestad NK, Veierod MB. Clinical course of pelvic girdle pain postpartum - impact of clinical findings in late pregnancy. Man Ther. 2014;19(3):190-6.

120. Malmqvist S, Kjaermann I, Andersen K, Gausel AM, Økland I, Larsen JP, et al. Can a bothersome course of pelvic pain from midpregnancy to birth be predicted? A Norwegian prospective longitudinal SMS-Track study. BMJ Open. 2018;8(7):e021378.

121. Williamson A, Hoggart B. Pain: a review of three commonly used pain rating scales. J Clin Nurs. 2005;14(7):798-804.

122. Fairbank JC, Pynsent PB. The Oswestry Disability Index. Spine (Phila Pa 1976). 2000;25(22):2940-52; discussion 52.

123. Leijon O, Wiktorin C, Harenstam A, Karlqvist L, Group MOAR. Validity of a self-administered questionnaire for assessing physical work loads in a general population. J Occup Environ Med. 2002;44(8):724-35. 124. Lorber M, Skela Savic B. Job satisfaction of nurses and identifying factors of job satisfaction in Slovenian Hospitals. Croat Med J. 2012;53(3):263-70. 
125. Bhatnagar K, Srivastava K, Singh A, Jadav SL. A preliminary study to measure and develop job satisfaction scale for medical teachers. Ind Psychiatry J. 2011;20(2):91-6.

126. Linton SJ, Melin L. The accuracy of remembering chronic pain. Pain. 1982;13(3):281-5.

127. Mogren I. Perceived health, sick leave, psychosocial situation, and sexual life in women with low-back pain and pelvic pain during pregnancy. Acta Obstet Gynecol Scand. 2006;85(6):647-56.

128. Nilsson-Wikmar L, Holm K, Oijerstedt R, Harms-Ringdahl K. Effect of three different physical therapy treatments on pain and activity in pregnant women with pelvic girdle pain: a randomized clinical trial with 3, 6, and 12 months follow-up postpartum. Spine (Phila Pa 1976). 2005;30(8):850-6.

129. Ostgaard HC. Assessment and treatment of low back pain in working pregnant women. Semin Perinatol. 1996;20(1):61-9.

130. Axen I, Bodin L, Bergstrom G, Halasz L, Lange F, Lovgren PW, et al. The use of weekly text messaging over 6 months was a feasible method for monitoring the clinical course of low back pain in patients seeking chiropractic care. J Clin Epidemiol. 2012;65(4):454-61. 
131. Spielberger CD, Gorsuch, R. L., Lushene, R., Vagg, P. R., Jacobs, G. A. Manual for the State-Trait Anxiety Inventory. Palo Alto, CA: Consulting Psychologists Press; 1983.

132. Mens JM, Vleeming A, Snijders CJ, Koes BW, Stam HJ. Reliability and validity of the active straight leg raise test in posterior pelvic pain since pregnancy. Spine (Phila Pa 1976). 2001;26(10):116771.

133. Laslett M, Williams $M$. The reliability of selected pain provocation tests for sacroiliac joint pathology. Spine (Phila Pa 1976). 1994;19(11):1243-9.

134. Mogren IM. BMI, pain and hyper-mobility are determinants of long-term outcome for women with low back pain and pelvic pain during pregnancy. Eur Spine J. 2006;15(7):1093-102.

135. Mogren IM. Previous physical activity decreases the risk of low back pain and pelvic pain during pregnancy. Scand J Public Health. 2005;33(4):300-6.

136. Haakstad LAH, Voldner N, Bo K. Pregnancy and advanced maternal age-The associations between regular exercise and maternal 
and newborn health variables. Acta Obstet Gynecol Scand. 2020;99(2):240-8.

137. Katz N, Borenstein DG, Birbara C, Bramson C, Nemeth MA, Smith MD, et al. Efficacy and safety of tanezumab in the treatment of chronic low back pain. Pain. 2011;152(10):2248-58.

138. Sheahan PJ, Diesbourg TL, Fischer SL. The effect of rest break schedule on acute low back pain development in pain and non-pain developers during seated work. Appl Ergon. 2016;53 Pt A:64-70.

139. Stuart EA. Matching methods for causal inference: A review and a look forward. Stat Sci. 2010;25(1):1-21.

140. Cohen J. Statistical power analysis for the behavioral sciences. 2nd ed. Hillsdale, NJ: Erlbaum; 1988.

141. Bjelland EK, Stuge B, Vangen S, Stray-Pedersen B, EberhardGran M. Mode of delivery and persistence of pelvic girdle syndrome 6 months postpartum. Am J Obstet Gynecol. 2013;208(4):298 e1-7.

142. Howell E. Pregnancy-related symphysis pubis dysfunction management and postpartum rehabilitation: two case reports. J Can Chiropr Assoc 2012;56(2):102-11. 
143. OZDEMIR S. BH, ORTABAG T. ACIKEL C. Evaluation of the efficacy of an exercise program for pregnant women with low back and pelvic pain: a prospective randomized controlled trial. Journal of Advanced Nursing. 2015;71(8):1926-39.

144. Saxena AK, Chilkoti GT, Singh A, Yadav G. Pregnancy-induced Low Back Pain in Indian Women: Prevalence, Risk Factors, and Correlation with Serum Calcium Levels. Anesth Essays Res. 2019;13(2):395-402.

145. Meucci RD, Perceval AH, Lima DR, Cousin E, Marmitt LP, Pizzato P, et al. Occurrence of combined pain in the lumbar spine, pelvic girdle and pubic symphysis among pregnant women in the extreme south of Brazil. Rev Bras Epidemiol. 2020;23:e200037.

146. Kuciel N, Sutkowska E, Cienska A, Markowska D, Wrzosek Z. Myoelectrical activity of muscles stabilizing the sacroiliac joints before and after the use of elastic tapes in women suffering from Pregnancyrelated Pelvic Girdle Pain. Ginekol Pol. 2020;91(4):223-30.

147. Dawson EG, Kanim LE, Sra P, Dorey FJ, Goldstein TB, Delamarter RB, et al. Low back pain recollection versus concurrent 
accounts: outcomes analysis. Spine (Phila Pa 1976). 2002;27(9):984-93; discussion 94.

148. Linton SJ. Memory for chronic pain intensity: correlates of accuracy. Percept Mot Skills. 1991;72(3 Pt 2):1091-5.

149. Bolton JE. Accuracy of recall of usual pain intensity in back pain patients. Pain. 1999;83(3):533-9.

150. Von Korff M, Jensen MP, Karoly P. Assessing global pain severity by self-report in clinical and health services research. Spine (Phila Pa 1976). 2000;25(24):3140-51.

151. Bryant RA. Memory for pain and affect in chronic pain patients. Pain. 1993;54(3):347-51.

152. Haas M, Nyiendo J, Aickin M. One-year trend in pain and disability relief recall in acute and chronic ambulatory low back pain patients. Pain. 2002;95(1-2):83-91.

153. Rasmussen CDN, Holtermann A, Jorgensen MB. Recall Bias in Low Back Pain Among Workers: Effects of Recall Period and Individual and Work-Related Factors. Spine (Phila Pa 1976). 2018;43(12):E727E33. 
154. Davies SJ, Lum JA, Skouteris H, Byrne LK, Hayden MJ. Cognitive impairment during pregnancy: a meta-analysis. Med J Aust. 2018;208(1):35-40.

155. Ouellette SJ, Hampson E. Memory and affective changes during the antepartum: A narrative review and integrative hypothesis. J Clin Exp Neuropsychol. 2019;41(1):87-107.

156. Visser PS KJ, Marquette J, Curtin M. Mail surveys for election forecasting? An evaluation of the Columbus Dispatch poll. Public Opinion Quarterly. 1996;60(2):181-227.

157. Holbrook AL KJ, Moore D, Tourangeau R Response Order Effects in Dichotomous Categorical Questions Presented Orally: The Impact of Question and Respondent Attributes. Public Opinion Quarterly. 2007;71(3):325-48.

158. Mealing NM, Banks E, Jorm LR, Steel DG, Clements MS, Rogers KD. Investigation of relative risk estimates from studies of the same population with contrasting response rates and designs. BMC Med Res Methodol. 2010;10:26. 
159. Curtin R, Presser S, Singer E. The effects of response rate changes on the index of consumer sentiment. Public Opin Q. 2000;64(4):413-28.

160. Salen BA, Spangfort EV, Nygren AL, Nordemar R. The Disability Rating Index: an instrument for the assessment of disability in clinical settings. J Clin Epidemiol. 1994;47(12):1423-35.

161. Stuge B, Garratt A, Krogstad Jenssen H, Grotle M. The pelvic girdle questionnaire: a condition-specific instrument for assessing activity limitations and symptoms in people with pelvic girdle pain. Phys Ther. 2011;91(7):1096-108.

162. Rejano-Campo M, Ferrer-Pena R, Urraca-Gesto MA, GallegoIzquierdo T, Pecos-Martin D, Stuge B, et al. Transcultural adaptation and psychometric validation of a Spanish-language version of the "Pelvic Girdle Questionnaire". Health Qual Life Outcomes. 2017;15(1):30.

163. Acharya RS, Tveter AT, Grotle M, Khadgi B, Koju R, EberhardGran M, et al. Cross-Cultural Adaptation and Validation of the Nepali Version of the Pelvic Girdle Questionnaire. J Manipulative Physiol Ther. 2020;43(3):257-65. 
164. Gutke A, Stuge B, Elden H, Sandell C, Asplin G, Fagevik Olsen M. The Swedish version of the pelvic girdle questionnaire, cross-cultural adaptation and validation. Disabil Rehabil. 2020;42(7):1013-20.

165. Dunn KM CP. Classification of Low Back Pain in Primary Care: Using "Bothersomeness" to Identify the Most Severe Cases. Spine. 2005;30(15):1887-92.

166. Bo K, Backe-Hansen KL. Do elite athletes experience low back, pelvic girdle and pelvic floor complaints during and after pregnancy? Scand J Med Sci Sports. 2007;17(5):480-7.

167. Naugle KM, Fillingim RB, Riley JL, 3rd. A meta-analytic review of the hypoalgesic effects of exercise. J Pain. 2012;13(12):1139-50.

168. Owe KM, Nystad W, Bo K. Correlates of regular exercise during pregnancy: the Norwegian Mother and Child Cohort Study. Scand J Med Sci Sports. 2009;19(5):637-45.

169. Madeira HG, Garcia JB, Lima MV, Serra HO. [Disability and factors associated with gestational low back pain]. Rev Bras Ginecol Obstet. 2013;35(12):541-8. 
170. Olsson C, Nilsson-Wikmar L. Health-related quality of life and physical ability among pregnant women with and without back pain in late pregnancy. Acta Obstet Gynecol Scand. 2004;83(4):351-7.

171. Hansen ML, Thulstrup AM, Juhl M, Kristensen JK, RamlauHansen $\mathrm{CH}$. Occupational exposures and sick leave during pregnancy: results from a Danish cohort study. Scand J Work Environ Health. 2015;41(4):397-406.

172. Henrotin JB, Vaissiere M, Etaix M, Dziurla M, Malard S, Lafon D. Exposure to occupational hazards for pregnancy and sick leave in pregnant workers: a cross-sectional study. Ann Occup Environ Med. 2017;29:12.

173. Juhl M, Andersen PK, Olsen J, Andersen AM. Psychosocial and physical work environment, and risk of pelvic pain in pregnancy. A study within the Danish national birth cohort. J Epidemiol Community Health. 2005;59(7):580-5.

174. Hammer PEC, Garde AH, Begtrup LM, Flachs EM, Hansen J, Hansen AM, et al. Night work and sick leave during pregnancy: a national register-based within-worker cohort study. Occup Environ Med. 2019;76(3):163-8. 
175. Murakami E. Sacroiliac Joint Disorder. Singapore: Springer Nature Singapore Pte Ltd.; 2019.

176. Gilleard W, Crosbie J, Smith R. Effect of pregnancy on trunk range of motion when sitting and standing. Acta Obstet Gynecol Scand. 2002;81(11):1011-20.

177. Gilleard WL, Crosbie J, Smith R. Static trunk posture in sitting and standing during pregnancy and early postpartum. Arch Phys Med Rehabil. 2002;83(12):1739-44.

178. Byrd-Craven J, Massey AR. Lean on me: effects of social support on low socioeconomic-status pregnant women. Nurs Health Sci. 2013;15(3):374-8.

179. Ozturk G, Geler Kulcu D, Aydog E, Kaspar C, Ugurel B. Effects of lower back pain on postural equilibrium and fall risk during the third trimester of pregnancy. J Matern Fetal Neonatal Med. 2016;29(8):135862.

180. Davenport MH, Ruchat SM, Poitras VJ, Jaramillo Garcia A, Gray CE, Barrowman N, et al. Prenatal exercise for the prevention of gestational diabetes mellitus and hypertensive disorders of pregnancy: a 
systematic review and meta-analysis. $\mathrm{Br} \mathrm{J}$ Sports Med. 2018;52(21):1367-75.

181. Casagrande D, Gugala Z, Clark SM, Lindsey RW. Low Back Pain and Pelvic Girdle Pain in Pregnancy. J Am Acad Orthop Surg. 2015;23(9):539-49.

182. Koukhan S, Rahimi, A., Ghasemi, M., Naimi, S. S.,Akbarzadeh Baghban, A. Postural Changes during First Pregnancy. Br J Med Med Res. 2015;7(9):744-53.

183. Rainville J, Hartigan C, Martinez E, Limke J, Jouve C, Finno M. Exercise as a treatment for chronic low back pain. Spine J. 2004;4(1):106-15.

184. Rasmussen M-LH SM, Wohlfahrt J, Videbech P, Melbye M. Risk, treatment duration, and recurrence risk of postpartum affective disorder in women with no prior psychiatric history: A population-based cohort study. . PLoS Med. 2017;14(9).

185. Dipietro L, Evenson KR, Bloodgood B, Sprow K, Troiano RP, Piercy KL, et al. Benefits of Physical Activity during Pregnancy and Postpartum: An Umbrella Review. Med Sci Sports Exerc. 2019;51(6):1292-302. 
186. Karoly P, Ruehlman LS. Psychological "resilience" and its correlates in chronic pain: findings from a national community sample. Pain. 2006;123(1-2):90-7.

187. Stendal Robinson H, Lindgren A, Bjelland EK. Generalized joint hypermobility and risk of pelvic girdle pain in pregnancy: does body mass index matter? Physiotherapy Theory and Practice. 2021:1-8.

188. Wergeland E, Strand K. Work pace control and pregnancy health in a population-based sample of employed women in Norway. Scand J Work Environ Health. 1998;24(3):206-12.

189. Andersen LK, Backhausen M, Hegaard HK, Juhl M. Physical exercise and pelvic girdle pain in pregnancy: A nested case-control study within the Danish National Birth Cohort. Sex Reprod Healthc. 2015;6(4):198-203.

190. Committee Opinion No. 650 Summary: Physical Activity and Exercise During Pregnancy and the Postpartum Period. Obstet Gynecol. 2015;126(6):1326-7. 


\section{Erratum}

In Paper III, "Discussion" section, it is written “As indicated in this study and confirmed in previous studies, most pregnant women seem to benefit from exercise as it increases pain tolerance, improves or maintains physical fitness, helps with weight management, reduces the risk of gestational diabetes in obese women, and enhances psychological wellbeing". The paragraph should read "As indicated in this study, and confirmed in other research, many pregnant women seem to benefit from exercise as it increases pain tolerance, improves or maintains physical fitness, helps with weight management, reduces the risk of gestational diabetes in obese women, and enhances psychological well-being." 


\section{PAPERS}

7.1 Paper I 


\section{Prevalence of Low Back and Pelvic Pain During Pregnancy in a Norwegian Population}

Stefan Malmqvist, DC, MSc, Inger Kjaermann, MSChir, Knut Andersen, DC, ${ }^{\text {b }}$ Inger OKdand, MD, Kolbjom Bronnick. PhD, and Jan Petter Larsen, MD, PhD ${ }^{\text {e }}$

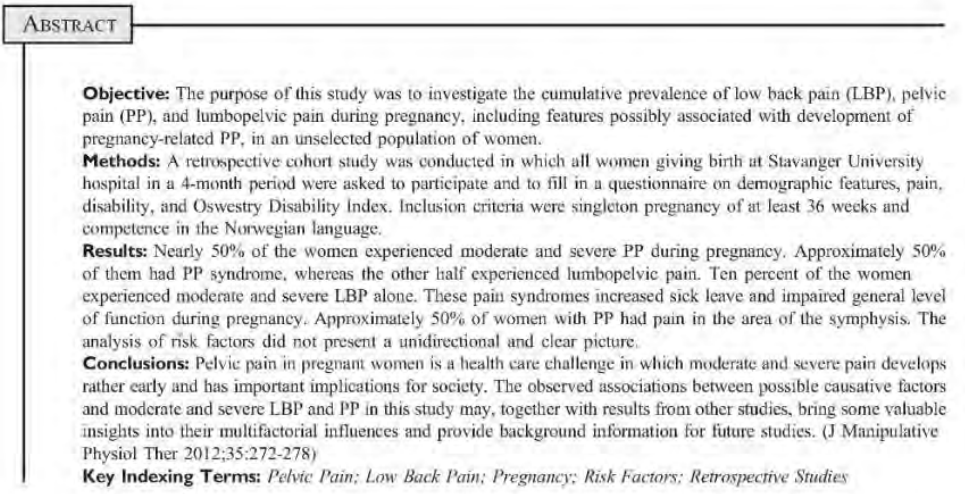

ow back pain (LBP) and pelvic pain (PP) are common conditions in many cultures during pregnancy. ${ }^{1.8}$ Two Swedish studies presented

"PhD Student, The Department of Health Studies, University of Stavanger, and The Norwegian Centre for Movement Disorders. ${ }^{b}$ Chiropmeter, The Depurtment of $\mathrm{N}$ (

University Hospital, Stavanger, Norway.

"Consultant, Department of Obstetrics and Gynaecology, Stavanger University Hospital, Stavanger, Norway.

Associate Professor, The Norwegian Centre for Movemen Disorders, Stavanger University Hospital, Stavanger, Norway.

'Professor, The Norwegian Centre for Movement Disorders.
Stavanger University Hospital, Stavanger, Norway. Stavanger University Hospital, Stavanger, Norway.

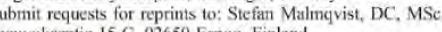

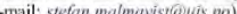

Paper submitted June 11, 2011: in revised form November 30, 2011; accepted January 13, 2012 .

$0161-4754 / \$ 36.00$

Copyright 12012 by National University of Health Sciences. doi: 10.10I6/j, jumpt.2012.04,004

272 prevalence of $54 \%$ for PP. $17 \%$ for LBP, and $29 \%$ to $72 \%$ for combined symptoms. ${ }^{1,2}$ One Dutch study showed prevalence of $7 \%$ for self-reported PP during pregnancy, whereas an Iranian study revealed that $28 \%$ of pregnan women had PP, $13 \%$ had LBP and $8 \%$ had combined symptoms. ${ }^{3.4}$ An international study concluded that PP in pregnancy does not vary according to geography of socioeconomy and presented a pp prevalence of $49 \%$ in Sweden, $66 \%$ in Tanzania, $77 \%$ in Finland, and $81 \%$ in Zanzibar, with an overall similarity of symptom location and degree of pain. ${ }^{3}$ Furthermore, an Australian retrospective study showed that $35 \%$ of women had experience LBP during pregnancy ${ }^{6}$; in a Danish study, Albert et al found a $20 \%$ cumulative prevalence of isoluted PP in preonancy, and two-thirds of the pregnant women repon CBP in a coss-sectiont study in the United Stapo SkP in a cos ${ }^{8}$ Skaggs a dil. Interestingly, most women report their firs A

Although these are common complaints in pregnancy, the etiology is still unknown, and the pathophysiology is unclear. In addition, low back and pelvic disorders during 
pregnancy are considered a major public health issue." Sick leave for LBP or PP during pregnancy has been shown to occur in $37 \%$ to $72 \%$, and the period of sick leave is on average between 12 and 15 weeks."

The wide range of the reported frequency of these complaints during pregnancy may be caused by methodological differences. Most of the previous studies are based on selected populations of pregnant women, and a clearly defined clinical diagnosis of PP is missing. In lack of a clear definition, a diverse nomenclature for these conditions has been used: pelvic in ficiency, LBP. Lumbosacral pain. symphysiolysis, pelvic syndrome, posterior PP, and preg-

Guidelines for identification and classification of pregnancy-related PP have been established in later years. based on physical examination and history taking. ${ }^{1}$ However, studies of risk factors related to the developmen of PP during pregnancy have not yet been able to reveal one single dominant causative factor, but several different physical and psychosocial factors have been found to
correlate with self-reported pain. ${ }^{3,913-15}$ An increased abdominal diameter, higher body mass index (BMI), muscle dysfunction, and fetal weight are clearly associated with LBP and PP during pregnancy. ${ }^{16.18} \mathrm{~A}$ general increase in mobility of joints during pregnancy has also been in mobility of joints during pregnancy has also been
described, ${ }^{19}$ and Sipko et al ${ }^{20}$ found that the most fredescribed, and Sipko et al found that the most frequently irritated ligaments during
interspinous, iliolumbar, and sacroiliac.

However, some suggest that pain during pregnancy is not only explained by biomechanical factors alone psychosocial factors too seem to be important.

The objectives of this study were to investigate the cumulative prevalence of LBP, PP, and combined lumbopelvic pain (LBPP) in an unselected population of women, giving birth during a 4-month period, and to study clinical and demographic features possibly associated with the development of pregnancy-related PP.

\section{Methods}

This study is a retrospective longitudinal cohort study with data collection over the period of March to June 2009 at the maternity ward of Stavanger University Hospital, Norway. All women giving birth at the hospital during this period were asked to participate and to fill in the questionnaire. Inclusion criteria were a term singleton pregnancy of at least 36 weeks and good competence in the Norwegian language. The hospital has the only bith department in the southern part of the county of Rogland with a population of approximely 330000 Rogaland, With a population of approximately 33000 inhabitants. The annual number of deliveries at the hospital varies

Within 24 hours after delivery, the women received both oral and written information from a midwife. Participation was voluntary, but to obtain inclusion of an unselected sample, all women were encouraged to give their informed consent to participate. The study was carrie out in accordance with the Helsinki Declaration II an was approved by the Regional Ethics Committee of Western Norway. All subjects consented to participate in this study,

To assess if the study population was a representative sample of the delivering women, we compared demographic and clinical characteristics of the study population with that of the general delivery database at the hospital The women completed a questionnaire on demographic eatures and pain, disabiliy, and exercising before an during pregnancy. The question specially designed by the research group, based on previou studies and the experience of the team.

Information on presence of pain, pain distribution, and level of pain intensity was collected for both previous an present pregnancies. Pain intensity for both LBP and PP was rated retrospectively on a numerical rating scale (NRS) from 0 to 100 for each month of the pregnancy, to collect information on appearance of symptoms and peak intensity pain during pregnancy. There are 2 versions of the NRS: 0 to 10 and 0 to 100 , and in this study, the latter one was used to record a detailed pain level. ${ }^{23}$

Reports on pain distribution were obtained by asking for drawings on figures of the lower back and pelvic areas. Studies evaluating pelvic girdle pain occasionally use pain Studies evaluating pelvic girdle pain occasionally use pain
drawings, in spite of clinical experience showing that some women have difficulties in anatomically locating the pai on a drawing, ${ }^{23,17,25,26}$ In this study, there were 3 figures: low back and 2 pelvic (front and back), all with explanation of the regions involved. The pain drawings were used to differentiate between low back and PP and to identify location of pain in either area.

Information on disability was collected through the Oswestry Disability Index (ODI), which is one of the principal condition-specific outcome measures for defining

The questionnaires also provided information on The questionnaires also provided information on
number of years of education, level of physical work number of years of education, level of physical work
load (a 5-level scale running from "very light" to "very heavy" - a score of 3 or more was used to characteriz women with a heavy work load), work satisfaction (a 5 level scale running from "very bad" to "very good"score of 3 or less was used to describe women with a low satisfaction at work), sick leave during pregnancy (time periods and percentages), height, and weight before pregnancy and at delivery, Body mass index was calculated and used in the data analyses,

Further variables included were number of previous births, pain in previous pregnancies, pain during the last year before pregnancy, and exercising habits ("Did you exercise regularly, at least 2-3 times per week before pregnancy/during pregnancy?"). 
Table I. Demographic and prepregnancy clinical features of the participating women according to perceived types of pain in the umbopelvic area churing pregnanc

\begin{tabular}{|c|c|c|c|c|c|c|}
\hline Demographic and clinical variables & No pain & $\begin{array}{l}\text { Mrild pain: } \\
\text { all types }\end{array}$ & $\begin{array}{l}\text { Moderate to } \\
\text { severe LBT? }\end{array}$ & $\begin{array}{l}\text { Moderate to } \\
\text { severe PP }\end{array}$ & $\begin{array}{l}\text { Modirate to } \\
\text { severe LBPP }\end{array}$ & $\begin{array}{l}\text { All } \\
\text { women }\end{array}$ \\
\hline$\pi(\%)^{2}$ & $158(27.8)$ & $73(12,8)$ & $56(9,8)$ & $148(26.0)$ & $123(21.6)$ & 569 \\
\hline Education years, mean (SD) & $14.9(3.6)$ & $15.6(2.9)$ & $14.6(3.6)$ & $15.0(2.9)$ & $14.1(3.5)$ & $14.7(3.3)$ \\
\hline BMI before pregnancy, mean (SD) & $22.8(3.6)$ & $23.3(3.4)$ & $23.1(4,1)$ & $24.5(4.8)^{*}$ & $24.9(4.5)^{\circ}$ & $23.8(4.2)$ \\
\hline LBP in previous pregnancies, $\mathrm{n}(\%)$ & If (6.9) & $18(24,6)$ & $20(35.7)^{*}$ & $24(16.2)^{*}$ & $56(45.5)^{*}$ & $124(21.8)$ \\
\hline PP in previous pregnancies, $10(\%)$ & $12(7.6)$ & $21(28.7)$ & $10(17.8)$ & $64(43,4)^{*}$ & $54(43,9)^{*}$ & $165(29,0)$ \\
\hline LBP in the year before pregnancy, $\mathrm{n}(\%)$ & $13(8.2)$ & $12(16.4)$ & $19(33,9)$ & $35(23.6)$ & $53(43.0)^{*}$ & $135(23.7)$ \\
\hline PP in the year before pregnancy, $n$ (\%) & $6(3.8)$ & $3(4.1)$ & $2(3,6)$ & $23(15.5)^{*}$ & $15(12.2)^{\circ}$ & $51(9.0)$ \\
\hline $\begin{array}{l}\text { Exercised at least } 2-3 \text { times a week } \\
\text { before pregnininy, } \mathrm{n}(\%)\end{array}$ & $68(43.1 .6)$ & $34(46.6)$ & $25(44.6)$ & $44(29.7)^{\circ}$ & $47(38.2)$ & $224(39.4)$ \\
\hline Physically heavy work, $n(\%)$ & $31(19.6)$ & $18(24,6)$ & $18(32.1)$ & $42(28.4)$ & $49(39.8)^{*}$ & $162(28.4)$ \\
\hline
\end{tabular}

* Nonparametric test showing significance in difference between asymptomatic group und symptomatic groups at $P \leq .05$. leve

"Eleven women did net Gil in the scales for low back od PP.

Statistical Analyses

Descriptive data are presented by mean values and standard deviations for continuous variables and by frequencies for categorical variables. The data on pain symptoms were classified into 3 pain level groups through analyses of variance. Cutoff point with the largest $F$ ratio analyses of variance. Cutoff point with the largest $F$ ratio
between mild and moderate and severe pain was found at 35 in the NRS $(0-100)$. Thus, for each type of pain variable, the patients were grouped into 3 categories according to their symptoms: One group with no pain (NRS $=0$ ), one group with mild pain (NRS $\leq 35$ ), and one group with moderate and severe pain (NRS > 35). Kruskal-Wallis statistics were used to explore the group differences between pain distribution and prepregnant and pregnant values.

Multivariate hierarchical binary logistic regression analysis was used to assess whether the prepregnancy and pregsis was used to assoss wher the prepregnancy and contrasted with no pain. Mild pain was omitted from the contrasted with no pain. Mild pan was onited from the analysis. In the fist block of the analysis, age, education level, and number of previous births were entered, followed by a block including average level of LBP throughout the pregnancy, and finally, the last block used backward stepwise regression using the likelihood ratio removal criterion, with the variables workload, BMI before the pregnancy, BMI at birth, feelings of depression during pregnancy, physical activity before, and physical activity during pregnancy. Thus, the first 2 blocks served mainly as statistical controls with forced entry of all variables, before entering the variables to be explored in the final block All anases were perford in SPSS 16 (IBM, Now Y A $\mathrm{NY})$, and results were considered significant at $P \leq .05$.

\section{RESULTS}

\section{Study Population}

Women who gave birth at Stavanger University Hospital during the inclusion period (n $=1204$ ) were invited to participate in the study. Alter exclusions, there were 994 women eligible for the study. In addition, 336 women did not return a questionnaire, and 89 did not complete a received questionnaire. The final study population thus consisted of 569 women, which was $58 \%$ of the total possible sample.

To examine if the study population was representative, we compared age and parity variables from the study population with that of all women who gave birth durin the study period and found a near complete match (results not shown).

Tables 1 and 2 show demographic and clinical data for the women included in the study. The mean age of the population was 30 years, mean years of education was 14.7 years, and slightly more than one-third of the women were giving birfh for the first time, The mean BMI was $23.8 \mathrm{~kg} / \mathrm{m}^{2}$, and close to half of the women exercised 2 to 3 times per week before pregnancy. The mean amount of (a)

\section{requency of Moderate and Severe Pain in Lumbar and Pelvic Area}

\section{Ouring Pregnanco}

Approximately a quarter of the women did not report any LBPP during the pregnancy. A further $13 \%$ had only experienced mild pains. For moderate and severe pain during pregnancy, the cumulative prevalence was $57.4 \%$ $n=327$ ) (Table 3). Moderate and severe combined LBPP was experienced by $21.6 \%(\mathrm{n}=123)$, and moderate and severe PP was experienced by $26.0 \%(n-148)$. Almost $10 \%$ of the wonen $(n=56)$ by (07 of the women (n - 56) had moderate and severe pai solely in the luber a erate an severe pain, had such pain already after 5 months of pregnancy (Table 3 )

Table 4 shows the distribution of pain in the pelvic are for all women with PP, for women with moderate an severe combined LBPP, and for those with moderate and severe PP alone. Among all women with such pain, more than half of them $(55 \%)$ experienced pain at the symphysis Approximately $20 \%$ experienced pain only in this ares. 
Table 2. Demographic and clinical features of the participating women accarding to perceived types of pain in the lumbopetic area during pregnancy

\begin{tabular}{|c|c|c|c|c|c|c|}
\hline Demographic and clinical variables & No pain & $\begin{array}{l}\text { Mild pain, } \\
\text { all types }\end{array}$ & $\begin{array}{l}\text { Modente b } \\
\text { severe LBP }\end{array}$ & $\begin{array}{l}\text { Modente bo } \\
\text { severe PP }\end{array}$ & $\begin{array}{l}\text { Modense to } \\
\text { severe LBPP }\end{array}$ & $\begin{array}{l}\text { All } \\
\text { wornent }\end{array}$ \\
\hline $\mathrm{n}(\%)^{n}$ & $158(27.8)$ & $73(128)$ & $56(9.8)$ & $148(26,0)$ & $123(21.6)$ & 569 \\
\hline Age at delivery $(y), n$ & $30.0(4.8)$ & $30.1(4.8)$ & $29.4(6.2)^{*}$ & $30.5(4.2)$ & $29.6(4.4)$ & $30.0(4.7)$ \\
\hline BMI al delivery, mean (SD) & $27.7(3.7)$ & $27.9(3.2)$ & $28.2(4.4)$ & $29.6(5.1)$ & $30.3(4.8)^{*}$ & $28.8(4.5)$ \\
\hline Primuparcuss, n $(\%)$ & 71 (45) & $36(49.3)$ & $25(44.6)$ & $43(29.0)$ & $44(35.8)$ & $219(38.5)$ \\
\hline $\begin{array}{l}\text { Exercised at least } 2-3 \text { times a week during } \\
\text { pregiancy, } \mathrm{n}(\%)\end{array}$ & $43(272)$ & $20(27.4)$ & $9(16.0)$ & $28(18.9)$ & $12(9.7)^{*}$ & $117(20.6)$ \\
\hline $\begin{array}{l}\text { Weeks of fulltime sick leave during } \\
\text { pregancy, mean (SD) }\end{array}$ & $5.4(8.82)$ & $6.5(8.62)$ & 9.1 (10.13) & $10.7(12.26)$ & $155(15.25)$ & $9.6(12.20)$ \\
\hline Received treatment for $\mathrm{LBP}$ and or $\mathrm{PP}, \mathrm{n}(\%)$ & & $14(19.2)$ & $12(2 \mathrm{~L}, 4)$ & $63(42,6)$ & $64(52)$ & $156(27.4)$ \\
\hline Mean ODI scone (n) & $4.68 \%(35)$ & $14.11 \%(70)$ & $21.92 \%(52)$ & $33.24 \%(145)$ & $37.66 \%(118)$ & $27.57 \%(429)$ \\
\hline
\end{tabular}

- Nenpanmetric test showing significance in differenoe between symplomatic group and symptomatic groups at $P \leq .05$ level

- Eleven women did not fill in the scales for LBP and PP

Table 3. Prevalence of moderate and severe pain at different stages of pregnancy

\begin{tabular}{|c|c|c|c|c|c|c|c|c|c|}
\hline Prevalence & $\begin{array}{l}\text { Lumbart } \\
\text { pain }\end{array}$ & $\begin{array}{l}95 \% \mathrm{Cl} \\
\text { lower }\end{array}$ & $\begin{array}{l}99 \% \mathrm{Cl} \\
\text { uppor }\end{array}$ & PP & $\begin{array}{l}95 \% \mathrm{Cl} \\
\text { bwer }\end{array}$ & $\begin{array}{l}95 \% \mathrm{Cl} \\
\text { upper }\end{array}$ & LBPP & $\begin{array}{l}95 \% \mathrm{Cl} \\
\text { bwer }\end{array}$ & $\begin{array}{l}95 \% \mathrm{Cl} \\
\text { upper }\end{array}$ \\
\hline & 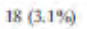 & 0567 & 1040 & & m8 & 378 & & 0.57 & 97 \\
\hline Af $y$ & & & 1.6 & & 1.4 & & 6) & Las & 949 \\
\hline Cunnuative & $56(9.8 \%)$ & 0.074 & 0.123 & $148(26.00 \%)$ & 1.098 & 1.375 & $123(21.6 \%)$ & 0.182 & 0.250 \\
\hline
\end{tabular}

Approximately $40 \%$ had pain at all 3 pelvic joints, and $20 \%$ had pain at 1 sacroiliac joint alone. For those with LBP in addition to $\mathrm{PP}$, a pain distribution to all 3 pelvic joints was more common.

Table 2 also shows that women with moderate and severe LBPP have an average sick-leave period of 15.5 weeks, moderate to severe PP 10.7 weeks, and women with moderate to severe LBP 9.1 weeks. Women with mild pain revealed a mean sick-leave period of 6.5 weeks, indicating that moderate to severe pain was clinically different from those with less pain. The same pattern was also found for disability as measured with the ODI. For seeking treatment for LBP and PP during the pregnancy, PP was a stronger driver for this than lumbar pain, and again, moderate to severe pain needed more treatment than mild pain (Table 2).

\section{Potential Risk factors for Lumber and PP During Pregrancy}

Nonparametric test for exploring group differences between demographic and clinical features, before and during pregnancy for the participating women, are shown according to pain categories in Tables 1 and 2 . In the multivariate analysis, we examined the impact of different clinical and demographic variables on all women with moderate and severe PP vs those without any pain. The first block of the binary logistic regression analyses was not statistically significant $(P=.379)$, indicating that age, education, and number of previous births did not contribute to the prediction of moderate to severe PP. Block 2, however, was highly significant $(P<.001)$, as a high level of LBP reduced the risk of $\mathrm{PP}(P<.001$; odds ratio, 0.845 ; $95 \%$ confidence interval [C], 0.798- 0.894$)$. The final step of the final block consisted of the previously entered variables and the variables remaining (BMI before pregnancy and physical activity before the pregnancy) after the backward stepwise procedure and was also highly significant $(P=.001)$. The resulting omnibus logistic regression model was significant $(P<.00 \mathrm{I}$, Nagelkerke $\left.R^{2}=.319\right)$. Average LBP $(P<.001 ;$ odds ratio, $.837 ; 95 \%$ CI, $0.790-0.887)$, BMI before pregnancy $(P=.01 \mathrm{I}$; odds ratio, 1.074; $95 \% \mathrm{CI}, 1.016-1.134$ ), and physical activity before pregmancy $(P=015$; odd ratio, $1.826 ; 95 \%$ C 1.126-2.960) were significant predictor variables in the full multivariate model. Thus, both higher BMI before pregnancy and more physical activity before pregnancy were independent potential risk factors for PP after controlling for age, education, number of previous pregnancies, and LBP. Low back pain reduced the risk of moderate to severe PP.

\section{Discussion}

This study shows that nearly $50 \%$ of Norwegian women experience moderate and severe PP during pregnancy. Approximately half of them had only PP syndrome, whereas the other half experienced PP combined with LBP. In addition, $10 \%$ of the women experienced moderate 
Table 4. Prevalence of moderate and severe pain distribution according to pain drawing

\begin{tabular}{|c|c|c|c|c|c|c|c|c|c|}
\hline $\begin{array}{l}\text { Pain } \\
\text { prevalence }\end{array}$ & $\begin{array}{l}\text { All wonen } \\
\text { with PP (348) }\end{array}$ & $\begin{array}{l}95 \% \mathrm{CI} \\
\text { lower }\end{array}$ & $\begin{array}{l}95 \% \mathrm{CI} \\
\text { upper }\end{array}$ & $\begin{array}{l}\text { Moderate and } \\
\text { severe PP (148) }\end{array}$ & $\begin{array}{l}95^{9 \%} \mathrm{Cl} \\
\text { lower }\end{array}$ & $\begin{array}{l}95 \% \mathrm{CI} \\
\text { lower }\end{array}$ & $\begin{array}{l}\text { Moderate and } \\
\text { severe LBPP (123) }\end{array}$ & $\begin{array}{l}95 \% \mathrm{CI} \\
\text { lower }\end{array}$ & $\begin{array}{l}95 \% \mathrm{Cl} \\
\text { upper }\end{array}$ \\
\hline At all pelvic joints & $113(32.5 \%)$ & 0.804 & 0.931 & $40(27.0 \%)$ & 0.264 & 0.44 & $58(47.2 \%)$ & 0.420 & 0.607 \\
\hline At symphysis & $67(19.3 \%)$ & 0.656 & 0.866 & $33(22.3 \%)$ & 0.370 & 0.615 & $18(14.6 \%)$ & 0.160 & 0.378 \\
\hline At $1 \mathrm{SI} \mathrm{joint}$ & $83(23.9 \%)$ & 0.651 & 0.842 & $38(25.790)$ & 0.348 & 0.567 & $24(19.5 \%)$ & 0.190 & 0.389 \\
\hline At both Sl joints & $60(17.2 \%)$ & 0.599 & 0.834 & $27(16,2 \%)$ & 0.320 & 0.580 & $16(130 \%)$ & 0.151 & $0.3 \times 2$ \\
\hline Oher areas & $7(2,0 \%)$ & -0.066 & 0.923 & $1(0.7 \%)$ & -0.207 & 0.492 & $2(1.6 \%)$ & -0.166 & 0.737 \\
\hline Missing data & $18(5,2 \%)$ & 0.734 & 0.824 & $9(6.1 \%)$ & 0.368 & 0.475 & $5(4.1 \%)$ & 0.306 & 0.410 \\
\hline
\end{tabular}

\$t, sacroiliac.

and severe $\mathrm{LBP}$ alone. These pain syndromes increased the number of weeks of sick leave and impaired the general level of function during pregnancy. Approximately $50 \%$ of women with PP had pain in the area of the symphysis. Analysis of risk factors did not present a unidirectional and clear picture. The features that showed a significant association with moderate and severe PP bad rather low odd ratios, but the observed influence of a higher BMI before pregnancy may have implications for preventive measures for this important complaint of pregnancy.

Several methodological issues must be considered when measuring the frequency of a disease or complaint in a mopulation A high diagnestic acciracy of the stidied the resulta disorder is needed, and he result als depends on the use of an unselected patient population. Unfortunately, in both this and in previous studies, ${ }^{2-6.17}$ pregnancy-related LBP and PP have not been examined using standardized measurements that have received an international acceptance. This is partly because of the self-perceived nature of the complaints themselves and, as in this study, the use of retrospectively collected data on pain during pregnancy. In addition, the European guidelines for pelvic girdle pain require elinical examinations. ${ }^{17}$ To perform examinations several times throughout pregnancy could have improved the diagnostic accuracy but was not part of the study design

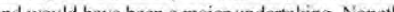
believe hat our a deach be believe hat approach by using moderate and severe pain as crictia for the agrosis of pp a mprovement in study design as compared with previous works. $23,5,6,17$ This strategy will reduce the methodological problems related to recall bias and the impact by minor pains experienced only for shorter periods.

Our aim was to enroll all women who fulfilled the inclusion criteria during a given period. Unfortunately, ou response rate was rather low, probably reflecting other priorities of the women in the stressful situation shortly after delivery. We did, however, introduce several measures to obtain a high awareness of the importance of the study both among the women und midwives. The rather low res both mone could be caused by a selective lower interest in the

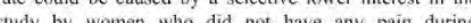
study by wenen who did not have any pain during pregnancy and therefore introducing a bias toward over-
estimating the frequency of moderate to severe pelvic and estimating the frequency of moderate to severe pelvic and cannot be ruled out completely, we found that the age and parity of the studied population were identical to the general population of women who give birth at the hospital. We therefore believe the results from this study to be representative for pregnant women in the study area and most probably also in Norway.

In this study, we examined the cumulative prevalence of noderate to severe pain in the lumbopelvic area during pregnancy. $\Lambda$ very high proportion $(57 \%)$ of pregnant women had such pain. In a Swedish study, $72 \%$ of preunan women bad LBP or PP during preonency 2 In our study, $71 \%$ had experienced any pain. The identical results from 2 different Scundinavian countries lend strength to the vality of our vit he complaint

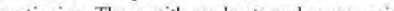
functioning. Those with moderate and severe pain had 2 t 3 times more sick leave days than women without or wit only mild pain. In addition, the ODI showed that these complaints bave a major impact on the functioning of pregnant women. These findings underline the importance of $\mathrm{PP}$ in pregnancy for women and society.

\section{Limitation}

Although the retrospective data in this study is bampered by some uncertainty, it revealed that most women who developed moderate and severe PP also had his at the termination of pregnancy and that already $40 \%$ had such pain after 5 months of pregnancy. This shows that these pains develop rather early and persist throughout pregnancy.

In this study, we used pain drawings to reveal the pain distribution. The lack of clinical examinations limits the value of these observations, but interestingly, more than $50 \%$ experienced pain at the symphysis and nearly $25 \%$ had predominating unilateral pain at 1 sacroiliac joint.

The observed associations between possible causative factors and moderate and severe PP did not provide clear answers. The demographic and clinicel features fovide clear and and ding stud could pregnancy-related mechanisms not examined in this study may have an important impact on the development of PP 


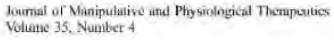

other studies may bring some valuable insights into the multifactorial influences on PP in pregnancy,

\section{Conciusion}

Our study has shown that PP is a major health care challenge in pregnant women with implications for society Our results may provide important background information on potential risk factors for PP, which in future studies should be investigated in a prospective study, controlling for confounders, and include clinical examinations of subgroups of pregnant women who are offered therapeutic interventions in a blinded design.

\section{Practical Application}

- Nearly $50 \%$ of the women in this study experienced moderate and severe PP during pregnancy.

- Pelvic pain and LBPP increased the number of weeks of sick leave and impaired the general level of funetion during pregnancy.

- Analysis of risk factors did not present unidirectional and clear picture

\section{ACKNOWIEDGMENT}

The authors acknowledge the assistance of the midwive at the Stavanger University Hospital in collecting the data.

Funding Sourges and Potential Confucts of Interes

No funding sources or conflicts of interest were reporte for this study.

\section{REFERENCES}

1. Gutke A, Ostgaard HC, Oberg B. Pelvic girdle pain and lumbar pain in pregnancy: a cohort study of the consequenc

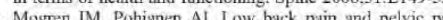
during pregnancy: prevalence and risk factors, Spine 2005;30: 983-91

3. Van De Pol G, Van Brummen HJ, Bruinse HW, Ifeintz AP, Peter M, Van Der Vaart CH. Pregn Bar pain in the Netherlands. Acta Obstet Gynecol Scand 2007;86:

4. Mousavi S, Pamianpour M, Vleeming A, Pregnancy related elvic girdle pain and low back pain in an Iratrian population

. Björklund K, Bergström S. Is pelvic pain in pregnancy a welf
complaint? Acta Obster Gynecol Scand 2000:79:24-30.

6. Stapleton DB, Macleman AH, Kristiansson P. The prevalenee of recalled low back pain during and after pregnancy: South Australian population survey. Aust N Z J Obstet Gynaecol 2002;42:482-5
7. Alben IIB, Godskesen M, Westergaard JG. Incidence of four

8. Skaggs CD, Prather H, Gross G, George JW, Thompson United States tive survey. J Manipulative Physiol Ther 2007;30:130-4. 9. Svenssun HO, Andersson GB, Hagstad A, Jansson PO. The Orvieto R, Achiron A, Ben-R

-Rafaci Z, Gelernter I. Achiron R. (1994, 73:209-1

I. Wu WH, Meijer OG, Uegaki K, Mens JMA, van Dieen JH, Wuismat PIJM, et al. Pregnancy-related pelvic girdle pain (PPP), 1: rerminology, clinical presentation, and prevalence. Eur Spine J 2004;13:575-89.

12. Vermani $E$, Mittal $R$, Weeks $A$. Pelvic girdle pain and low back pain in pregnancy; a review, Pan Pract 2010,10:60-71. Vleeming A, Albern HB, Ostgaara HC. Sturesson B, Sruge B. girdle pain. Fur Spine J 2008:17:794-819.

14. Albert HB, Godskesen M, Korsholm L, Westergaand JG, Risk factors in developing pregnancy-related pelvic girdle pain Acta Obstet Gynecol Scand 2006;85;539-44

5. Linton SJ. A review of psychological risk factors in back and heck pain. Spine 2000;25:1148-56 Influence of some biomechanical factors on low-back pain in pregnancy. Spine (Phila Pa 1976) 1930 is 61.5 .

of long-term outcome for women with low back pin pelvic pain Juring pregnancy. Eur Spine J 2006, 15:1093-102. 18. Mens JM, Vleeming A, Snijders CJ, Stam HJ, Ginai AZ. The active straight leg raising test and mobility of the pelvic joints. Eur Spine J 1999:8:468-73.

9. Ostgaard HC, Andersson GB, Karlsson K. Prevalence of back pain in pregnancy, Spine 1991:16:549-52.

Sipko T, Grygier D, Barczyk K, Eliasz G, The occurrence of strain symploms in the lumbosacral region and pelvis during 2010:33:370-7.

21. Sithonen T, Huttunen M, Makkonén M, Airaksinen O Functional changes in back muscle activity correlate with pain intensity and prediction of low back pain during pregnancy Arch Phys Med Rehabil 1998;79:1210-2.

Goldsmith L Shenton D, Silva Schauberger CW, Rooney BL, Goldsmith L, Shenton D, Silva
PD, Schaper A. Peripheral joint laxity increases in pregnancy D. Schaper A. Pcripheral joint laxity increases in pregnancy Gynecol 1996;174:667-71

23. Lofiren M Nortrink C. Pain relief in women with fibromyalgia: a cross-over study of superficial warmth stimulation and transculancous electrical herve stimulation. J Rehabil Med 2009:41:557-62.

4. Marty M, Rozenburg S, Legout V, Durand-Zaleski I, Moyso D, Henrotin $Y$, et al. Influence of time, activities, and memory on the assessment of chronic low back pain intensity. Spine

5. Mogren I. Perceived bealth, sick leave, psychosocial situation, during pregnancy. Acta Obstet Gynecol Scand 2006:85. 647-56.

. Olsén MF, Gutke A, Elden H, Nordenman C, Fabricius L. Gravesen $M$, et al. Self-administered tests as a screening procedure for pregnancy-rolated pelvic girdle pain. Fur Spine syndromes of preynancy-related pelvic joint pain Spine 2002: relationship of low-back pain to pregnancy and gyuecologic

6. Ostgaard HC, Andersson GB, Schultz AB, Miller JA

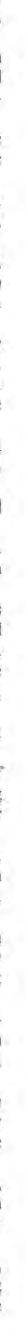


27. Robinson HS, Menyshoel AM, Bjelland EK, Vellestad NK. 30. Miron-Schatz T, Sione A, Kahnemann D. Memories of Pelvic girdle pain chin, Bjelland EK, Vellestad NK Pelvic girdle pain, clinical tests and disability in late yesterday's emotions: does the valence of experience affec

28. Fairbank JCT, Couper J, Davies JB. The Oswestry low back 31. Coughlin SS. Recall bias in epidemiologic studies. I Clin

pain questionnairc, Physiotherapy 1980;66:271-3.
Fairbank JC, Pynsent PB. The Oswestry Disability Index. 32. Macarthur C. Macarthur A, Weeks S. Accuracy of recall of
Spine Spine 2000;25:2940-52

back pain uffer delivery. BMJ 1996;313:467 
7.2 Paper II 
The association between pelvic girdle pain and sick leave during pregnancy; a retrospective study of a Norwegian

\section{population}

Stefan Malmqvist ${ }^{1 *}$, Inger Kjaermann ${ }^{3}$, Knut Andersen ${ }^{1,2}$, Inger Økland ${ }^{4}$, Jan Petter Larsen ${ }^{5}$ and Kolbjørn Brønnick

\section{Abstract}

Background: The incidence of pelvic girdle pain (PGP) in pregnancy is wide ranged depending on definition, the utilised diagnostic means, and the design of the studies. PGP during pregnancy has negative effects on activities of daily living and causes long sickleave, which makes it a major public health issue. Our objectives were to explore the frequency of sick leave in pregnancy due to PGP, assess the relationship between different types of pain-related activities of daily living, examine physical workload, type of work in relation to sick leave, and to explore factors that make women less likely to take sick leave for PGP.

Methods: All women giving birth at the maternity ward of Stavanger University Hospital, Norway, were asked to participate and complete a questionnaire on cemographic features, PGP, pain-related activities of daily living sick leave in general and for PGP, frequency of exercising before and during pregnancy, Drawings of pelvic girdle and low back area were used for the localization of pain. PGP intensity was then rated retrospectively on a numerical rating scale Non-parametric tests, multinomial logistic regression and sequential linear regression analysis were used in the statistical analysis.

Results: PGP is a frequent and major cause of sick leave during pregnancy among Norwegian women, which is also reflected in activities of daily living as measured with scores on all Oswestry disability index items. in the multivariate analysis of factors related to sick leave and PGP we found that work satisfaction, problems with lifting and sleeping, and pain intensity were risk factors for sick leave. In addition, women with longer education, higher work satisfaction and fewer problems with sitting, walking and standing, were less likely to take sick leave in pregnancy, despite the same pain intensity as women being on sick leave

Conclusions: A coping factor in pregnant women with PGP was discovered, most likely dependant on educationassociated with work situation and/or work posture, which decreases sick leave. We recommend these issues to be further examined in a prospective longitudinal study since it may have important implications for sick leave

frequency during pregnancy.

Keywords: Pelvic girdle pain, Sick leave, Pregnancy, Coping

"Corespondences stefrialmesgmall con

of Stavanger, Stavange, Norway

Stavanges, Nurwa

C Biomed Central

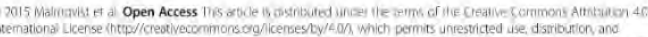

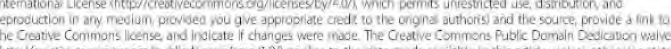

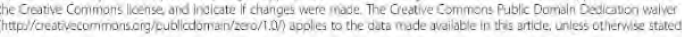


Background

Pelvic girdle pain (PGP) in pregnancy is an unclear and poorly understood condition. There is no official acknowledged nomenclature, hence an abundance of different terminologies have been used in studies to describe it $[1,2]$. The European guidelines for the diagnosis and treatment of PGP describe the localization of pain as"... experienced between the posterior iliac crest and the gluteal fold, particularly in the vicinity of the sacroiliac joints (SII), The pain may radiate in the posterior thigh and can also occur in conjunction with/or separately in the symphysis" [3].

The incidence of pain in the pelvic girdle region in pregnancy ranges from 4 to $76 \%$ depending on the defthe studies [4]. On review study concludes that apthe studies [4]. One review study concludes that approximately $45 \%$ of all pregnant women suffer from lumbopelvic pain in pregnancy, and approximately $20 \%$ of these have isolated PGP

PGP accounts for $37-72 \%$ of sick-leave in pregnancy and length of the sick leave had been found to be 12-15 weeks on average [4-8]. Other pregnancy complications may also occur in women with PGP, leading to sick leave [7]. However, women with a high degree of self-reported PGP have longer sick-leave duration than others, and these pain symptoms were in one study reported to bring about $80 \%$ of sick leaves during pregnancy. The authors argued that this makes PGP during pregnancy a major public health issue [7].

Several risk factors for developing PGP during pregnancy have been identified, such as work load, previous PGP, and previous trauma to the pelvis $\{1,3,7-10\}$. PGP during pregnancy also has negative effects on activities of daily living (ADL) [7-11]. On average, these women do not experience continuous PGP, but activities of daily living such as walking, standing, sitting, lying down, or changing positions may become painful after some time. There is commonly a difficulty in walking fast or over long distances [1]. Disabling problems among women with lumbopelvic pain during pregnancy range from 21 to $81 \%$ (median $28 \%$ ) [1]. A moderate to high Oswestry Disability Index (ODI) in women with pelvic pain during pregnancy has been identified as a risk factor for persistent PGP 3-6 months after birth (12)

The objectives of this study were to explore the frequency of sick leave in pregnancy due to PGP and to assess the relationship of different types of pain-related ADLS, physical workoad, and type of work with sick leave due to PGP. Further we wanted to explore factors lont induce loss sick leave due to PGP, by contrors that induce less sick love we wat by contrasting women who were matched for PGP, but differed by having been versus not having been on sick leave for PGP. The final objective was to explore the relative contribu-
tion of PGP to total amount of sick leave in pregnancy.

\section{Methods}

The data used in this study were collected in the period March - June 2009 at the maternity ward of Stavanger University Hospital, Norway [13]. All women giving birth at the hospital during this period were asked to participate and to fill in a study questionnaire. Inclusion criteria were a term singleton pregnancy of at least 36 weeks and good competence in the Norwegian language. The hospital has the only birth department in the southern part of the county of Rogaland, with a population of about 330,000 inhabitants.

Within $24 \mathrm{~h}$ after the delivery, the women received both oral and written information about the study from midwife. To obtain inclusion of an unselected sample, all women were encouraged to give their informed conant to participa. The study was carried out in conaccordcocher To assess if the sty popition was a represenay. To assess if the study population was a representative sample of the delivering women, we compared demographic and clinical characteristics of the study population with that of the general delivery database at the hospital and found a nearly complete match [13]

The women completed a questionnaire on demographic features, pain in pelvic girdle area, pain-related $A D L$, sick leave in general and due to PGP, and frequency of exercising before and during pregnancy. The questionnaire was produced and specially designed by the research group, based on previous studies and the experience of the team [13].

The women marked location of pain on drawings of the pelvic girdle and low back included in the questionaire package The pelvic pirdle and the low back were naire package. The pelvic girdle and the low back were abelled, and separated acouding to boundaries decribed in the European guidelines for the diagnosis and a rated retrospectively on a numerical rating scale (NRS) from 0 to 100, for each month of the pregnancy, in order to collect information on appearance of symptoms and peak intensity pain during pregnancy, In this study the score 0 meant "No pain" and 100 "Unbearable pain", and average pain intensity for PGP was calculated from the values reported in all months.

Information on pain-related ADL was collected through the Oswestry Disability Index (ODI), which is one of the principal condition-specific outcome measures for defining disabling effects from spinal disorders and pelvic girdle pain $[3,14,15]$

The questionnaires also provided information on number of years of education, level of physical work load (a five level scale running from very light to very heavy), type of work (in free text but coded into mainly seated, mainly standing, mainly mobile), work satisfaction (a five level scale running from very bad to very good), and height and 
weight before pregnancy and weight at delivery, Further variables included number of previous births, exercising habits before pregnancy, defined as regular exercise at least twice weekly (yes or no). Body mass index (BMI) was calculated as weight/length ${ }^{2}$.

In Norway the employer is obliged to pay sick pay for the first 16 calendar days (employer's period) [16]. After that, the Norwegian Labour and Welfare Service (NAV) will take over the responsibility. The employee is required to notify the employer as soon as possible of any absence due to illness. The duty to report includes only information regarding the absence. The obligation to pay sick pay commences from the day the employer is notified about the absence, unless the employee has been prevented from notifying the employer immediately.

In the present study sick leave was assessed in two dif In the present sty sick leave was assessed in two different ways. First, the women were asked about the total number of weeks of full-time sick leave in the pregnancy, as well as the total number of weeks with parttime sick leave and sick leave percentage. Weeks of sick leave in total were calculated by adding the full-time sick leave weeks to the part time weeks adjusted for sick leave percentage. After reporting the total amount of sick leave, the women were asked to indicate a primary cause of their sick leave, Second, in association with the section of the questionnaire concerning NRS of pain during the pregnancy, the women were also asked whether they had been on sick leave due to PGP in any month of the pregnancy and to indicate when. It was not possible to determine the number of consecutive weeks of $100 \%$ sick leave due to any specific cause from the avalable information. For instance, several women only reported "pain" without any specific detals as the only reported "pain without any spectife details as the main cause of sick-leave in pregnancy. To determine whether the women had sick leave due to PGP, we combined the anis ble inforis any sick leave due to PGP in any month of the pregnancy, they were classified as having sick leave due to PGP. Women, who explicitly stated that PGP was the primary cause of their sick leave, but who did not indicate sick leave due to PGP in any specific month of pregnancy in the NRS-section of the questionnaire, were also classified as having sick leave due to PGP. This procedure resulted in three groups: women with no reported sick leave, women with sick leave but without any indication of PGP being the cause, and finally, women who had sick leave and reported PGP as the cause of, at least, parts of their sick leave.

Descriptive data are presented as mean values and standard deviations for continuous variables and as frequencies for categorical variables. For comparisons between groups the non-parametric Kruskal-Wallis statistics were used, applying Bonferroni correction. Pairwise follow-ups were applying Bonferroni correction. Pairwise follow-ups were
performed with the group who had sick leave due to PGP as reference, whenever significant omnibus group differnces were found. For categorical data, chi-square statistics were computed, and $2 \times 2$ table follow-ups were used for pairwise comparisons between the group with sick-leave due to PGP vs the other groups.
duatis

Multinomial logistic regression analysis was used to investigate the independent contribution of variables hypothesized to affect whether the women had been on sick leave due to PGP. Forced entry was used with age, education, parity, and average PGP in order to adjust for these variables in the final model. As an exploratory approach, single items from ODI (except sex and pain intensity) were entered in a stepwise procedure together with workload, work satisfaction and seated work, using a likelihood ratio based criterion with $p<.05$ for entry and $p<.10$ for removal.

In order to explore factors associated with the total ln or to explal In order to exploce factors asoction of ession analysis was conducted, using total number f calculated weeks of sick leare (weeks of 100 as sickleave + weeks of part-time sick leave multiplied by sick leave percentage) for any reason as dependent variable. In the first block, the grand average of monthly reported PGP was entered, in order to analyse the unadjusted effect of PGP on weeks of sick leave. In block 2 , all relevant $\mathrm{ODI}$ items were entered using a stepwise procedure $(p<.05$ to enter, $p<.01$ to exclude a variable), In block 3, years of education, pre-pregnant BMI, workload, age, standing work and mobile work were entered, using the same type of stepwise procedure as in block 2. Finally, in block 4, work satisfaction and depression in pregnacy were entered also with a stepwise procedure. Thus, only block 1 included a forced included a forced entry variable, average PGP, as we wanted to explore 作 sck leave.

In order to investigate factors that may decrease the effect of PGP on sick leave, we identified all women with PGP who did not have any sick leave in pregnancy. A macro written in Microsoft Excel (Visual Basic) then chose a random woman having been on sick leave, and who matched the average PGP score of a woman without sick leave. If a perfect match was not found, a difference of $+1-1$ point on the PGP score was accepted. If still no match was found, the subject was discarded. Hence, this procedure chose two equivalent groups with regard to average PGP, but with and without sick leave. We then compared these groups on the same variables We then compared these groups on the same variables leave due to other reasons Effect sizes were reported as standardized mean differences (Cohen's D), using Bonferroni correction, which can be interpreted as small (around 0.3 ) medium (around 0.5) and large (0.8 to infinity) [17]. 
All analyses were performed using SPSS 21 (IBM, New York, NY), and results were considered significant at $p<.05$.

Results

Study population

all, 1204 won who gave bint at Stavanger University Hospital whe gave birth at Stavanger Univerparticipate in the study. After exclusions, there were 994 women eligible for the study. In addition, 336 women did not return a questionnaire and 89 did not complete a received questionnaire. One woman did not report having a job or profession, nor any workload, and was excluded from the analyses. The final study population thus consisted of 568 men. Of these, 165 (29 \%) the ported that they had experienced isolated PGP during
the pregnancy.

The sample's demographic data and descriptive statistics for the variables used in the multivariate analyses are shown in Table 1. Several significant differences are shown between subjects who reported sick leave due to PGP vs. those who did not [Table 1]. In Table 2 we compare the group with sick leave due to PGP with the no
sick leave group and the group with sick leave due to other causes on single items from the ODI. We report effect sizes to enable a direct comparison using a standardized scale [Table 2].

All ODI-items were significantly higher in the group who had been on sick leave for PGP than in both the other groups. The effect sizes were all moderate to large (Cohen's d > 0.6).
Factors associated with sick leave due to PGP

Individual risk factors with odds-ratios and confidence limits resulting from the multinomial regression analysis re shown in Table 3.

All results in Table 3 refer to the group with sick leave due to PGP as reference category. The estimated pseudo $\mathrm{R}^{2}$ was quite high (Nagelkerke $\mathrm{R}^{2}=.40$ ) and the total correct classification percentage was $62 \%$. We see that work satisfaction, as well as lower scores for ODI-lifting, sleep and average pain intensity, significantly predicted affliation to the no sick leave group. The group with sick leave due to other reasons had lower score on average pain intensity and ODI-lifting [Table 3].

\section{Coping with the effects of pelvic girdle pain}

The matching procedure resulted in two groups with 50 subjects in each group. The group with sick leave due to PGP and the group with no sick leave (coping group) had similar PGP intensities of approximately 18. Univarate Mann-Whitney $U$ test revealed that the coping group on average had longer education (15.8 vs 14.8 years), $p=.022$ and higher work-satisfaction ( 4.66 vs 4.32 ), $p=.014$. Finally, the scores on several ODIitems were lower in the coping group [Table 4].

These results differ from the ODI-results in Table 2, as the effect sizes between the groups are very different for the different items. If a strict Bonferroni-correction is applied, only the ODI score for sitting is higher in the group with sick leave due to PGP $(p<.003)$. However, also walking and standing differ if uncorrected $p$-values are applied.

Table 1 Descriptive statistics

\begin{tabular}{|c|c|c|c|c|c|}
\hline & Sick leave for PGP & No sick leave & Sick leave for other reason & $D^{*+4}$ & Total \\
\hline N(W) & $199(3496)$ & $139(24 \%)$ & $236(42 \%)$ & & $568(100 \% 6)$ \\
\hline Age & $29.7(4.3)$ & $305(48)$ & $29.8(5.0)$ & $=254$ & $300(4 \pi)$ \\
\hline Educarion & $14.5(2.4)$ & 15.) $(2.4)^{*}$ & $154(26)^{\circ}$ & $<000$ & $15.1(26)$ \\
\hline BMi before pregnanicy & $24.8(4.6)$ & $23.1(36)^{*}$ & $23.4(4.2)^{*}$ & $<.001$ & $23.8(4.3)$ \\
\hline Total sick leave weeks. & $10,8(94)$ & $00(0.0)^{\circ}$ & $84\langle 8,9\rangle^{\circ}$ & $<001$ & $72(9.0)$ \\
\hline Workload & $3.0\{1.1\}$ & $2,4(1,1)^{*}$ & $2.6(1.2)^{*}$ & $<001$ & $2.6(1.1)$ \\
\hline Work satisfaction & $4.4(0.8)$ & $45(0,7)^{*}$ & $43(0.9)$ & $<001$ & $4.4(0.8)$ \\
\hline Average PGP & 26.8 (15.11 & $67(104)^{4}$ & of 100,0$)^{\circ}$ & 2001 & $13.3(155)$ \\
\hline Averáge $L B P$ & $13.2(169)$ & $47(21)^{*}$ & $6.6(11.4)^{*}$ & $<001$ & $8.4(13,4)$ \\
\hline Pain-elated ADL (ODI) & $1,9\{0.8\}$ & $0.9(0.9)^{\circ}$ & $10(0.8))^{*}$ & $<001$ & $14\langle 0.9\}$ \\
\hline Depressed & $1.4(0.5)$ & $13(0.5)$ & $1,4(0.6)$ & $=055$ & IA (A0.5) \\
\hline Mear no, of previous birthis & $1.00(0.06)$ & $0.94(0.09)$ & $0.79(0.05)^{2.2 x}$ & $<05$ & $090(100)$ \\
\hline Regular exercise before pregnancy & $63(3376)$ & $67\left(49 \% g_{j}\right)^{*}$ & $94(40 \% 6)$ & $\Rightarrow 013$ & $224(3996)$ \\
\hline Seated work & sit (27 96) & $68(499) j^{*}$ & Bi (34 96i) & $<001$ & $200(3596)$ \\
\hline
\end{tabular}


Table 2 Oswestry disability index items

\begin{tabular}{|c|c|c|c|c|c|c|}
\hline \multirow[b]{3}{*}{ ODl item } & \multirow{3}{*}{$\begin{array}{l}\text { Sick leave for PGP } \\
N=190 \\
\text { Mean (SD) }\end{array}$} & \multirow{2}{*}{\multicolumn{2}{|c|}{$\begin{array}{l}\text { No sick leave } \\
N=96\end{array}$}} & \multirow{2}{*}{\multicolumn{2}{|c|}{$\begin{array}{l}\text { Sick leave for other reason } \\
N=154\end{array}$}} & \multirow{3}{*}{$\begin{array}{l}\text { Total } \\
N=440 \\
\text { Mean (SO) }\end{array}$} \\
\hline & & & & & & \\
\hline & & Mean (SD) & ES. . $^{a}$ & Mean (SD) & E.S. ${ }^{4}$ & \\
\hline Pain intensity & $2.76(0.86)$ & $1.67(1.13)$ & 1.142 & $1.81(0.99)$ & 1.024 & $2.19(1.09)$ \\
\hline Personal care & $1.23(1.40)$ & $0.59(0.97)$ & 0.591 & $0.53(0.98)$ & 0.655 & $0.85(1.10)$ \\
\hline Lifting & $2.18(1.19)$ & $0.95(1.12)$ & 1.056 & $1.30(1.16)$ & 0.751 & $1.60(1.27)$ \\
\hline Walking & $1.63(0.99)$ & $0.65(0.94)$ & 1.007 & $0.85(1.05)$ & 0.762 & $1.15(1.09)$ \\
\hline Sitting & $1.68(0.96)$ & $0.80(0.98)$ & 0.905 & $1.07(1.11)$ & 0.589 & $1.28(1.08)$ \\
\hline Standing & $2.44(1.24)$ & $1.17(1.28)$ & 1.018 & $1.48(1.27)$ & 0.769 & $1.83(1.37)$ \\
\hline Sleeping & $1.67(1.02)$ & $0.82(0.88)$ & 0.872 & $1.04(0.88)$ & 0.657 & $1.26(1.01)$ \\
\hline Sex & $1.75(1.50)$ & $0.76(1.19)$ & 0.707 & $0.76(1.30)$ & 0.701 & $1.18(1.45)$ \\
\hline Social function & $1.89(1.26)$ & $0.83(1.17)$ & 0.862 & $0.79(1.14)$ & 0.911 & $1.27(1.31)$ \\
\hline Traveling & $1.63(1.26)$ & $0.61(1.00)$ & 0.860 & $0.82(1.11)$ & 0.680 & $1.12\langle 124\rangle$ \\
\hline
\end{tabular}

ES: Effect size (Cohen's $d$. $>0.8$ is considered large)

\section{Discussio}

This study shows that PGP is frequent and a major cause of sick leave during pregnancy among Norwegian women, which is also reflected in problems with ADL as measured with scores on all ODI items. In the multivariate analysis of factors related to sick leave and PGP we
found that work satisfaction, problems with lifting and found that work satisfaction, problems with lifting and addition, we found that women with longer education,

Table 3 Multinomial regression with sick leave due to PGP as reference category

\begin{tabular}{|c|c|c|c|c|}
\hline & $p$ & Odds ratio & CL. Low & CL. Hig \\
\hline \multicolumn{5}{|l|}{ No sick-leave } \\
\hline Age & .157 & 1.056 & .979 & 1.138 \\
\hline Education & .074 & 1.113 & 990 & 1.252 \\
\hline Pelvic pain & .001 & .955 & .930 & .981 \\
\hline No. of previous births & .667 & .915 & .612 & 1.369 \\
\hline ODt: Lifting & .011 & .622 & .432 & .895 \\
\hline ODI: Sleep & .008 & .521 & .321 & .846 \\
\hline ODt: Social life & .294 & 1.206 & .850 & 1.713 \\
\hline Work Satisfaction & .049 & 1.607 & 1.001 & 2.580 \\
\hline \multicolumn{5}{|c|}{ Sick-leave due to other reason } \\
\hline Age & .129 & 1.051 & .985 & 1.122 \\
\hline Education & .262 & 1.054 & .961 & 1.157 \\
\hline Pelvic pain & .000 & .951 & .932 & .971 \\
\hline No. of previous births & .128 & .760 & 533 & 1.083 \\
\hline ODI: Lifting & .020 & .708 & .530 & .946 \\
\hline ODI: Sleep & .622 & 916 & .646 & 1.299 \\
\hline ODE: Social life & .105 & .785 & 586 & 1.052 \\
\hline Work Satisfation & .814 & .960 & .681 & 1.352 \\
\hline
\end{tabular}

Che 950 higher work satisfaction and less problems with sitting, walking and standing, were less likely to take sick leave during pregnancy, despite having the same pain intensity as women being on sick leave. These findings may have implications for planning of measures that could reduce sick leave among pregnant women.

Most studies describe percentages of pregnant populations on sick leave, and mainly use lumbopelvic pain as a general term, describing the location of pain. Few specify length of sick leave or differentiate PGP from low back pain for a more specific location of pain. Also, the majority of studies are prospective or cross-sectional Our study was retrospective and shows a sick leave perOur study was retrospective and shows a sick leave percentage and span similar to other studies with the same a d a do ween on a median of eleven weeks sick leave for PGP during
the pregnancy. In a Swedish retrospective study, sick

Table 4 ODI in women who had PGP, with and without sick. leave for PGP

\begin{tabular}{lllll}
\hline ODI item & No sick-leave for PGP & Sick-leave for PGP & ES. & $P$ \\
\hline Pain intensity & $2.30(0.84)$ & $2.33(0.88)$ & $0.039=.954$ \\
Personal care & $0.90(1.11)$ & $0.94(1.14)$ & $0.033=889$ \\
Lifting & $1.40(1.21)$ & $1.90(1.29)$ & $0.395=0.044$ \\
Walking & $0.96(1.01)$ & $1.44(0.97)$ & $0.483=0.11$ \\
Sitting & $0.96(1.00)$ & $1.46(0.87)$ & $0.528=.003$ \\
Standing & $1.50(1.33)$ & $2.00(1.22)$ & $0.392=0.031$ \\
Sleeping & $1.12(0.85)$ & $1.48(1.03)$ & $0.379=.113$ \\
Sex & $1.18(1.41)$ & $1.23(1.49)$ & $0.037=.969$ \\
Social function & $1.26(1.27)$ & $1.33(1.31)$ & $0.056=677$ \\
Travelling & $0.92(1.12)$ & $1.25(1.23)$ & $0.280=.180$ \\
\hline
\end{tabular}

ES Effect size (Cohen's d): Bonferronicorrected alpha $=0.005$ 
leave for pain in the pelvic girdle area was reported among $48 \%$ of the pregnant women, with a mean span f sick leave of 12 weeks [11] In another retrospective study, $41 \%$ had been on sick leave for PGP, but duration was not described [18]. Taken together, our and previous studies underline the importance of PGP as a major cause of sick leave during pregnancy.

A previous Norwegian study showed that sick leave increases for each trimester in pregnancy. It revealed that fatigue and sleep problems seem to be the main risk factor for sick leave, followed by nausea, vomiting, exercising less than weekly, chronic PGP before or during pregnancy, conflicts in the workplace, and lower education [18]. In contrast, Mogren in a retrospective study found lumbopelvic pain to be the main cause of sick forve during preg leave during pregnancy [11]. This finding is supported by our study, and Robinson and co-workers who showed that almost a third of all delivering women were sick listed due to PGP dung pregnancy [18], A result confirming that PGP accounts for a great part of sick leave during pregnancy.

Our study shows that ADL, were significantly more difficult to carry out for pregnant women on sick leave for PGP than for women on sick leave for other causes. We found independent significant risk factors to be lower education, heavy workload and low work satisfaction. This association has previously been shown in three other studies in which pregnant women with demanding working conditions presented increased incidence of PGP in pregnancy, while those with opportunity to adjust their work pace reported a better health status than women without this possibility [19-21]. Risk in than wom to wisk indicators for long-tern sick leave during pregnancy queavy work load [22]. Lower education level has also been
found to associate with higher pain intensity during pregnancy [23]

The ODI score on sitting scored the highest significant effect size in the group with sick-leave due to PGP ( $p$ $<, 003)$, It is known that prolonged sitting may alter the passive stiffness of the lumbar spine. Erector spinae muscles fatigue induces a shift in load-sharing towards passive stabilizing structures. Loss of muscle contribution together with or without laxity in the viscoelastic tissues may have a substantial impact on post fatigue stability [24].

In our study, a matching procedure revealed that the group with sick leave due to PGP had a lower PGP in tensity score than the group with no sick leave. The tensity score then the group who sick leave. The reason for this unexpected find may be that pain is a complex construct that contributes to profound physical and psychological dysfinction, and the experience of it is modulated by physical and psychological factors
[25]. Following the bio-psychosocial model, emotional distress may predispose people to experience pain or may be a moderator that amplifies or inhibits the severity of pain [26]. Traumatic experiences related to pregnancy seem to be associated with lumbopelvic pain and physical ability up to 6 months after delivery [27]

Certain individuals can stand the pain, have less catastrophizing tendencies, show more positive social responses to pain, and more organized health care and medication patterns. These coping skills are displayed as effective functioning despite exposure to stressful circumstances and/or internal distress [28]. Most important psychological contributors to individual well-being and coping stress responses are positive emotions, which appear to buffer individual reactivity to pain [25].

In a retrospective study, with a similar design to ours, the authors found that pregn a similar design to ours, che to be influenced by attudes and coping strateges in order to achieve eeded rest prior to delivery [29. They concluded that eetain socal conditions and attidus are likely to explain why pregnant women are on sick leave [29]. Chang and co-workers suggest that education and interventions targeting passive coping and stimulating resilience may be useful to prevent PGP during pregnancy turning chronic [23]. In Korea, a back-pain-reducing program was effective in reducing the intensity of back pain experienced by pregnant women [30]

Our findings show that women may benefit from a pre-pregnancy and pregnancy strategy program decreasing the risk for pregnant women to end up on sick leave for PGP. According to our results the strategy should contain information about the value of cor whysical workload during pregnancy. In order to boost coping tohy phy in pregnancy, should be included. Employers should through an incentive be encouraged to ergonomically adapt the pregnant employees' workplace in order to decrease work load and thus maintain, or even improve, work satisfaction

There are limitations in the present study. We introduced several tactics to obtain a high awareness of the importance of the study, both among the women and assisting midwives, with the objective to enrol all women who fulfilled the inclusion criteria during a given time period. Nevertheless, our response rate was rather low, in spite of aforementioned initiatives, but we did find hat age and parity of the studied population was idential the the gives birth chis this study to be representive for pregnant women in the rest of Norway. 
Ideally, to use the term PGP a physical examination is required, but it could not be done in this study. Another limitation is that all our data are based on questionnaires with retrospective data collection. We are aware that recalling pain and disability experienced long time ago is considered an unreliable way to collect information. Regarding the occurrence and duration of sickness absence during pregnancy has the agreement between self-report and a public registry been investigated [31]. Mainly because of low precision the agreement on the duration of sickness absence was poor, but the agreement regarding the occurrence of sickness absence was good.

\section{Conclusions}

PGP is a frequent and major cause of sick leave in pregnancy. We have retrospectively identified how it affects pregnant women's ADL, and found unexpected differences in pain appreciation between women on sick leave and not on sick leave during pregnancy. A coping factor seem to be present, most likely dependent on education, associated with work situation and/or work posture, which decreases sick leave. IX/e recommend that these issues should be further examined in a prospective longitudinal study since it may have important implications for sick leave frequency during pregnancy.

Competing interests
The authors declar that they have no compering interests

\section{Authors' contribution}

W

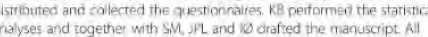
ithors rad and approved the final manuscript.

\section{Authors' information
Not applicable}

Availability of data and materials

Acknowledgement

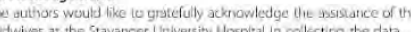

Funding
No funding was received for this study:

Author details

Heath Studies, Universty of Stavanger, Stavanger, Nonwal. Honweglan Centre for Movement Disorders, Stavanger University Hospita. Stavanger, Norway. "Private practice, Kistiansand, Norway. "Department of Obsterrics and Gynaecology, Stavanger University Hosoital, Stavanget. Norway. The Norwegian Centre for Movement Disorders, Stavanger

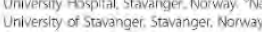

Received: 2 june 2015 Accepted 22 September 2015

\footnotetext{
neferences

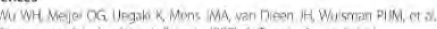

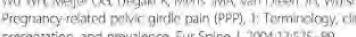
gresentation, and prevalence. Eur Spine 1, 2004, $33.575-89$.

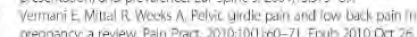

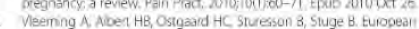

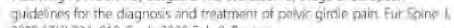
2008:17(6)791 812 Epub 2008 Fot 8. Reney

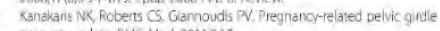

concto

i, Notiror R L Low back pario

ongludina study of rates and ilsk factors in a Norvegian population.

CHancen A, vendelbo Jensen $D$, Johansen Ninck H, et at Symptom giving pervic girdilo relasullori in pregnancy

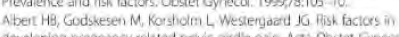

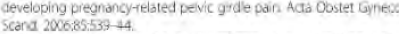

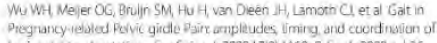

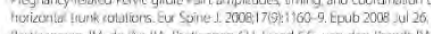

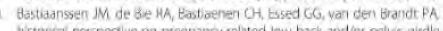
pain Eur J Obstet Gynecol Reprod Bol 2005:1201/3-14 Revew Nogren I. Perceived heath, sicktesve, osychosocial situation, and sexual ife

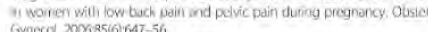

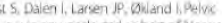

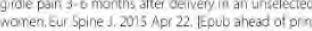

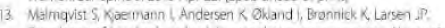
.

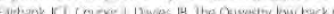

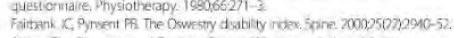

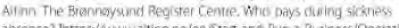

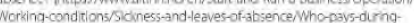

7 sickness-absencee/lepslanguage eri]

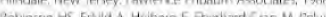

Felvk girde pata

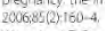

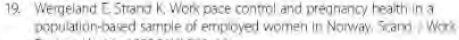

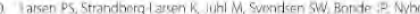

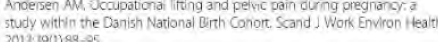
$2013.3901488-958$

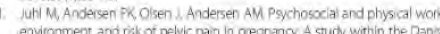

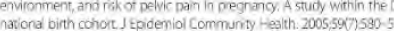

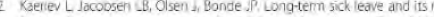

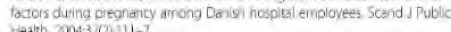

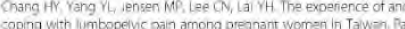
Ned. 2011:1216:34:56-53

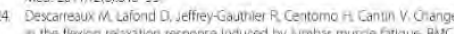

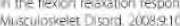

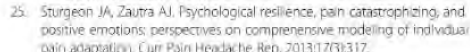
vain adadation Cur Pain Headache Rep, 2013:17(3):317.
} 


$$
\begin{aligned}
& \text { 2. Gatchel Rl, Peng YB, Petets ML. Fuchs PN, Terk DC The biobsychosocial } \\
& \text { (a) }
\end{aligned}
$$

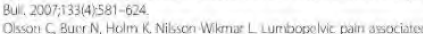

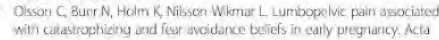

$$
\begin{aligned}
& \text { Obsiet Gyrecol Scand, 2009:88:44:378-95. } \\
& \text { Karoly P, Ruehiman IS. Psychological "resillence" and its correlates ) } \\
& \text { chronic pair findings from a rational connerunity sample. Pain. } \\
& \text { 2006; 231-21:90-7. Epub } 2006 \text { Mar } 24 . \\
& \text { Sycsio G, Sydsio A. Newly delivered women's evaduation of personal health }
\end{aligned}
$$

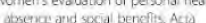

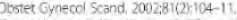

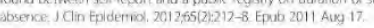

Submit your next manuscript to BioMed Central and take full advantage of:

- Convenient online submission

- Thorough peer review

- No space constraints or color figure charges

- Imimediate publication on acceptance

- inciusion in PubMed, CAS, Scopuis and Google schoiar

- Research which is freely availlable tor redistribution.

Submit your manuscript at
Www.blomedcentral.comsusubmit

O) Blomed Central 


\subsection{Paper III}


BMJ Open Can a bothersome course of pelvic pain from mid-pregnancy to birth be predicted? A Norwegian prospective longitudinal SMS-Track study

Stefan Malmqvist, ${ }^{1,2}$ Inger Kjaermann, ${ }^{1,3}$ Knut Andersen, ${ }^{1,3}$ Anne Marie Gausel, ${ }^{1,3}$ Inger Økland, ${ }^{4}$ Jan Petter Larsen, ${ }^{1,5}$ Kolbjorn S Bronnick ${ }^{6}$

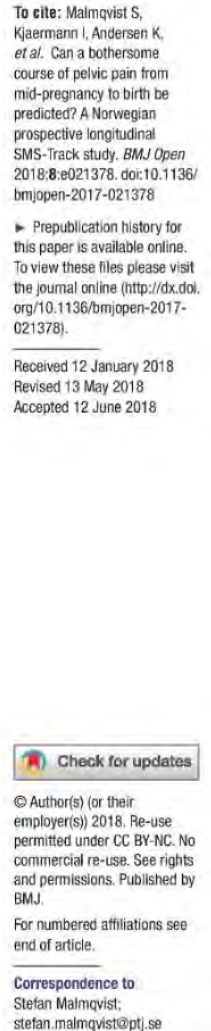

ABSTRACT

Objective To explore if pregnant women with pelvic gircle pain (PGP), subgrouped following the results from two clinical tests with high validity and reliability, differ in demographic characteristics and weekly amount of days with bothersome symptoms through the second half of pregnancy

Design A prospective longitudinal cohort study. Participants Pregnant women with pelvic and umbopelvic pain due for their second-trimester routine ultrasound examination

Setting Obstetric outpatient clinic at Stavanger University Hospital, Norway.

Methods Women reporting pelvic and lumbopelvic pain features. They were clinically examined following a test procedure recommended in the European guidelines for the diagnosis and treatment of PGP. Women without pain (a) data. All women were followed weekly through an SMSTrack survey until delivery.

Primary and secondary outcome measures The outcome measures were the results from clinical diagnostic tests for PGP and the number of days per week with bothersome pelvic pain

Results 503 women participated. $42 \%$ (212/503) reported pain in the lumbopelvic region and $39 \%$ (196/503) futfilled the criteria for a probable PGP diagnosis. 27\% (137/503) reported both the posterior pelvic pain provocation ( $\mathrm{P} 4$ ) and the active straight leg raise (ASLR) tests positive at baseline in week 18 , revealing 7.55 ( $95 \%$ Cl 5.54 to 10.29 ) umes higher mean number of days with bothersome pelvic pain compared with wormen with both tests negative. The presented the highest scores for workload, depressed mood, pain level, body mass index, Oswestry Disability Index and the number of previous pregnancies. Exercising regularly before and during pregnancy was more commo in women with negative tests.

Conclusion If both P4 and ASLR tests were positive mid-pregnancy, a persistent bothersome pelvic pain of more than 5 days per week throughout the remainder of pregnancy could be predicted. Increased individual con over work situation and an active lifestyle, including regular exercise before and during pregnancy, may serve
as a PGP prophylactic.

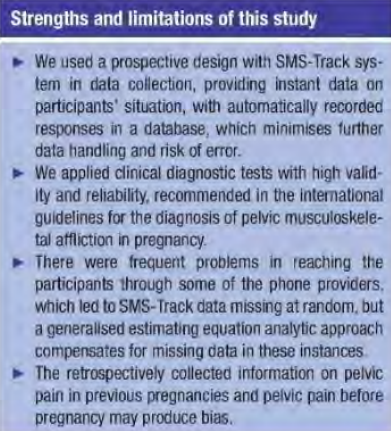

\section{INTRODUCTION}

Pelvic girdle pain (PGP) during pregnancy affects approximately half of all pregnan women, and for $25 \%-30 \%$ the condition becomes severe. ${ }^{2}$ The aetiology of PGP is still unknown, and the underlying mechanisms have not been fully investigated. $^{12}$ Researchers have explored the physical psychological and sococonomic physic, psychological and socioeconomic Paple red restion Paine been a have been described, both daring pregnancy and after childbirth, and the psychologica impact on perceived health, sexual life and quality of life has been explored, as well as the prevalence of sick leave due to PGP.

PGP is classified into specific (caused by rauma) or non-specific (multifactorial). Several clinical tests are needed to diagnose the latter, including pain provocation and functional ability tests. However, there is still no 'gold standard' for diagnosing PGP. The European guidelines present evidence-based 
recommendations for the diagnosis and treament of $\mathrm{PGP}$, but inconsistencies on the definition as well as treat ment still prevail. ${ }^{37}$

Classification of PGP can, according to guidelines, only be reached after lumbar causes have been excluded through a clinical examination. ${ }^{7}$ All tests recommended in the European guidelines have a very high specificity, bu generally a low sensitivity. Hence, it is recommended to perforn all the tests, as one negative test is not sufficient to rulc out $\mathrm{PGP}^{7}$ The poscrior pelvic pain provocation test (P4), for dia active straight leg raise test (ASLR), for delecting failing force elosure, have shown high validity and reliability. In a Swedish stady, substantial agrechent between exam. iners using ASLR and P4 tests was found in discriminating non-specific lumbopelvic pain into lumbar pain and PGP in pregnant women." Together with a description of pain location, these tests are considered relevant when evaluating affliction in pregnant women likely to have PGP. ${ }^{12}$ So far, the longitudinal course of PGP in pregnancy is incompletely examined. In prospective studies data are usually collected at baseline and at one or a few follow-ups. Mcasuring only at a few points in time mav indicate stability in the examined condition, and a flucruating course may be missed. $\Lambda$ difference could reflect only a temporary fluctuation in an otherwise stable condition Acool the stable is wavred to accurately describe he clinical cotion is warranted to accurately describe the dinical course. Mobile phones and text messages have previously been found feasible when collecting frequent longitudinal data in climical senis daily life; hence, this method yields a high response rate for weekly measures.

The objective of this study was to explore if preg. nant women with probable PGP, subgrouped following the results from two valid and reliable clinical tests recommended in the European guidelines, differ in demographic and clinical characteristics at mid-pregnancy and in weekly amount of days with bothersome symptoms through the second half of pregnancy. The hypothesis was that sacroiliac dystunction and failing force closure diagnosed at mid-pregnancy may predict a course of hodtersome symptoms through the second half of pregnancy.

\section{METHODS}

This is a prospective longitudinal cohort study of preg nant women who had their second-trimester routin ultrasound examination in pregnancy week 18 at an obstetric outpatient clinic at Stavanger University Hospital, Norway, from mid-March to mid-June 2010. At the hospital, all the women were asked by a midwife about their experience of pain in the lumbopelvic region. The inclusion criteria were current lumbopelvic pain or isolated pelvic pain, singleton pregnancy and good profi ciency in the Norwegian language. Women who met the criteria were informed about the study, handed a letter of consent to lill in if they agreed to participate, and an envelope with questionnaires on demographic and clinical data to complete at home. An appointment with chiropractor for a physical examination was arranged, and the women were asked to bring the completed que tionnaires with them to the consultation. Women withou pain symptoms were informed about the study, handed a letter of consent to fill in if they agreed to participate, and a questionnaire on demographic data to complete and leave at the reception on departure All consenting women were followed from week 18 with weckly antomated text mesiges (SMS-Tack).

Two chiropraciors (SM and IK) performed a physical examination of the pelvic region, including diagnostic ests recommended in the European guidelines for the diagnosis and treatment of $\mathrm{PGP}$, and a neurological examination of the lower exrremities,

\section{Sequence of stability and pain provocation tests for PGP}

Active straight leg raise

The test is performed with the patient in a supine position with a straight leg and the feet $20 \mathrm{~cm}$ apart. The tes is performed after the instruction 'try to raise your legs, one after the other, above the couch for $20 \mathrm{~cm}$ withou bending the knee'. The patient is asked to score impaitment on a 6-point scale: not difficult at all=0; minimally difficult=1: somewhat difficult; difficult=2; fairly difficult=3; very difficult $=4$; unable to do=5, The scores on both sides are added, so that the total score range from 0 to 10 .

Gaenslen's test

The patient, lying supine, flexes the knee and hip of the same side, the thigh being crowded against the abdomen with the aid of both the pationts hand clasped about

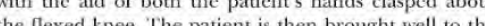
side or te the, and he opposie thigh is slowly hyper

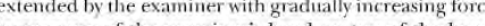
by pressure of the exatminer's hand on top of the knee. With the opposite hand, the examiner assists the patien in lixing the lumbar spine and pelvis by applying pressure over the patient's clasped hands. The test is positive if the patient experiences pain, either local or referred on the provoked side.

Long dorsal sacroiliac ligament test

The subject lies on her side with slight flexion in both 政 persists more than $5 \mathrm{~s}$ after removal of the examiner' hand, it is recorded as pain. If the pain disappears within $5 \mathrm{~s}$, it is recorded as tenderness, ${ }^{17}$

Modified Trendelenburg's test

The patient stands on one leg, and flexes the other at $90^{\circ}$ in the hip and knec. If pain is experienced in the symphysis, the test is positive."

Patrick's FABER test

The subject lies supine. One leg is flexed, abducted

Maimquist S, et al. BMJ Open 2018:8:e21378، đoi:10.1136/omjopen-2017-021378 
abduction and external rotation) so that the heel rests on the opposite knee. If pain is felt in the sacroiliac joints o in the symphysis, the test is considered positive."

Posterior pelvic pain provocation test

The test is performed with the woman supine and the hip flexed to an angle of $90^{\circ}$ on the side to be examined: a light manual pressure is applied to the patient flexed knee aloug the longitudinal axis of the femur while the pelvis is stabilised by the examiner's other hand resting

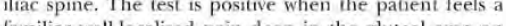
the provoked side. A similar test is described as posterior shear or 'thigh trust'.

Symphysis palpation test

The subject lies supine. The entire front side of the pubic symphysis is palpated gently. If the palpation causes pain that persists more than 5 s after removal of the examiner hand, it is recorded as pain. If the pain disappears within $5 \mathrm{~s}$, it is recorded as tenderness.

A demographic questionnaire used in an carlier studv on pelvic pain in pregnancy was filled in at baseline. The women marked the pain location on drawings with the pelvis and the low back demarcated. Pain intensily was rated on a Nemerical Rating Scale (NRS) from 10 100, where 0 meant 'No pain'

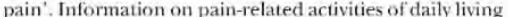
(ADI.) was collected through the Oswestry Disability Index (ODI), which at the time of the dara collection was one of the principal outcome measures for definin disabling effects from spinal disorders and PGP. ${ }^{70}$ it is a patient-completed questionnaire which gives a subje tive percentage score of the level of function (disabilit) in $10 \mathrm{ADLs}$ in patients with low back pain. Every activity contains six statements on how it is performed. The statements are scored from 0 to 5 , with the first state ment scoring 0 through to the last at 5. The scores for al questions answered are summed, then multiplied by 2 io obtain the index (range $0-100$ ). Zero is equated with no disability and 100 is the maximum disability possible.

Physical workload was measured through five answe categorics ranging from 'sedentary' to ' heavy', followin a scale used in Stockholm Public Health questionnaire The question on job satisfaction was a bipolar 5-point Likert scale with increments in two opposite directions ('Very bad' and 'Very good') and a neutral point in the

Every Sunday the women were asked through a short message service (SMS) how many days the previous week they had experienced bothersome pelvic pain: 'Ho many days during the previous week has your pelvic pai been bothersome, (ie, aflected vour daily activities routines)?' If there was no reply, the question was repeated 24 hours later. The question should be answered with on single number between 0 and 7 . The response was automatically entered into a darabase, which collected the

Malmavist S, et al. BMJ Open 2018:8e021378, doi:10.1136/omjopen-2017-021378 continuous information from cach participant over the duration of the study.

Demographic descriptive data are presented as median alues with IQRs for continuous variables, and as frequencies for categoncal variables, For univariate comparisons between svmptomatic and asvmptomatic subgroups, the non-parametric Kruskal-Wallis statistics were used Categorical predictors in our model were four groups following the outcome from the ASLR and P4 tests (1: P4 positive, 2: ASLR positive, 3; both P4 and ASLR positive, 4 ASLR and Pt nepative), time (pregancy week), and the

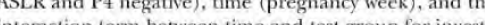
. bothersome days differed between the test groups. Othe predictors in the model were age, number of previou deliveries and body mass index (BMI) before pregnancy. The longitudinal trajectory of the SMS-Track response was modelled using a generalised estimating equation GEE) approach, extending the generalised linear mode to correlated longitudinal data and clustered data within subjects. The within-subject dependencies resulting from repeated medsurenem were modelled assuming an attoregressive relationship in the working correlation matrix. As the outcome variable was count data (weekly number of bothersome davs with pain), the Poisson disubution was assumed with a log-link function.

Data were analvsed using SPSS V.22.0 software. The Strengthening the Reporting of Observational Studies in Ficlemiology reporting guideline was used during the t.pictemiology repo

\section{Patient and public involvement}

Patients and the public were not involved in developing the research questions, outcome measures, as well as in the design and conduct of the study, or in the recruitment of patients.

\section{RESULTS}

Overall, 506 women agreed to participate in this study, Three were excluded due to incomplete data. On ultrasound examination in pregnancy week 18 did $42 \%$ $(212 / 503)$ of the women report pain in the lumbopelvic region. A clinical examination revealed that $39 \%$ $(196 / 503)$ of the women fulfilled the criteria for a prob(196/5CP of  tive response reported pelvic pain but did not respond to recommended clinical tests, and were therefore placed in the 'ASLR and P4 tests negative group".

There were significant differences in some demographic and clinical features at baseline between the women with and without pelvic pain and with different test outcomes (tables 1-2).

Women with positive P4 and ASLR tests experienced heavier workload. They also presented higher BMI at week 18, exercised less both before and during pregnancy, and slightly more than one-third reported feeling depressed 


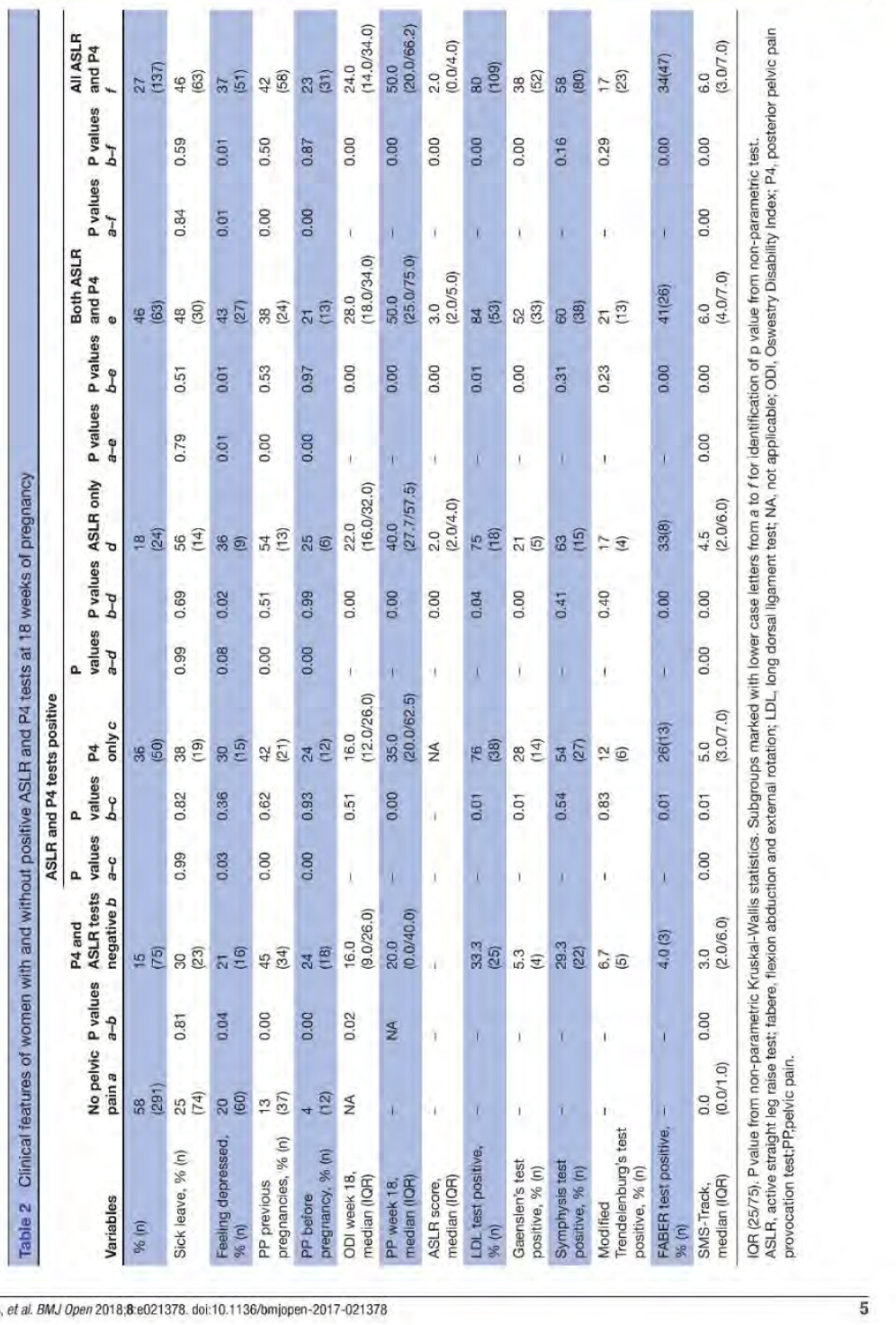



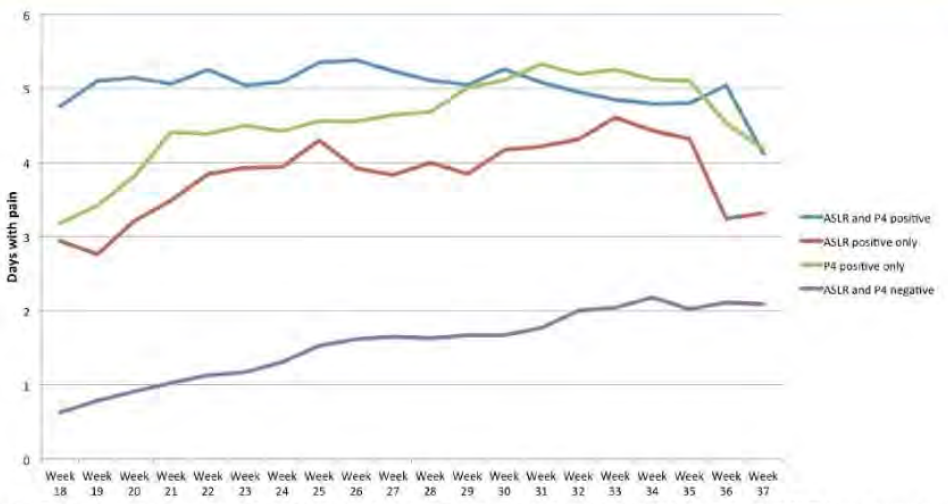

Figure 1 Estimated mean number of bothersome days in the latter half of pregnancy. If both P4 and ASLR tests were positive at week 18 (blue), the highest mean weekly number of days with bothersome pelvic pain throughout the second half could be expected. If both tests were negative, the mean nurnber of bothersome days would never reach the amount reported by wornen with positive tests (purple). Women with a positive P4 test and a negative ASLR test (green) presented approximately 3 days of bothersome pelvic pain in week 18 , with the mean number of days increasing rapidly until week 29 , equalling the group with both tests positive (blue). Interestingly, women with a positive ASLR and a negative P4 test (red) also showed 3 days of bothersome pelvic pain at week 18 , but never reached the mean number of bothersome days reported by women with P4 and both tests positive. ASLR, active straight leg raise test; $\mathrm{P} 4$, posterior pelvic pain provocation test.

during the pregnancy. Physical disability (ODI) and pain level (NRS) at week 18 were considerably higher in women with positive tests than in women reporting pain but having negative P4 and ASLR tests (table 2).

Women with a positive ASLR, but negative P4 test, had the highest number of previous pregnancies. Almost half of the women with both P4 and ASLR tests positive had been on sick leave during their pregnancy. A part from the P4 and ASLR, the long dorsal ligament test showed the highest positive response rate, followed by the symphysis provocation test (table 2 )

The SMSTrack response rate was $75 \%$ (2148 response to $2877 \mathrm{sent}$ messages). Due to a declining SMS-Track SYS Track a (a) predictors for the number of dhyswihbothersome pelvic pain, and there was a significant interaction between diagnostic group and time, implying that the time course of days with bothersome pelvic pain was different for the different test groups.

The estimated weekly mean number of days with bothersome pelvic pain for the different test groups is presented in ligure 1 . Women with both P4 and $\mathrm{SSLR}$ tests positive experienced from week 18 a high weekly mean number of days $(\approx 5)$ with bothersome pelvic pain throughout the pregnancy. Women with both tests negative shoved a steadily rising number of bothersome days throushou the pregnancy from 0.5 day in weck 18 , w 2 days in week 37 . The group with a P4 positive and an ASL.R negative test had approximately 3 davs of bothersome pelvic pain in week 18 , which was considerably lower than the group with both tests positive, but showed rapidly increasing number of days with pain. In week 29 the number of days with bothersome pelvic pain equalled that of the oroup with both tests positive, and thereafier negative P4 lest also showed 3days of bothersome pelvic pain in week 18 , but never reached the mean number of bothersome days reported by women with $\mathrm{P} 4$ and both tests positive

The parameter estimates output showed the estimated rate for experiencing bothersome days to be 7.5 time higher in women with both ASLR and P4 tests positive, compared with the estimate for women with both test negative. Women with both teats positive were estimated with twice the anount of bothersome days per week (tale 3). For wore and a lower incidence rate, the mean amoun of some days was lower, but still estimated as approximately 1.5 times higher than for women with both tests negative. For every pregnancy, the mean number of bothersome days increased by $13.5 \%$. Even a slightly higher BMI had a significant impact on the mean amout of bothersom days. Age had no impact. 


\begin{tabular}{|c|c|c|c|c|c|}
\hline \multirow[b]{2}{*}{ Parameter } & \multirow[b]{2}{*}{ B } & \multirow[b]{2}{*}{ SE } & \multicolumn{3}{|c|}{$95 \%$ Wald $\mathrm{Cl}$} \\
\hline & & & Lower & Upper & Significance \\
\hline P4 and ASLR positive & 2.021 & 0.1581 & 1.712 & 2.331 & 0.001 \\
\hline ASLR positive & 1.540 & 0.2297 & 1.090 & 1.991 & 0.001 \\
\hline P4 positive & 1.617 & 0.1832 & 1.258 & 1.976 & 0.001 \\
\hline Negative tests & $0^{*}$ & - & - & - & - \\
\hline Age & -0.009 & 0.0067 & -0.022 & 0.004 & 0.179 \\
\hline Number of births & 0.135 & 0.0415 & 0.053 & 0.216 & 0.001 \\
\hline BMI before pregnancy & 0.013 & 0.0065 & 0.000 & 0.026 & 0.047 \\
\hline
\end{tabular}

\section{- Set to 0 because this paraneter is redundant.}

ASLR, active straight leg raise test; BMI, body mass index; P4, posterior pelvic pain provocation test

\section{DISCUSSION}

To our knowledge, this is the only study in which women with pelvic pain in pregnancy have been followed wit SMS-Track. The main result of this study was that both P4 and ASLR lests were positive in pregnancy weck 18, a persistent pelvic pain of more than 5 days/ week throughout the remainder of pregnancy could be predicted. If either test was positie in week 18 , a sid prediced. in either be rimila coire was shom, bure revention ast a positive ASLR test, who never reached the botherson levels of the other groups. Robinson and coworkers reported a similar outcome for the P4 lest in a prospective cohort study on the ats graphics, psychological and climical factors measured mid-pregnancy, and disability and pain intensity at week 30. However, their data showed no significant association between the ASLR test result and the disability and pain intensity in pregnancy week 30 .

Although women who had a positive ASLR lest and negative $\mathrm{P} 4$ test ar baseline presented a comparatively low mean number of bothersome days with pain, they do had the highest mean number of previons promancice and the highest mea ra

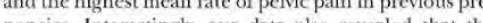

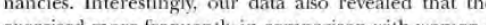
che during the present pregnancy.

\section{Interpretation}

Since sufficient force closure of the sacroiliac joints requires appropriate muscular, ligamentous and fascial interac tion, may women with pelvic pain in previous pregnancic have experienced that exercising improves muscle activ tion, recovers function and decreases pain. Additio ally, experiences of pain prevention and rehabilitation in previous pregnancies may work as an incitement to engag in physical activity and regular exercise, both before and during pregnancy.

Our analysis also revealed a significant difference between the test groups in women described feelin depressed, and that a prepregnancy BMI slightly higher than average had a signilicant impact on the mean

Malmovist S, et al. BMJ Open 2018:8 e021378 doi:10.1136/omiopen-2017-021378 number of bothersome days. Distress has previously been identified as a factor associated with a highe likelihood of PGP in pregnancy, as have a higher BMI and a higher gestational age. ${ }^{27}$ One previous study ss contributing to disability, but not to pain intensity.

Nevertheless, some individuals seem to tolerate pain better have leas casarophising tendencies and show more positive sociat replose to pain regardess of exposire 10 sises fil cirche

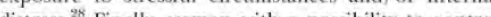
their own work situafon have bester health durin pregnancy than women without such chances. As indcated in this study and confirmed in previous studies, most pregnant women benefit from exercise since it increases pain tolerance, improves or maintains physical fitness, helps with weight management, reduce the risk of gestational diabetes in obese women, and enhances psychological well-being.

\section{Limitations}

A limitation of this study is the retrospectively collected information on pain in previous pregnancies and pain before pregnancy, which may produce biased resu ts. Another limitation was found in the data collection vi the SMS-Track system. In Norway, at the time of the siudy, there were more mobile phone service proviters than in neigltouring counures, where SMS-T

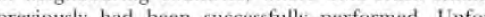

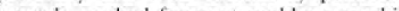
thre the data missing at random, but the GEE analytic approach may in these instances compensate for missing data. However, using the SMS-Track systemn in data collection is also a strength in our study, since it provides instan data on participants situation, and responses are immediately recorded in a datasheet, which minimises further data handling and risk of error.

\section{CONCLUSION}

If both ASLR and P4 tests are positive at a clinical examination in mid-pregnancy, a course of persistent 


\section{Open access}

bothersome pelvic pain for more than 5 days per wee throughout pregnancy may be predicted. The number of days per week with bothersome pelvic pain increases for every added pregnancy, but individual control over wo situation and regular exercise may work as a PGP proph lactic since it invigorates a positive impact on optim force closure of the pelvis, rednces risk of instability in the pelvic joints and enhances overall well-being.

Since there is still no gold standard for diagnosing PGP parientarly revarding the mumber of aests a the clinicalex this area, aiming at predictive, preventive and diagnostic measures for identifying wemen at risk of developing $\mathrm{PC}$ in pregnancy. It would, for example, be interesting to sec if women with a history of $\mathrm{PGP}$ have a higher pain-relate anxiety and if it influences pain.

Author affiliations

The Norwegian Centre for Movement Disorders, Stavanger University Hospital Stavanger, Norwar

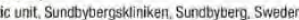
"Department of Health Studies, University of Stavanger, Stavanger, Norway

Stavanger, Norway
SNewwork for Medical Sciences, University of Stavanger, Stavanger, Norway ERegional Centre for Psychosis Research, Helse Stavanger HF, Stavanger, Norway

Acknowledgements The authors gratefully acknowledge the midwives at

Contributors SM, IK, JPL, KA and Iø made substartial contributions to the con data. SM and KSB analysed the data. SM, JPL. KA. AMG, KSB and 10 made final approval of the version to be published. SM agrees to be accountable for all aspecta of the work in ensuring that questions related to the accuracy or integrity of any part of the work are appropriately investigated and resolved

Funding The Norweglan Chroppractic Association (kiroprakilikk.no; Storgata, Osio, Norway) fundad the acquistion of an SMS-Track liceno.

Competing interests None declared.

Patient consent obt

Ethics approval The study was carried out in accordance with the Helsink on Research Eth $2010 / 174)$.
Provenang

Provenance and peer review Not commissioned; extemally peer reviewed. Data sharing statement The data sets supporting the conclusions of this articte

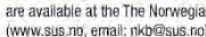

Open access This is an open access articicle distributed in accordance with the Creative Commons Atrribution Non Commercial (CC BY-NC 4.0) i irense, which permits others to distribute, remix, adapt, build upon this work non-commercially and license their derivative works on difierent terms, provided the original work is properiy chted, appropriate credit is given, any changes made indicated, and the us

REFERENCES

Wu WH, Meijer OG, Uegaki K, et af. Pregnancy-retated peivic

prevalence. Eur Spine $J$ 2004:13:575-89.

Albert H, Godskesen M, Westergaard J, Prognosis in four syndromes of pregnancy-related pelvio pain. Acta Obster
Gynecol Scand 2001 80 -505-10.
Verstiaete EH, Vanderstraeten G, Parewijck W. Pelvic Gircle Pain care path porposal. Fects Views Vis Otgenn 2013:5:33:-43.

Gausel AM, Kiæmann 1, Malmquist S, et al. Pelvic girdle pain
3-6 months atter delivery in an unselected cohort of Norwegia -6 monthis atter delivery in an unselected cohort on Norveghan
women. Eur Spine $J$ 2016:25: 1953-9. 5almqvist S, Kjaermann I, Andersen K, et al, The association etrospective study of a Norwegian population. BMC Pregnancy Mens JM, Vleeming A, Stoeckart R, et al. Understanding peripartum pelvic pain. Implications of a patient survey Spine 1996:21:1363-9. Veerning A, Albert HB, Ostgaard HC, et al, European guidelines
lor the diagnosis and treatment of pelvic girdle pain. Eur Spine $J$ Tor the diagnosis and treatment of pelvic girde pain. Eur Spine $J$
2008; $17: 794-819$.

B. Gutke A, Harisson ER, Zetherstrōm G, et al. Posterior pelvic pain provocation test is negative in patients with lumbar herniated discs. Eur Spine J 2009:18:1008-12.

ist, et al. Rellablity and validity of the active straight leg raise test in posterior pelvic pain since pregnancy.

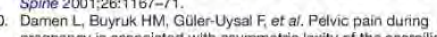

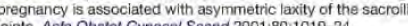
1. Gutke A, Kjellby-Wendt G, Oberg B. The inter-rater rellability of a
standardised classification system for pregnancy-related lumbopeivi pain. Man Ther 2010,15.1

pain, clinical tests and disability in inte EKe et at. Pelvic gircle 2010;15:280-5.

3. Axén L, Bodin L, Bergstroom G, et al. The use of weekly text messaging over 6 months was a feasible method for monitoring the
clinical course of low back pain in patients seeking chiropractic care $J$ Clin Epiderniol 2012;65:454-61,
Christie A, Dagfinrud H, Dale $ఠ$, et al. Collection of patient-

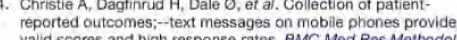
valid scores and high response rates. BMC Med Res Methodol

15. Kew S. Text messaging: an innovative method of data collection in medical research. BMC Res Notes 2010;3:342, and end-results. JAMA 1 1927:86:2031-5. Albert H, Godskesen M, Westergaard J. Evaluation of clinical tests used in classication procedures in prognancy-related pelvic join tests for sacrolliac joint pathology. Sp selected pain provocation Malmavist S, Kjaermann I. Andersen $K$, et al. Prevalence of low

20. Fairbank JC, Pynsent PB. The oswestry disability index. Spine $2000 ; 25: 2940-53$.
1. Leijon O, Wiktorin C. Härenstam A, et al. MOA Research Group. physical work loads in a general population. $J$ Occup Enviran Med 2002:44:724-35.

2. Stals data-collection/writing-questionnaire/structure.aspx Robinson HS, Veierod MB, Mengshoel AM, et al. Pelvic girdlie pain-
associations between nisk tactors in early pregnancy and disability associations between nisk tactors in early pregnancy and disabiliti
or pain intensity in late pregnancy: a prospective cohort study. BMC Musculloshelet Disord 2010;11:91.

24. O'Sullivan PB, Beales DJ. Diagnosis and classification of pelvic
girdle pain disorders--Part 1: a mecharism based approach within girdle pain disorders-Part 1: a mechanism based approach within a
biopsychosocial framework. Man Ther 2007:12:86-97.

Beales DJ, O'Sullivan PB, Brifta NK. Motor control patterns during an active straght leg raise in chronic pelvic girdele pain subjects. Spine
$2009: 34: 861-70$ 2009;34:861-70.

26. Stuge $B$, Laerum $E$, Kirkesola $G$, et al. The efficacy of a treatment program focusing on specific stabillzing exercises for pelvic
girdie pain after pregnancy: a randomized controlled trial. Spine 2004:29:351-9.

27. Kovacs FM, Garcia E, Royuela A, et al. Prevalence and factors pregnancy: a multicenter study conducted in the Spanish National Heath Service. Spine 2012;37:1516-33.

28. Karoly. Pueniman LS. Psychological "resillencee" and its correlates in chronic pain; findings from a national community sample. Pain
$2006: 123: 90-7$.

Maimavist S, et al. BMJ Open 2018:8.e021378. doi-101136/Lmiopen-2017-021378 
29. Wergeland $E$, Strand $K$. Work pace control and pregnancy health in a population-based sample of employed
Work Environ Health 1998;24:206-12,

. Owe KM, Bjelland EK, Stuge B, et al. Exercise level before pregnancy chenger pain: a population-bas
Med 2016:50:817-22.
31. Andersen $L K$, Backhausen $M$, Hegaard HK, et al. Physical exercise and pelvic girdile pain in pregnancy: A nested case-control study
within the Danish National Birth Cohort Sex Reprod Healthc 2015;6:198-203.
Anon. Committee Opinion No, 650 Summary: Physical activ And exercise during pregnanoy and the postpartum period Obster and execol 2015:126:1326-7. 


\section{APPENDICES}

8.1 Questionnaire for the retrospective data collection 


\section{Rygg- og bekkensmerter i svangerskapet}

- en spørreundersøkelse

Dette er en spørreundersøkelse om forekomsten av korsrygg- og bekkensmerter $i$ svangerskapet. Under finner du illustrasjoner på hvordan vi definerer de to ulike områdene.
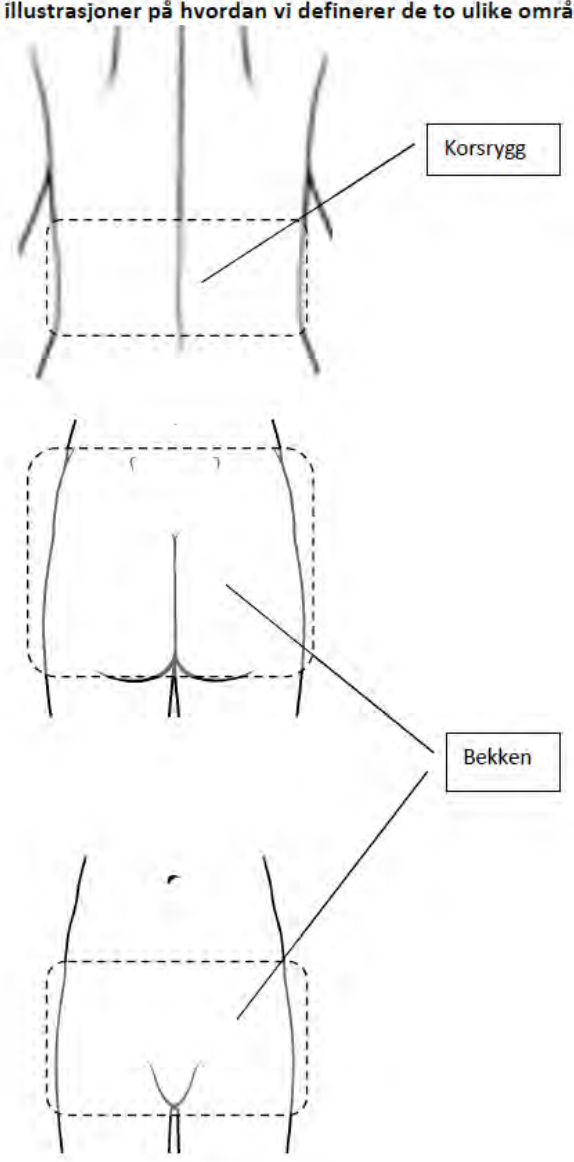
(ID-kode)

Rygg- og bekkensmerter i svangerskapet - en spørreunders $\varnothing$ kelse

Initialer:

Fødselsdato: Dagens dato:

1. Hvor mange års utdanning har du (inkludert folkeskole/grunnskole)? år

2. Hvor fysisk tungt jobber du? Sett ett kryss.

\begin{tabular}{|l|l|l|l|l|}
\hline $\begin{array}{l}\text { Veldig lett } \\
\text { arbeid }\end{array}$ & Ganske lett arbeid & $\begin{array}{l}\text { Verken lett eller } \\
\text { tungt arbeid }\end{array}$ & $\begin{array}{l}\text { Ganske tungt } \\
\text { arbeid }\end{array}$ & Veldig tungt arbeid \\
\hline
\end{tabular}

3. Yrket ditt:

4. Hvor bra trives du på din jobb eller der du jobbet sist? Sett ett kryss.

\begin{tabular}{|l|l|l|l|l|}
\hline Veldig dårlig & Ikke så bra & $\begin{array}{l}\text { Verken bra eller } \\
\text { dårlig }\end{array}$ & Ganske bra & Veldig bra \\
\hline
\end{tabular}

5. Hvor mange uker i svangerskapet har du vært sykmeldt?

100\%: antall uker.

Delvis:_ $\%$ ____ antall uker.

6. Oppgi den/de viktigste årsakene til sykmeldingen(e):

7. Din høyde: $\mathrm{cm}$

8. Din vekt før svangerskapet: $\mathrm{kg}$

9. Din vekt like før fødselen: $\mathrm{kg}$

10. Har du vært deprimert i løpet av svangerskapet? Sett ett kryss.

\begin{tabular}{|l|l|l|l|}
\hline Aldri & Av og til & Ofte & Nesten hele tiden \\
\hline
\end{tabular}

11. Dersom du har vært deprimert, i hvilken måned/er var du det? Sett ett eller flere kryss.

\begin{tabular}{|l|l|l|l|l|l|l|l|l|}
\hline 1 & 2 & 3 & 4 & 5 & 6 & 7 & 8 & 9 \\
\hline
\end{tabular}


12. Har du en kronisk sykdom: $\mathrm{Ne}$

13. Hvis ja; hvilken sykdom

14. Antall tidligere fødsler:

15. I tidligere svangerskap har du hatt

a) Korsryggsmerter? _ Ja _

b) Bekkensmerter? - Ja

16. Fikk du hormonbehandling for å bli gravid før dette svangerskapet? __a _ _ Nei

17. Trente du regelmessig (minst 2-3 ganger i uka) før svangerskapet?

Ja $\quad$ Nei

18. Har du trent regelmessig (minst 2-3 ganger i uka) i svangerskapet?

Ja $^{\mathrm{Nei}}$

19. Har du hatt vondt i korsryggen siste år før svangerskapet? Ja $\quad \mathrm{Nei}$

20. Har du hatt vondt i bekkenet siste år før svangerskapet?

21. Har du noen gang skadet korsryggen eller bekkenet slik at du måtte oppsøke lege/sykehus? - Ja ${ }^{\mathrm{Nei}}$

22. Hvis ja, hva slags type skade hadde du?

23. Har du hatt vondt i korsryggen eller bekkenet i løpet av dette svangerskapet? Ja

Hvis svaret ditt var Nei på spørsmål 23 kan du stoppe her. Var svaret ditt Ja på spørsmål 23 trenger vi litt mer informasjon. Vennligst fortsett med å svare på spørsmålene under.

\section{Dersom du har hatt KORSRYGGSMERTER}

(har du ikke hatt korsryggsmerte, gå til spørsmål 28)

24. I hvilken måned i svangerskapet begynte korsryggsmerten? Markér med kryss i riktig rute.

\begin{tabular}{|l|l|l|l|l|l|l|l|l|}
\hline 1 & 2 & 3 & 4 & 5 & 6 & 7 & 8 & 9 \\
\hline
\end{tabular}


25. Vis på figuren nedenfor hvor korsryggsmerten var lokalisert ved å sette kryss i smerteområdet.

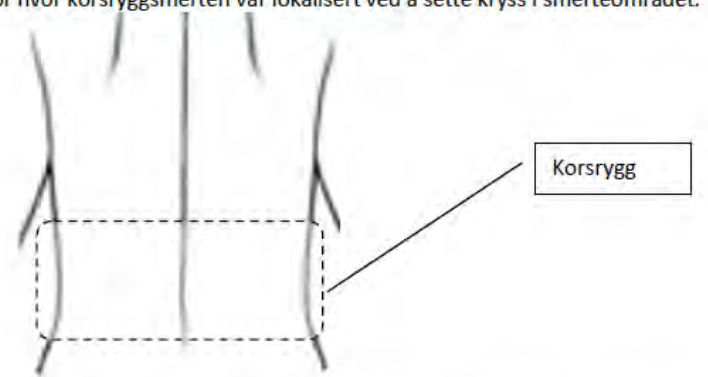

26. Markér i hver rute, som representerer hver måned i svangerskapet, i gjennomsnitt hvordan du har opplevd korsryggsmerten.

Bruk tall fra $0-100(0=$ ingen smerte; $100=$ uutholdelig smerte $)$.

\begin{tabular}{|l|l|l|l|l|l|l|l|l|}
\hline 1 & 2 & 3 & 4 & 5 & 6 & 7 & 8 & 9 \\
\hline
\end{tabular}

27. Dersom du har vært sykmeldt pga. korsryggsmerte: Markér nedenfor i hvilke måneder i ditt svangerskap du har vært sykmeldt. (Markér med kryss i riktig rute eller ruter.)

\begin{tabular}{|l|l|l|l|l|l|l|l|l|}
\hline 1 & 2 & 3 & 4 & 5 & 6 & 7 & 8 & 9 \\
\hline
\end{tabular}

\section{Dersom du har hatt BEKKENSMERTER}

(Dersom du ikke har hatt bekkensmerte, kan du fortsette til spørsmål 32)

28. I hvilken måned i svangerskapet begynte bekkensmertene? Markér med kryss i riktig rute.

\begin{tabular}{|l|l|l|l|l|l|l|l|l|}
\hline 1 & 2 & 3 & 4 & 5 & 6 & 7 & 8 & 9 \\
\hline
\end{tabular}


29. Vis på følgende figurer nedenfor hvor bekkensmerten din var lokalisert ved å skravere smerteområdet og sette kryss der smerten var mest intens.

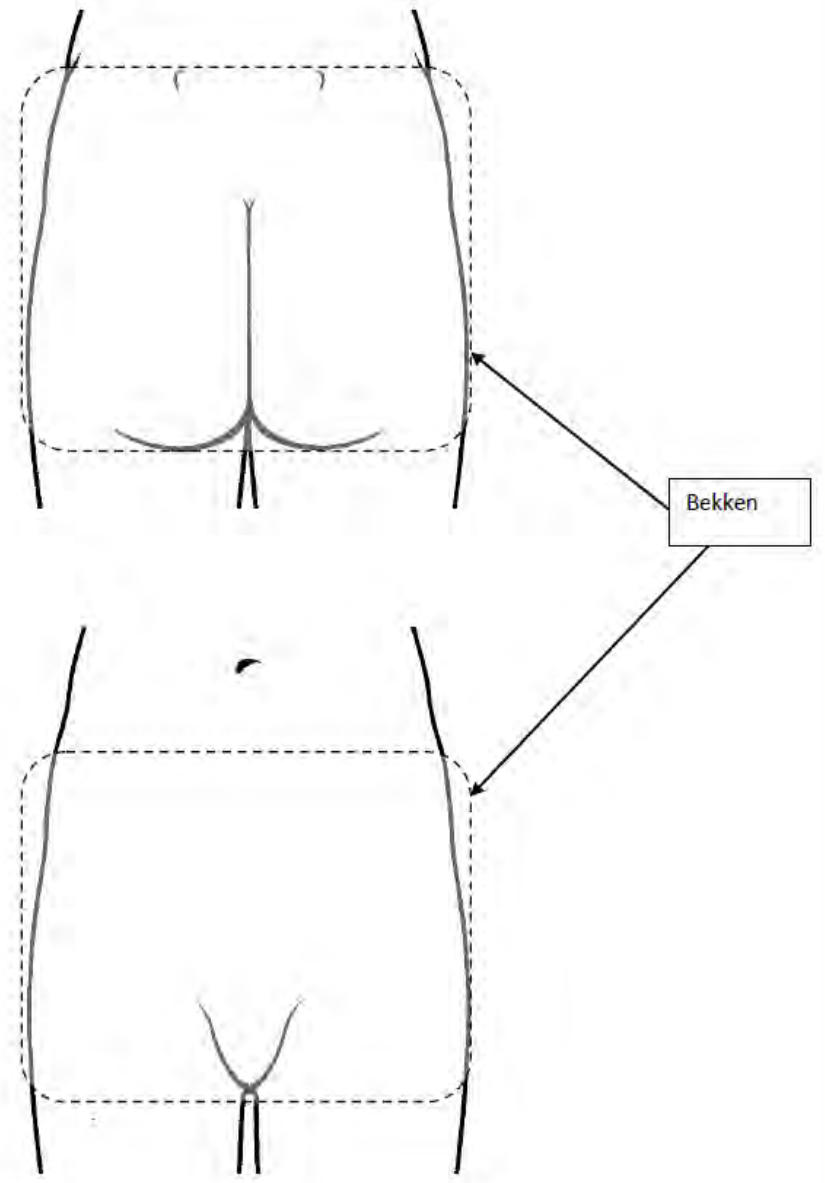


30. Markér i hver rute, som representerer hver måned i svangerskapet, hvordan du i gjennomsnitt har opplevd bekkensmerten. Bruk tall fra $0-100(0=$ ingen smerte; $100=$ uutholdelig smerte

\begin{tabular}{|l|l|l|l|l|l|l|l|l|}
\hline 1 & 2 & 3 & 4 & 5 & 6 & 7 & 8 & 9 \\
\hline
\end{tabular}

31. Dersom du har vært sykmeldt pga. bekkensmerte: Markér nedenfor i hvilke måneder i svangerskapet du har vært sykmeldt.

\begin{tabular}{|l|l|l|l|l|l|l|l|l|}
\hline 1 & 2 & 3 & 4 & 5 & 6 & 7 & 8 & 9 \\
\hline
\end{tabular}

32. Markér måned for måned hvordan du klarte deg i dagliglivet med dine bekkensmerter gjennom dette svangerskapet. Bruk tall fra $0-100(0=$ ingen problem, jeg klarte meg på egenhånd; $100=$ veldig dårlig, jeg måtte ha hjelp til alt)

\begin{tabular}{|l|l|l|l|l|l|l|l|l|}
\hline 1 & 2 & 3 & 4 & 5 & 6 & 7 & 8 & 9 \\
\hline
\end{tabular}

33. Har smerten vært så sterk i svangerskapet at du har trengt hjelpemidler?

\begin{tabular}{|c|c|}
\hline Krykker & _Ja \\
\hline Rullestol & _Ja \\
\hline "Glidelaken" & Ja \\
\hline Bekkenbelte/korsett & $\ldots$ \\
\hline
\end{tabular}

34. Har du fått behandling under svangerskapet pga korsrygg- eller bekkensmerter?

- Ja Nai

(Hvis Nei, så er du nå ferdig med dette spørreskjemaet.)

35. Hvem oppsøkte du for behandling?

Lege:

Kiropraktor:

Fysioterapeut:

Manuell terapeut:

Andre behandlere ? i så fall hvilke? 
Vi er interessert i å vite hva slags behandling du har gjennomgått. Nedenfor finner du spørsmål om eventuelle behandlingsmetoder som er blitt brukt. Hvis du har vært hos flere terapeuter sett gjerne i parentes hvem som gjorde hva.

36. Råd om å takle hverdagen med smerter? _ Ja - Nei

Hvor god effekt/utbytte hadde du av rådene?

\begin{tabular}{|l|l|l|l|l|}
\hline Verre & Ingen & Litt & God & Symptomfri \\
\hline
\end{tabular} effekt effekt effekt

Hvem (mer enn en?) ga hvilke råd:

37. Ble det brukt varme? Ja Nei

\begin{tabular}{|l|l|l|l|l|}
\hline Verre & $\begin{array}{l}\text { Ingen } \\
\text { effekt }\end{array}$ & $\begin{array}{l}\text { Litt } \\
\text { effekt }\end{array}$ & $\begin{array}{l}\text { God } \\
\text { effekt }\end{array}$ & Symptomfri \\
\hline
\end{tabular}

38. Ble det brukt akupunktur? Ja Nei \begin{tabular}{|l|l|l|l|l|}
\hline Verre & $\begin{array}{l}\text { Ingen } \\
\text { effekt }\end{array}$ & $\begin{array}{l}\text { Litt } \\
\text { effekt }\end{array}$ & $\begin{array}{l}\text { God } \\
\text { effekt }\end{array}$ & Symptomfri \\
\hline
\end{tabular}

39. Var du med på bassengtrening? Ja Nei

\begin{tabular}{|l|l|l|l|l}
\hline Verre & Ingen & Litt & God & Symptomfri \\
\hline
\end{tabular} effekt effekt effekt

40. Fikk du massasje? Ja

\begin{tabular}{|l|l|l|l|l|}
\hline Verre & Ingen & Litt & God & Symptomfri \\
\hline
\end{tabular}

effekt effekt effekt

41. Fikk du hjemmeøvelser? Ja__ Nei

\begin{tabular}{|l|l|l|l|l|}
\hline Verre & Ingen & Litt & God & Symptomfri \\
\hline
\end{tabular} effekt effekt effekt

42. Trening med veiledning ? Ja N Nei

\begin{tabular}{|l|l|l|l|l|}
\hline Verre & Ingen & Litt & God & Symptomfri \\
\hline
\end{tabular} effekt effekt effekt

43. Fikk du medikamenter? Ja Nei

\begin{tabular}{|l|l|l|l|l|}
\hline Verre & $\begin{array}{l}\text { Ingen } \\
\text { effekt }\end{array}$ & $\begin{array}{l}\text { Litt } \\
\text { effekt }\end{array}$ & $\begin{array}{l}\text { God } \\
\text { effekt }\end{array}$ & Symptomfri \\
\hline
\end{tabular}

44. Ble det brukt TNS maskin/strøm? Ja Nei

\begin{tabular}{|l|l|l|l|l|}
\hline Verre & Ingen & Litt & God & Symptomfri \\
\hline
\end{tabular} \begin{tabular}{l|l|l|l|} 
effekt & effekt & effekt
\end{tabular}

45. Fikk du manipulasjonsbehandling ?__a _ _ Nei

Hvis Ja, av hvem: Kiropraktor, Manuell terapeut. Andre utøvere ? Oppgi hvilke/n

\begin{tabular}{|l|l|l|l|l|}
\hline Verre & Ingen & Litt & God & Symptomfri \\
\hline
\end{tabular}

(Hvis ja, hvilken terapeut?
(Hvis ja, hvilken terapeut?

(Hvis ja, hvilken terapeut?

(Hvis ja, hvilken terapeut?

(Hvis ja, hvilken terapeut?

(Hvis ja, hvilken terapeut?

(Hvis ja, hvilken terapeut?

(Hvis ja, hvilken terapeut?

effekt effekt effekt


46. Har du hatt noen annen form for behandling? Ja Nei Hvis Ja, hva slags type behandling?

\begin{tabular}{|l|l|l|l|l}
\hline Verre & Ingen & Litt & God & Symptomfri \\
\hline
\end{tabular}

effekt effekt effekt

47. Antall ganger du var til behandling?

48. I ca hvor mange uker fikk du behandling?

49. Har du en kommentar til behandlingen(e)?

50. Hvor godt fornøyd er du med behandlingen du fikk i svangerskapet? Fra null til ti ( $0=i k k e$ fornøyd i det hele tatt, $10=$ veldig fornøyd). Sett ett kryss.

$$
0-1-2-3-4-5-6-7-8-9-10
$$

51. Generelt hvor godt fornøyd er du med behandlingstilbudet for korsrygg- og bekkensmerter under svangerskapet? Fra null til ti ( $0=i k$ ke fornøyd i det hele tatt, $10=$ veldig fornøyd). Sett ett kryss.

$$
0-1-2-3-4-5-6-7-8-9-10
$$

Takk for hjelpen så langt!

Husk å fylle ut de 2 andre skjemaene og! 
8.2 Questionnaire for the prospective data collection 


\section{Rygg - og bekkensmerter $\mathrm{i}$ svangerskapet}

Spørreskjema ved rutineundersøkelsen

Vi ønsker å kartlegge forekomsten av bekkensmerter i svangerskapet. For å kunne tolke

resultatene må vi gi en definisjon av hvor bekkenet er lokalisert. Nedenfor finner du en illustrasjon av hvor vi definerer bekkenområdet.

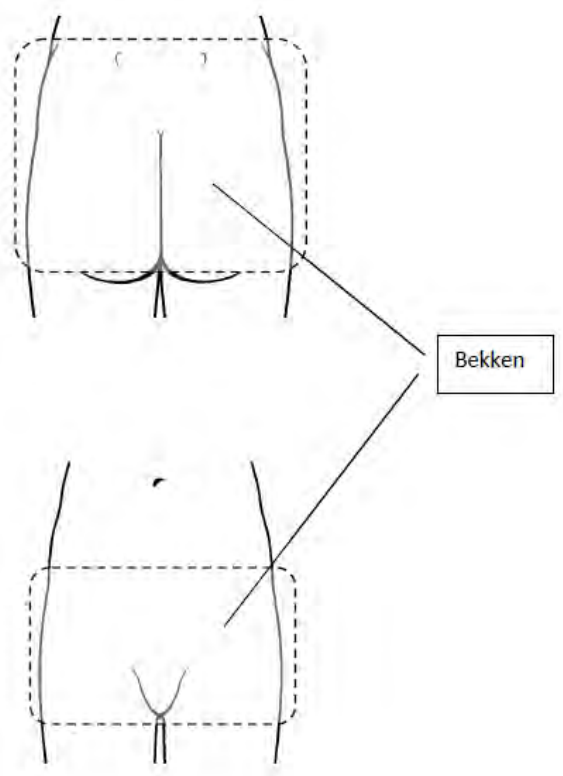


ID-kode:

Rygg- og bekkensmerter i svangerskapet

Spørreskjema ved rutineundersøkelsen

Initialer:

Fødselsdato: Dato i dag:

1. Hvor mange års utdanning har du (inkludert folkeskole/grunnskole)? år

2. Hvor fysisk tungt jobber du?

Sett ett kryss.

\begin{tabular}{|l|l|l|l|l|}
\hline $\begin{array}{l}\text { Veldig lett } \\
\text { arbeid }\end{array}$ & Ganske lett arbeid & $\begin{array}{l}\text { Verken lett eller } \\
\text { tungt arbeid }\end{array}$ & $\begin{array}{l}\text { Ganske tungt } \\
\text { arbeid }\end{array}$ & Veldig tungt arbeid \\
\hline
\end{tabular}

Jobber ikke

3. Yrket ditt:

4. Hvor bra trives du på din jobb eller der du jobbet sist? Sett ett kryss.

\begin{tabular}{|l|l|l|l|l|}
\hline Veldig dårlig & Ikke så bra & $\begin{array}{l}\text { Verken bra eller } \\
\text { dårlig }\end{array}$ & Ganske bra & Veldig bra \\
\hline
\end{tabular}

5. Hvor mange uker har du vært sykmeldt til nå i svangerskapet?

Har ikke vært sykmeldt

100\%:_ antall uker.

Delvis \%: antall uker.

6. Oppgi den/de viktigste årsakene til sykmeldingen(e):

7. Din høyde: $\mathrm{cm}$

8. Din vekt: $\mathrm{kg}$

9. Din vekt før svangerskapet: $\mathrm{kg}$

10. Har du vært deprimert til nå i svangerskapet? Sett ett kryss.

\begin{tabular}{|l|l|l|l|}
\hline Aldri & Av og til & Ofte & Nesten hele tiden \\
\hline
\end{tabular}

11. Dersom du har vært deprimert, i hvilke uker er/var du det? Sett ett eller flere kryss.

1-4

\begin{tabular}{|l|l|l|}
\hline $5-8$ & $9-12$ & $13-16$
\end{tabular}


12. Har du en kronisk sykdom: Nei

13. Hvis ja; hvilken sykdom:

14. Antall tidligere fødsler:

15. Har du hatt bekkensmerter i tidligere svangerskap? _ _a _

16. Fikk du hormonbehandling for å bli gravid før dette svangerskapet? _ Ja _ Nei

17. Trente du regelmessig (minst 2-3 ganger i uka) før svangerskapet? _ _a _

18. Har du trent regelmessig (minst 2-3 ganger i uka) til nå i dette svangerskapet?

Ja $\mathrm{Nei}$

20. Har du hatt vondt i bekkenet siste år før svangerskapet? _ Ja _ _Nei

21. Har du noen gang skadet bekkenet slik at du måtte oppsøke lege/sykehus?

- $^{\mathrm{da}}$ - $^{\mathrm{Nei}}$

22. Hvis ja, hva slags type skade hadde du?

23. Har du hatt vondt i korsryggen til nå i dette svangerskapet?

$$
\text { Ja }
$$

24. Har du hatt vondt i bekkenet til nå i dette svangerskapet?

$$
\text { Ja }
$$

(Hvis Nei på spørsmålene 23 og 24 er du nå ferdig med dette spørreskjemaet)

\section{Dersom du har hatt KORSRYGGSMERTER}

(har du ikke hatt korsryggsmerte, gå til spørsmål 29)

25. I hvilke uker i svangerskapet begynte korsryggsmerten? Markér med kryss i riktig rute.

$1-4$

5-8

9-12

13-16


26. Vis på figuren nedenfor hvor korsryggsmerten var lokalisert ved å sette kryss i smerteområdet.

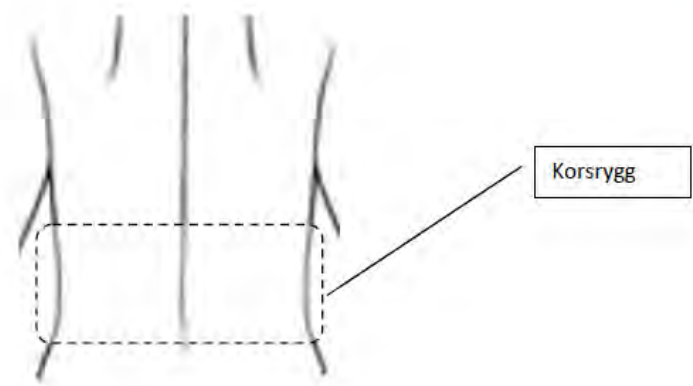

27. Markér i hver rute i gjennomsnitt hvordan du har opplevd korsryggsmerten. Bruk tall fra $0-100(0=$ ingen smerte; $100=$ uutholdelig smerte $)$.

\begin{tabular}{|l|l|l|l|l|}
\hline $1-4$ & $5-8$ & $9-12$ & $13-16$ & $17-20$ \\
\hline
\end{tabular}

28. Dersom du har vært sykmeldt pga. korsryggsmerte: Markér nedenfor i hvilke uker i ditt svangerskap du har vært sykmeldt. (Markér med kryss i riktig rute)

\begin{tabular}{|l|l|l|l|l|}
\hline $1-4$ & $5-8$ & $9-12$ & $13-16$ & $17-20$ \\
\hline
\end{tabular}

\section{Dersom du har hatt BEKKENSMERTER}

(Dersom du ikke har hatt bekkenplager, kan du gå til spørsmål 33)

29. I hvilke uker i svangerskapet begynte bekkenplagene? Markér med kryss i riktig rute.

\begin{tabular}{|l|l|l|l|l|}
\hline $1-4$ & $5-8$ & $9-12$ & $13-16$ & $17-20$ \\
\hline
\end{tabular}


30. Vis på følgende figurer nedenfor hvor bekkensmerten din var/er lokalisert ved å skravere smerteområdet og sette kryss der smerten var/er mest intens.

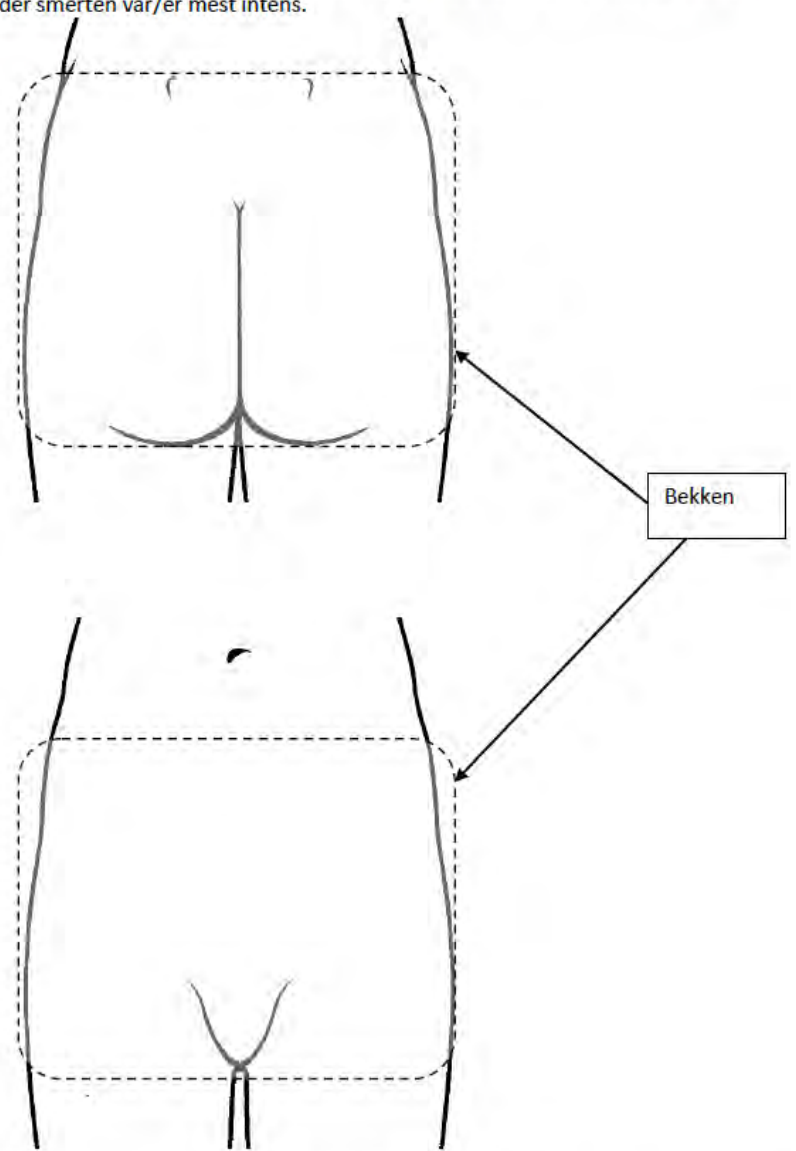

31. Markér i hver rute, som representerer uker i svangerskapet, hvordan du i gjennomsnitt har opplevd bekkensmerten. Bruk tall fra $0-100(0=$ ingen smerte; $100=$ uutholdelig smerte $)$

\begin{tabular}{|l|l|l|l|l|}
\hline $1-4$ & $5-8$ & $9-12$ & $13-16$ & $17-20$ \\
\hline
\end{tabular}

32. Dersom du har vært sykmeldt pga, bekkensmerte: Markér nedenfor i hvilke uker i svangerskapet du har vært sykmeldt.

1-4

$5-8$

$9-12$

13-16

$17-20$ 
33. Markér nedenfor hvor godt du har fungert i dagliglivet til nå i svangerskapet. Bruk tall fra $0-100(0=$ ingen problem, jeg klarte meg på egenhånd; 100 = veldig dårlig, jeg måtte ha hjelp til alt)

\begin{tabular}{|l|l|l|l|l|}
\hline $1-4$ & $5-8$ & $9-12$ & $13-16$ & $17-20$ \\
\hline
\end{tabular}

34. Har smerten vært så sterk at du har trengt hjelpemidler?

\begin{tabular}{|c|c|}
\hline Krykker & _Ja \\
\hline Rullestol & _Ja \\
\hline "Glidelaken" & _Ja \\
\hline Bekkenbelte/korsett & - \\
\hline
\end{tabular}

35. Har du fått behandling pga bekkensmerter i dette svangerskapet?

$$
\text { - Ja _Nei }
$$

(Hvis Nei er du nå ferdig med dette spørreskjemaet)

36. Hvem oppsøkte du for behandling? (f.eks. Lege, Kiropraktor, Fysioterapeut , Akupunktør, Osteopat, Manuell Terapeut, Naprapat, annet)?

Vi er interessert i å vite hva slags behandling du har gjennomgått. Nedenfor finner du spørsmål om eventuelle behandlingsmetoder som er blitt brukt. Hvis du har vært hos flere terapeuter sett gjerne i parentes hvem som gjorde hva.

37. Råd om å takle hverdagen med smerter? __a _ _ Nei Hvis ja, hva slags type råd?

38. Hvor god effekt hadde du av rådene?

\begin{tabular}{|l|l|l|l|l|}
\hline Verre & $\begin{array}{l}\text { Ingen } \\
\text { effekt }\end{array}$ & $\begin{array}{l}\text { Litt } \\
\text { effekt }\end{array}$ & $\begin{array}{l}\text { God } \\
\text { effekt }\end{array}$ & Symptomfri \\
\hline
\end{tabular}

39. Ble det brukt varme? __a _

40. Ble det brukt akupunktur? _ Ja _

41. Var du med på bassengtrening? Ja _ N Nei

42. Fikk du massasje? __a _

43. Fikk du hjemmeøvelser? Ja Nei
(Hvis ja, hva slags terapeut?

(Hvis ja, hva slags terapeut?

(Hvis ja, hva slags terapeut?

(Hvis ja, hva slags terapeut?

(Hvis ja, hva slags terapeut? 
44. Trening med veiledning ?__a _

(Hvis ja, hva slags terapeut?

45. Fikk du medikamenter? Ja Nei

(Hvis ja, hva slags terapeut?

46. Ble det brukt TENS-maskin/strøm? Ja Nei

(Hvis ja, hva slags terapeut?

47. Fikk du manipulasjonsbehandling ? _ Ja __ Nei

Hvis ja, av hvem: Kiropraktor, Manuell Terapeut, Osteopat, Naprapat eller annet?

48. Har du hatt noen annen form for behandling? _Ja $\mathrm{Ne}$

Hvis Ja, hva slags type behandling?

49. Hvor mange ganger har du har vært til behandling til nå i svangerskapet?

50. I ca hvor mange uker har du fått behandling?

51. Hvor godt fornøyd er du med behandlingene du har fått i svangerskapet? Fra null til ti ( $0=i k k e$ fornøyd $i$ det hele tatt, $10=$ veldig fornøyd). Sett ett kryss.

$$
0-1-2-3-4-5-6-7-8-9-10
$$

52. Generelt hvor godt fornøyd er du med behandlingstilbudet for korsrygg- og bekkensmerter svangerskapet?

Fra null til ti $(0=i k k e$ fornøyd $i$ det hele tatt, $10=$ veldig fornøyd). Sett ett kryss.

$$
0-1-2-3-4-5-6-7-8-9-10
$$

\section{Takk for all informasjion!}

